\title{
Potatoes and Rice: Exploring the Racial Politics of Gay Men's Desires and Desirability
}

\author{
By \\ Emerich Daroya, BA (Hons) \\ A thesis submitted to the Department of Sociology and Anthropology \\ in partial fulfillment of the requirements for the degree of \\ Master of Arts
}

to

The Faculty of Graduate Studies and Research

Department of Sociology and Anthropology

Carleton University

Ottawa, Canada

April, 2011

CCopyright 2011, Emerich Daroya 
Library and Archives

Canada

Published Heritage

Branch

395 Wellington Street

Ottawa ON K1A ON4

Canada
Bibliothèque et

Archives Canada

Direction du

Patrimoine de l'édition

395 , rue Wellington

Ottawa ON K1A ON4

Canada
Your file Votre référence

ISBN: 978-0-494-87810-1

Our file Notre référence

ISBN: $978-0-494-87810-1$

\section{NOTICE:}

The author has granted a nonexclusive license allowing Library and Archives Canada to reproduce, publish, archive, preserve, conserve, communicate to the public by telecommunication or on the Internet, loan, distrbute and sell theses worldwide, for commercial or noncommercial purposes, in microform, paper, electronic and/or any other formats.

The author retains copyright ownership and moral rights in this thesis. Neither the thesis nor substantial extracts from it may be printed or otherwise reproduced without the author's permission.
AVIS:

L'auteur a accordé une licence non exclusive permettant à la Bibliothèque et Archives Canada de reproduire, publier, archiver, sauvegarder, conserver, transmettre au public par télécommunication ou par l'Internet, prêter, distribuer et vendre des thèses partout dans le monde, à des fins commerciales ou autres, sur support microforme, papier, électronique et/ou autres formats.

L'auteur conserve la propriété du droit d'auteur et des droits moraux qui protege cette thèse. $\mathrm{Ni}$ la thèse ni des extraits substantiels de celle-ci ne doivent être imprimés ou autrement reproduits sans son autorisation.
In compliance with the Canadian Privacy Act some supporting forms may have been removed from this thesis.

While these forms may be included in the document page count, their removal does not represent any loss of content from the thesis.
Conformément à la loi canadienne sur la protection de la vie privée, quelques formulaires secondaires ont été enlevés de cette thèse.

Bien que ces formulaires aient inclus dans la pagination, il n'y aura aucun contenu manquant. 


\begin{abstract}
Desires and desirability play an important role in theorizing sexuality, but largely ignored by scholars studying sexuality. In this thesis, I provide a study of the sociology of desire. I adopt Green's (2008) concept of 'erotic habitus' to examine the following: first, the dominant erotic habitus of gay white men; second, the erotic habitus of gay Asian men; and third, the erotic habitus of 'rice queens' (i.e., white men who are particularly attracted to Asian men). Situating the analysis via Pierre Bourdieu's field, capital, and habitus, I employ critical discourse analysis of popular cultural vehicles in the gay community such as personal ads on Craigslist's Men Seeking Men section, Fab Magazine, and Rice Queen Diaries to explore the social structural forces which shape what gay men consider to be desirable, which are also simultaneously reproduced through these vehicles. These structural forces put white, youthful, upper and middle-class, masculine and muscular men as the most desirable both by gay white and Asian men, creating hierarchies of desirability via 'erotic capital' which informs one's 'value' in the field of gay desire. Conversely, the rice queens' erotic habitus is largely informed by the Orientalist gaze based on stereotypes around the Asian male: having a small and smooth body, youthful, passive, and feminine. These stereotypes are used by Asian men, via self-Orientalization, as 'erotic capital' to increase one's desirability to the white gaze. Thus, structural forces influence our desires confirming that race, gender, class, and the body play an important role in creating a hierarchy of desires within the gay community.
\end{abstract}




\section{Acknowledgements}

The completion of this thesis has been a wonderful, challenging, and, at times, difficult journey which would not have been possible without the superb support and encouragement by numerous people. First, I owe my deepest gratitude to my supervisor, Dr. Patrizia Gentile, whose patience, support, guidance, knowledge, and wisdom made this thesis into what it is. I am also heartily thankful to Dr. Xiaobei Chen who acted as my second reader, providing guidance from the beginning to the end of this process. Thank you also to Dr. Ummni Khan for graciously lending her time and expertise acting as my internal/external examiner. I also would like to make a special reference to Dr. Aaron Doyle for kindly chairing my thesis defense. My heartfelt thanks also go to Carleton University and the Lambda Foundation for their financial support.

Of course, this thesis would not have been possible without the inspiration, encouragement, and motivation from my friends and family. Worth mentioning are the wonderful people from my cohort (the Motivational Monday group). You have pushed me to actually do my work and get things done before the next Monday! I would also like to thank my friends in and from Toronto. I could not be more grateful for having such inspiring friends around me. I would also like to offer my sincerest gratitude to my parents and my siblings. Last and certainly not the least, I want to thank Louis who, in this journey, encouraged, supported, and stood by me no matter how difficult it was. You are everything to me and without your love and understanding, I would not have been able to make it. You always push me to strive for the best, and this thesis is definitely one of them. Je t'aime beaucoup! It's finally done! 


\section{Table of Contents}

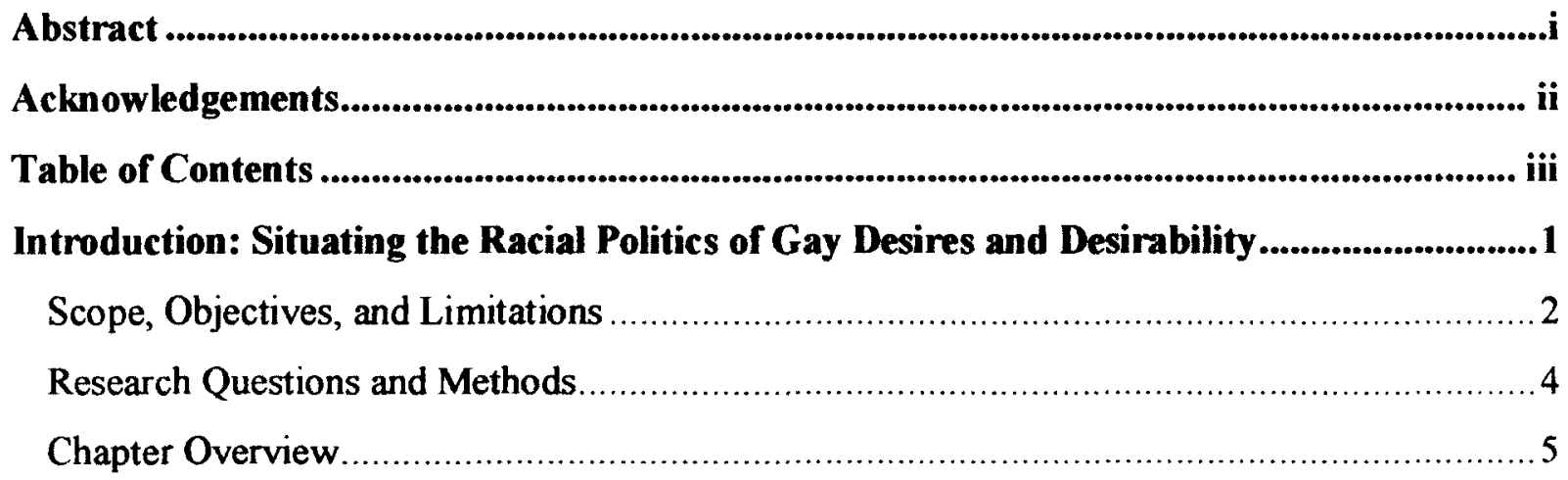

Chapter 1: Conceptualizing Gay Desires and Desirability: Race, Gender, the Body, and

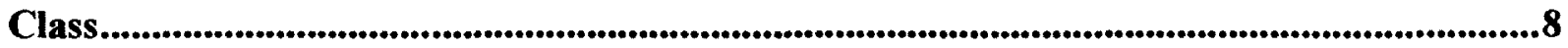

The Social Structural Forces in the Gay Male Community ........................................... 9

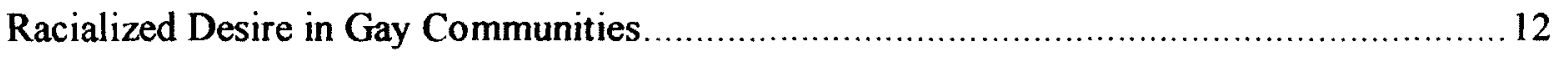

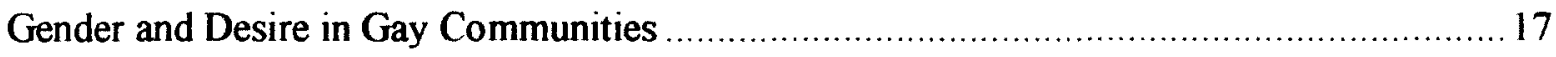

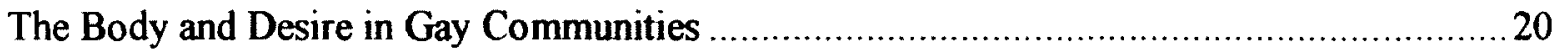

Race, Gender, the Body, Class, and Age: the Desires and Desirability of Gay Asian Men......22

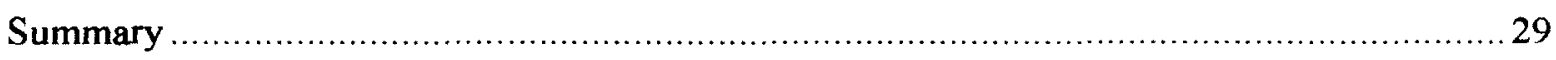

Chapter 2: Theorizing Erotic Desires and Desirability .........................................................31

Market Analogy and the Commodification and Consumption of 'Otherness' ....................... 33

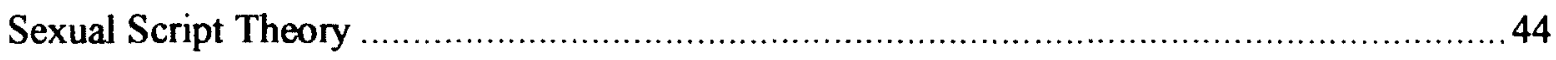

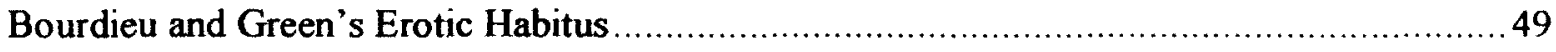

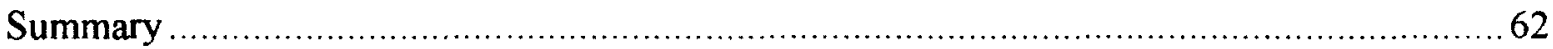

Chapter 3: Methodological Framework and Data Analysis Strategies................................64

Critical Discourse Analysis (CDA): A Discussion ................................................. 65

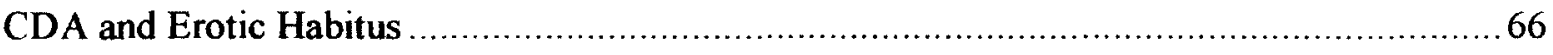

Feminist Methodologies: Standpoint Theory and Reflexivity ..................................69

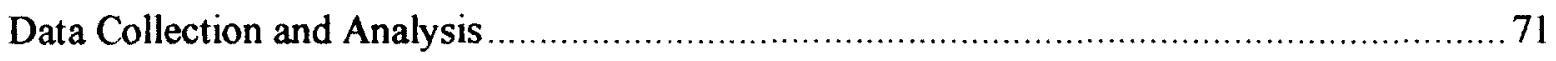

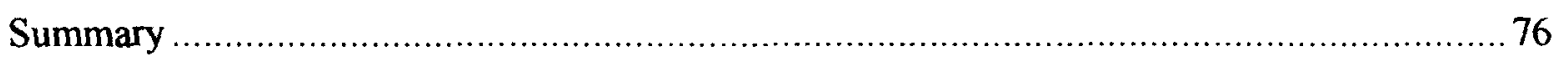


Chapter 4: Erotic Habitus and the Production and Reproduction of Desires and Desirability in Gay Cultural Products...............................................................................................................78

The Production and Reproduction of Desires and Desirability in Fab Magazine .................81

The Issues: Fab Magazine ............................................................................ 83

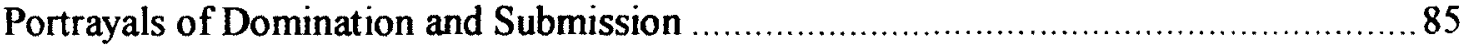

The Portrayal of Asian Men as Feminine through the 'Orientalist gaze' .......................88

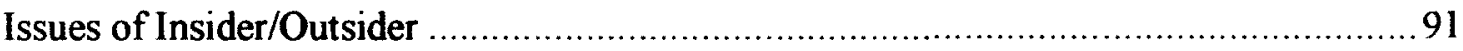

Exoticization and Fetishization of the 'Other' through Sexual Tourism.......................93

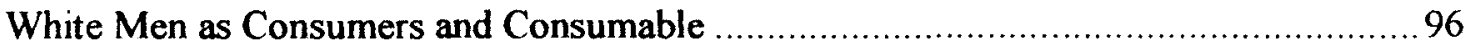

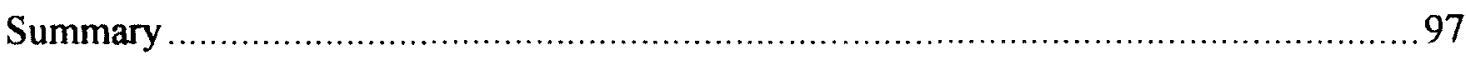

Chapter 5: The Erotic Habitus in Craigslist's Personal Ads and Rice Queen Diaries...........98

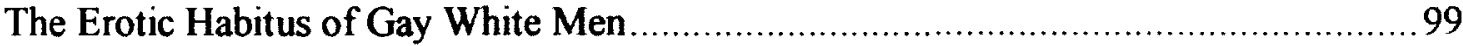

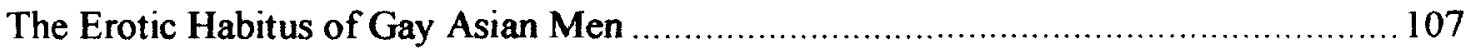

'Self-Orientalization': Asian Men's Subjectivities and Erotic Capital .............. 108

Asian Men's Erotic Habitus: Erotic Choices............................................ 114

The Erotic Habitus of 'Rice Queens' ............................................................ 116

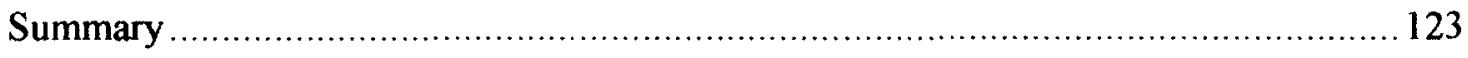

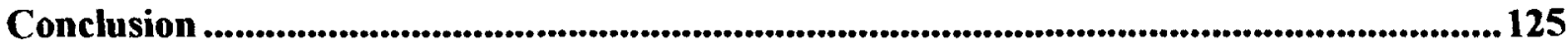

Bibliography ........................................................................................................................... 129

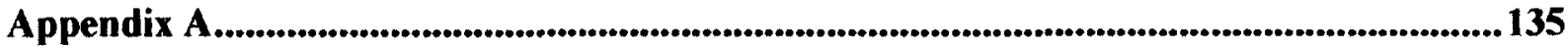

Appendix B

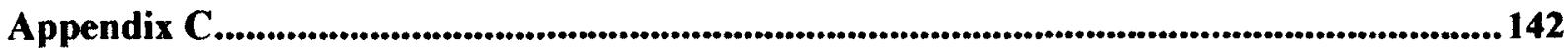




\section{Introduction: Situating the Racial Politics of Gay Desires and Desirability}

Green (2008) argues that, "[i]n the sociology of sexuality, desire is an elephant that sits upon the scholar's desk, seen by all but addressed by few" (Green 2008a: 597). Desires and desirability are central to theorizing sexuality but they also play a role in the practice of sex and sexuality. Recognizing or acknowledging someone or something as erotically arousing is an important aspect of sexuality. My thesis offers a preliminary exploration in an area that is undertheorized, namely the conceptualization of desires in sociology. The specific focus is the desire of gay white men for gay Asian men and vice-versa, a complex and inter-related phenomenon which receives comparatively little attention from sociologists. Although many authors write about some aspects of desires and desirability, clear definitions of these concepts have not been offered. Oxford Dictionary (2010) defines 'desire' as a "strong sexual feeling or appetite" and to "want (someone) sexually". In this thesis, I define these erotic (or sexual) desires as strong feelings to want someone sexually. These are different from romantic desires because, although romance may include sex, a strong sexual feeling does not necessarily involve romance and viceversa. The other related notion that is related to this concept is 'desirability'. According to the Oxford Dictionary, 'desirability' refers to the "quality of being desirable". In this thesis, I expand this concept to describe the following: how individuals subjectively see themselves as desirable (i.e., how they define themselves as sexually appealing) and how others perceive them as sexually arousing (i.e., how others assess their desirability). However, the complex feelings, ideas, and discourses associated with desire and desirability make it impossible for me to offer a definitive examination of desires in white men for Asian men or vice versa. Indeed, there are as many interpretations about how desire is formed as there are ways of desiring. The purpose is to offer an exploration of this topic using a particular sociological approach informed by concepts such as 
erotic habitus. My interest in this topic was instigated while browsing through gay personal and dating ads on the internet. Particularly, by ads that are blatantly racist and discriminatory against other men based on gender, age, class, and body types. Fascinatingly, these racist and discriminatory remarks are often excused by using the phrase, "Sorry, it's just a preference!" I wondered, however, if this 'excuse' can be demystified through a sociological analysis of desires and desirability.

Based on the personal and dating ads, desires are often perceived as just a matter of 'taste' and therefore 'personal' and somehow 'natural'. I explore how our 'erotic tastes' may be shaped by social structures. Social structures are basic components which consist of social relations. These social relations are patterned norms, practices, frameworks, and behaviours, formally or informally institutionalized, that construct the actions and behaviours of groups of social actors. Social structures are the basic components from which sociologists start any form of social analysis (Brym 2004; Henslin 2005). Social structures encompass systems such as economic and cultural, affecting and effecting social stratification and inequalities and informing the relations of social actors. While these structures act individually to influence patterns of inequality, they intersect together to maintain specific power relations. These structures also manifest themselves in our desires and desirability. The question that needs to be addressed is: what is the relationship between desire, desirability, power relations and social structures?

\section{Scope, Objectives, and Limitations}

To answer this, I will concentrate on the construction of discourses on desires and desirability by gay men in order to show how social relations of race, class, age, gender, sexuality, and body types (as social structures) are embodied in our desires and how power relations are maintained through these discourses. I will specifically look at personal ads on the popular classi- 
fieds/forums website Craigslist, Fab Magazine, and Rice Queen Diaries to explain how these discourses: first, represent what is desirable in gay communities; second, how whiteness, masculinity, muscularity, youthfulness, and middle-class lifestyles intersect and manifest in our desires; and third, how desires are racialized. 1 will focus on how discourses of desire are constructed around gay Asian men who are not only racialized but also feminized, such that they are seen as effeminate and have smaller and smooth bodies. I am particularly interested in gay men's desires because-while there is a wide scholarship on the sociology of gay men's sexuality and queer sexuality in general-there is a lack of scholarship on the sociology of desire. I am also interested in how racism and other forms of discrimination exist in gay communities and how they become manifested in our desires.

The issue of desire is very complex and it must be acknowledged that desires cannot be reduced to social structures. However, since my main concern is to show how desires can be sociologically explained, I will concentrate on providing a critical analysis of how discourses of desire constructed by gay white men around Asian men are embedded in the social structural forces that are present in gay culture. Due to the time limits allowed for an MA thesis, I will only concentrate on the discourses used in personal ads and images on gay magazines. I will not be conducting interviews, therefore, I will not be able to explain how desires and desirability are felt and experienced. Furthermore, I will only be analyzing personal ads by white men and Asian men, but not posts by other non-white men. The scope of this thesis encompasses the dichotomy between white and Asian gay men, discussed by various queer Asian scholars such as Fung (1991) and Han (2008). Consequently, I will focus on analyzing only representations and descriptions of desires and desirability rather than on the felt and experiential aspects of it. 


\section{Research Questions and Methods}

Taking into consideration the scope and objectives I outlined above, my main research question stands as follows: how do discourses of desire constructed by and for gay white men and gay Asian men-as found in popular cultural vehicles in the queer community such as Craigslist, Fab Magazine, and Rice Queen Diaries-help us understand the relationship of race, gender, age, class, and body types in the production and reproduction of desires and desirability? I aim to focus on the following aspects of the embodiment of desire through gay personal ads. First, I want to show the dominant 'erotic habitus' (a concept I borrowed from Green, explanation to follow) found in the gay male community'. Second, I will explore the 'erotic habitus' of gay Asian men and compare and contrast it with the dominant erotic habitus. Third, I will examine if discourses made by white men who are particularly attracted to Asian men (i.e., 'rice queens') have a different erotic habitus and compare and contrast it with the dominant. I will also explore how their erotic habitus complements the erotic habitus of Asian men. This research question deals specifically with how race, gender, age, class, and body types intersect with how we express our desires through language and images.

Through the use of critical discourse analysis (CDA) to explore Craigslist posts, Fab Magazine, and Rice Queen Diaries, I will discern how social structures are embodied in our desires. The following chapters will explore the theoretical and methodological concerns about desires and desirability, which will lead to the fusion of Pierre Bourdieu's theories and marketanalysis in order to analyze racialized desires. Of course, race in this context is always understood to be intersecting with gender, class, body, and age.

\footnotetext{
'I use the dichotomies of 'dominant' and 'dominated' based on Bourdieu, whose anatysis on class is influenced by Marx by using the concepts of 'dominant class' and 'dominated class'. For the purposes of this thesis, I delineate the 'dominant' as gay white men and the 'dominated' as non-white gay men. These are also used by various authors I cite throughout this thesis.
} 


\section{Chapter Overview}

Chapter 1 offers a review of the literature, presenting important frameworks on how racialized desires are conceptualized in gay communities. In this Chapter, important authors are discussed such as Barnard (2004), McBride (2005), and Phua and Kaufman (2003), whose works point to the centrality of whiteness as the most erotically desirable in the gay male community. The former two authors are particularly significant because their studies on gay pornography suggest that black men's desirability is constructed around the idea of exoticism and fetishism. ${ }^{2}$ This idea is also used by Fung (1991), Han, C. (2007, 2008), and Han, S. (2000) to explain the desirability of Asian men, largely derived from Orientalism. Orientalism is a notion originated from Edward Said used by these and other authors to construct Asian men as passive, submissive, with small, smooth, and thus feminine bodies. Some white men fetishize Asian men based on these constructions because they fulfill their desires to dominate. Some Asian men may also use Orientalism for their own pleasure. ${ }^{3}$

Chapter 2 charts the theoretical framework which I use in this thesis. In particular, this Chapter provides an analysis of Green's concept of erotic habitus, derived from Bourdieu. Habitus explains how the macro-structures penetrate the unconscious, which forms and informs our sexual desires and practices. Due to a long-term exposure to a particular social order, where whiteness is the most erotically desirable characteristic in the field of gay desire, some gay men

\footnotetext{
' In this thesis, I define 'exoticization' as the act of romanticizing the perceived 'difference' of non-white men by white men. This is related to the term 'fetishization'. According to the Oxford Dictionary (2011), 'fetish' is, "a form of sexual desire in which gratification is linked to an abnormal degree to a particular object, item of clothing, part of body, etc". Thus, 'fetishization' in this context is a form of sexual desire in which gratification is based on the objectification of 'race'. In this way, a non-white man (e.g. an Asian man) is fetishized based on their perceived qualities such as having a small and smooth body or other specific physical attributes that is linked with cultural traits (such as being submissive, passive, and feminine-i.e., cultural stereotypes about 'Asians'). For other definitions of 'fetishization', see Hennessy (2000) and McClintock (1995).

${ }^{3}$ Orientalism interprets small and hairless bodies as feminine. 'Small' and 'hairless' bodies are a reality for most Asian men, but how to interpret this reality is something that varies. Asians may very well interpret their hairless bodies as 'civilized'. Which version prevails is a question that correlates with power.
} 
come to recognize white men as the most valuable because they carry the most erotic capital. This Chapter also provides a discussion of the market-analogy, which Green rejects in his works. I argue, however, that the market-analogy is an important framework to understand desires in the field because gay men commodify and market themselves by highlighting their most desirable attributes, i.e., their erotic capital ${ }^{4}$ The market-analogy is also helpful in understanding the exchange-value of racialized non-white men, who are commodified based on the ideas of their fetishized differences from the 'norm'. In particular, some Asian men accrue their 'value' based on racist ideologies derived from Orientalism. Their bodies are commodified for being slim and smooth. The market-analogy becomes embodied in the erotic habitus of gay men, bearing an imprint of the structural forces, shaping our desires and desirability. Thus, our erotic habitus embodies what we come to recognize as desirable and undesirable, informed by the social order in the field of gay desire. Further, it also structures the 'rules of the game' in the field of gay desire. How this translates to actual practice, however, needs to be studied. Two of the mechanisms from which the erotic habitus becomes manifested are through personal ads and gay cultural products, such as gay magazines.

Chapter 3 outlines how I collect these personal ads on Craigslist and Fab Magazine. The choice of $F a b$ as one example of a gay cultural product is crucial in this study because, according to Bourdieu, it is through cultural products in which the dominant make their habitus universally significant which, in turn, shapes our erotic tastes. These erotic tastes are communicated through personal ads. In order to analyze these data, I apply CDA to emphasize power, dominance, and inequalities being reproduced through these discourses. Since discourses include text, talk, images, and also body language, I adopt Fairclough's (2001) idea of 'semiosis', to encompass all

\footnotetext{
${ }^{4}$ The commodification of the self via objectification is a form of agency, informed by the habitus.
} 
forms of meaning-making in which sexual desires and practices are communicated. These include the front covers of Fab Magazine, personal ads, and Rice Queen Diaries.

In Chapters 4 and 5, I present my analyses of these cultural products. I argue that some characteristics of our erotic 'tastes' are shaped through a long-term exposure in the field of gay desire, where representations of what are considered to be erotically desirable are produced through culture. Further, we also form our understanding of erotic capital, informing how we come to subjectively see and commodify ourselves as desirable. These erotic tastes and erotic capital become embodied in the erotic habitus, materialized through personal ads. Through these cultural vehicles, a hierarchy of desires is maintained wherein whiteness, youthfulness, masculinity, muscularity, and middle-class lifestyles are considered to be the most valuable erotic capital. These cultural vehicles also produce Orientalist discourses, exoticizing and fetishizing certain Asian men. Conversely, an 'Orientalist gaze' is produced through which Asian men 'selfOrientalize' themselves, as a form of commodifying to become desirable to 'rice queens'. analysis of Daniel Gawthorp's (2005) memoirs in Rice Queen Diaries will also show that colonialism and domination are eroticized by rice queens, informing their sexual desires for Asian men. Finally, I present the conclusions and further directions of my research. Through the analyses I offer, I conclude that our erotic habitus bears an imprint of the social inequalities based on race, body, age, gender, and class, which are largely present in the field of gay desire.

\footnotetext{
${ }^{5}$ In this thesis, self-Orientalization is understood as intemalizing Orientalist stereotypes in order to achieve certain ends that they desire (either to attract their object of desire or for their own pleasure). In other words, being the object of desire is a place of power and potentially, a place of objectification.
} 


\section{Chapter 1:}

\section{Conceptualizing Gay Desires and Desirability: Race, Gender, the Body, and Class}

Reflecting on popular cultural vehicles present in gay communities across North America, such as gay magazines catered towards gay men, the proliferation of images of white men with hard muscular bodies and with very masculine features are considered desirable. While most authors acknowledge this, they do not discuss how these images reflect the structural forces that are present in gay communities and how they are internalized, embodied, and reproduced in our desires through our 'erotic works' ${ }^{6}$ The articulation of race, gender, body types, class, and age in the production and reproduction of desires and desirability has not been explored thoroughly. Thus, I offer a critical reflection of the concepts of 'desire' and 'desirability' in relation to race, gender, body types, class, and age.

I divide this chapter into four related themes: racialized desire in gay communities; gender and desire in gay communities; the body and desire in gay communities; and race, gender, the body, class, and age: desires and desirability of gay Asian men. This literature review presents important frameworks from which desires in the gay community could be analyzed and theorized. This chapter provides relevant answers but, at the same time, it leaves some gaps that still need to be addressed. First, I offer a review of how 'racialized desire' is conceptualized. I emphasize the centrality of whiteness as the main force which informs the dynamics of desires and desirability in the gay community. However, this does not provide a complete picture of 'racia-

\footnotetext{
' According to Green (2008), erotic work is the transformation of sexual fantasies and sexual 'tastes' into sexual scripts. 'Sexual scripts' as taken from Gagnon and Simon's sexual script theory (SST). According to Kimmel (2007), Gagnon and Simon's notion of sexual scripts states that, "[s]cripts provide a cognitive map to the domain of the sexual-through scripts we learned how to have sex" (Kimmel 2007: xi). Sexual scripts, such as images on magazines, provide us with a window to what gay men consider desirable, which in turn, inform them of what can be considered as sexy or not, according to SST. This, however, does not provide us with a full account of the role of social structures in shaping these sexual scripts, which will be discussed in Chapter 2.
} 
lized desires', because 'whiteness' is always gendered, bodied, aged, and classed. Thus, I turn towards a discussion of masculinity. I discuss that the clone culture ${ }^{7}$, in the advent of the gay liberation movement, promoted and emphasized masculinity as something that is to be desired by all gay men. However, this 'desirable masculinity' needs to be unpacked. I then turn to Alvarez's valorization of gay gym culture, to explain that for gay men, masculinity is conflated with muscularity and vice versa.

Subsequently, I provide a review of Asian men's experiences with racialized desires and desirability. In this discussion, I offer a review of 'Orientalism', which depicts Asian men as feminine. I focus on scholarship examining Asian men's desires for white men. Because of the dearth of Asian male representation in popular gay culture, white men are constructed as the most desirable object choice for Asian men (as well as for all other men). Access to white privilege for Asian men choosing white men as object choices is also another reason. I also present scholarships on the conceptualization of Asian/white relationships in order to demonstrate that the concepts of 'desire' and 'desirability' have not yet been fully developed sociologically because there is no sufficient theoretical framework from which we can study how these desires and desirability exist in the first place.

\section{The Social Structural Forces in the Gay Male Community}

Before proceeding to these discussions, I want to focus first on the social structural forces that inform the dynamics of gay communities to explain why I choose to concentrate on these themes and not others (also explicating the dichotomies of 'dominant' and 'dominated' I discussed above). First is the issue of whiteness and white supremacy, specifically on how gay stays white. In the essay, "How Gay Stays White and What Kind of White It Stays," Bérubé (2001) makes a

\footnotetext{
${ }^{7}$ Clone culture emphasizes hyper-masculinity in gay communities in the 1970's. According to Alvarez (2008), the clone is ruggedly handsome and butch acting, which was the complete opposite of the sissy. The clone also, "represented the first official gay muscle man known to modern culture" (Alvarez 2008: 99).
} 
compelling argument explaining how being gay in the U.S. (and arguably, in Canada) remains white by promoting the 'positive image' of a gay community by gay organizations and the media. He argues that this 'positive image' consists of "an upscale, mostly male, and mostly white consumer market with mainstream, even traditional, values" (Bérubé 2001: 235). He provides excellent examples of the 'whitening processes' of being gay through the exclusion of racialized non-white gay men in gay establishments. For instance, a white gay bar would just be a gay bar, but if it is populated by non-white men, that bar becomes a racialized space (Bérubé 2001: 238). He suggests that, in the gay community itself, gayness is promoted as white. Furthermore, gay organizations are usually ran and attended by gay white men, who are politically invested in promoting an essentialized notion of the 'normal' gay identity. Attention tends to be focused on equality based on sexual orientation to the exclusion of 'non-gay issues' such as racism, sexism, poverty, and immigration (Bérubé 2001: 235). The 'whitening processes' point to the relevance of whiteness and class as important social structural forces in gay communities, which inform the actions of individuals. How these various exclusionary practices translate into desires and desirability, however, needs to be explored.

Racism and classism are evident in the exclusion of non-white gay men in gay establishments and the promotion of the 'positive image', based on a white middle-class lifestyle. Problematic in this discussion, however, is the absence of gender. As Seidman (2002) argues, "the normal gay is expected to be gender conventional, links sex to love and a marriage-like relationship, defend family values, personify economic individualism, and display national pride", in short, homonormative ${ }^{8}$ (Seidman 2002: 133). Although Seidman mentions gender conformity as

\footnotetext{
${ }^{8}$ Homonormativity refers to the process of embracing agendas that aims for acceptance within existing economic and political systems that are currently in place, abandoning commitments to economic redistribution and greater sexual freedom. Homonormativity embraces normative ideas about family, marriage, etc., mar-
} 
one aspect of the construction of the 'normal' gay identity, he does not go into depth about what this gender conformity entails. Furthermore, he also ignores the fact that this 'normal' gay identity includes whiteness as a major aspect of normalization. Phelan (2001) cites the pull of homonormativity to shed some light as to why gays and lesbians do not challenge prevailing gender structures. According to him, gays and lesbians conform to gender ideology because asserting that we are just like heterosexuals means we do not become a threat to the existing ideas of masculinity, femininity, or sexual difference thereby legitimizing our fight for equality (Phelan 2001: 118-199). This process of gender conformity becomes a basis for gays and lesbians to marginalize bisexuals and transgendered people. Evident in these discussions is that whiteness, class and gender conformity define the social and political dynamics in gay communities; such that race and gender are structural forces informing social relations within gay communities. In addition to race, gender, and class, age and the body are also structural forces which are present in gay communities. This is clear when Edwards (2006) argues:

gay men and gay culture are often the worst of all gladiatorial arenas of male body spectacle. I have not met a single gay man in the past ten years who does not suffer from major hang-ups concerning his appearance [...]. [This is due to the fact that] the gay press, gay bars, gay shops, gay websites, and most other gay institutions, formal or informal, promote if not flagellate their clientele with relentless imagery of the often white, usually toned, frequently naked and-above all-youthful model (Edwards 2006: 161).

Keeping in mind that social structures are basic components of social relations which are patterned norms, practices, and behaviours, informing the actions and behaviours of individuals (Brym 2004; Henslin 2005), we can see how race, gender, class, age, and youthful bodies all intersect to create patterned norms constructing the actions of gay men. These structures also create and maintain stratifications, inequalities, and power relations. Thus, I chose to concentrate

ginalizing LGBTQ individuals who are 'non-normative' such as polygamists, transsexuals, pansexuals, and bisexuals (see Duggan 2002) 
on these social structural forces as main themes because they drive the processes and practices in gay communities and gay men. Arguably, they also affect and become manifested in our desires and desirability.

\section{Racialized Desire in Gay Communities}

In this section, I concentrate on how scholars have come to conceptualize the relationship between race and desire to help me contextualize the desires and desirability of gay Asian men. But first, I want to define what 'racialization' means to analyze what 'racialized desire' entails. According to Kallen (2003), racialization is the process in which non-white people are socially constructed, "on the basis of various combinations of physical, cultural, and behavioural criteria" (Kallen 2003: 37). ${ }^{9}$ Satzewich implies that the important element in racialization is to characterize group boundaries and identities on the basis of physical and/or genetic criteria or by referring to the term 'race' (Satzewich in Kallen 2003: 38). Thus, the 'racialized' component of 'racialized desire' is taken to mean differences between people based on 'race' are objectified to be sexually desirable.

So what about 'racialized desire'? McBride (2005) provides an important explanation of the relationship of race and desire in the 'gay marketplace of desire'. McBride's central analytical framework is race as the salient factor which drives this marketplace. He calls it 'marketplace' because race, gender affect, body type, age, penis size, and style, "all work to construct and constitute what we come to accept [...] as our value" (McBride 2005: 88). These 'values' in turn get exchanged as 'currencies' to get ahead of some men, while leaving others behind. The

\footnotetext{
9 'Social construction' is the idea that describes the creation of 'race' based on perceived differences between people, conditional upon a society, rather than on any inherent biological differences. Social construction of race entails that the ideologies and practices that we affix on non-white people has a history and it changes over time based upon social, political, cultural, and economic contexts.
} 
relevance of his work lies in showing that race permeates virtually all aspects of American life and culture.

The ideas about what is beautiful and desirable are thoroughly racialized, showing that even our desires are permeated by race. McBride proves this by examining pornography and personal ads on the internet. By focusing on porn's representation of black men, he argues that this specific genre of cultural production represents the fetishistic nature of blackness including stereotypes about black masculinity that is brutish, socially and economically disempowered, animalistic sexuality that will fuck someone and be ready for more (McBride 2005: 102-103, 108). In the personal ads, he claims that whiteness is the salient variable which increases one's value in the gay marketplace of desire. As he argues:

[a] white man (in some cases, [...] a 'light-skinned latin man' may suffice - that is, if he is 'clean and safe'), who is 'very good-looking,' with 'a large penis,' a 'hot tight body,' and a masculine affect ('no fems' allowed after all), represents the ideal type, the sexy and desirable man that we should all want in the personals world" (McBride 2005: 117).

Acknowledging the importance of McBride's work in conceptualizing how desires are racialized in gay communities, there needs to be a more sociological explanation as to how these macro-level social forces (i.e., race) permeate into the micro-level (i.e., our desires), i.e., what processes are involved? It will be helpful if he conceptualized and treated pornography and personal ads as 'erotic works' to show how race becomes manifested in our desires. While he describes some of the features of how desires are racialized, he does not pay attention to how the variables he mentioned (i.e., race, gender affect, body types, penis size, and style) intersect to inform racialized desires. Rather, his main concern, it seems, is only about race. What is very interesting to note in his analysis of personal ads, methodologically speaking, is that his sample only includes whites and blacks and it is a very small sample to begin with. If he had a larger sample, he could draw more analyses as to how gay men in general (regardless of race, which 
would in turn inform us about the dynamics of the social structures found in gay communities), produce and reproduce their desires through this cultural vehicle and how they understand their desirability.

On a theoretical level, McBride's findings are beneficial in formulating how race permeates our desires. However, it will be more relevant if personal ads are used as 'erotic works', which would not only reflect the social structural forces in which an individual is located but also inform us how the desires and desirability of these individuals reproduce these social structures (this will be much clearer when I discuss my theoretical frameworks in the next chapter).

McBride suggests that race is the most important factor which dictates the dynamics of the gay marketplace of desire and he argues that black men who ascribe and embrace their fetishized representation to attract white men are strongly affected by the hegemony of whiteness, i.e., objectifying based on the white gaze (McBride 2005: 124). But not all black men are caught up in this net of white hegemony because there are some who declare their exclusive desire for other black men. However, this "does not resonate with equal systemic weight in the gay marketplace of desire" (McBride 2005: 118). McBride seems to celebrate these black-on-black desires and relationships without necessarily being critical of it. One scholar who provides a critical analysis of the discourses of interracial desires and relationships between gay white and nonwhite men is Ian Barnard (2004). In his chapter on "Representing Race in the Discourse of Desire," he charts some of the discourses about interracial relationships, which he describes as either racist or non-racist. He argues, however, that these discourses reproduce racism, but how and what processes are involved in the reproduction of racism is unclear in his discussion. Barnard's analysis of gay pornography parallels with McBride. Barnard argues that in the context of 
racist social structures, the objectification of non-white men is racist because white desire for black and Latino men are always linked with 'orgies' and 'shaved sex' (Barnard 2004: 38).

What is more interesting in Barnard's analysis is that he moves beyond the discourse of fetishization by providing a critical analysis of interracial relationships between white and nonwhite people. In this analysis, he aims to illustrate that racist stereotypes are either hidden or completely disowned in interracial relationships, in 'color-blind' discourses and 'black men loving black men' discourses. Although the discourse on 'black men loving black men' might be seen as a positive representation, he puts them through a critical lens because he believes that they replicate racist power relations. In the first instance (i.e., interracial relationships), the desiring subject (either a white or non-white man) claims that his preference is personal rather than political and that they are equal with any other preferential characteristics that mark people's erotic tastes such as gender, class, physical attributes, etc. (Barnard 2004: 42). However, he argues that the denial of racism within these relationships, "only emphasizes their inscription in racist power relations" (Barnard 2004: 44). The meaning of this is unclear because he does not go into much detail. It can be speculated that by distancing themselves from racist practices, they actually confirm racialized power which plays an important factor in these relationships.

Another form of discourse about inter-racial relationships is the claim to be colour blind'. In this particular discourse, race and racism are ignored by alluding to the humanistic principle that all people are equal. However, as in the former discourse discussed, the possibility of the existence of racism surrounding these relationships and within them is almost always denied or by referring to 'differences' without politicizing it (Barnard 2004: 44-45). Barnard does not provide enough discussion as to why he argues this, but Poon and Ho's (2008) research contend that these 'differences' often always refer to differences between white and non-white 
people, but not between non-white people. As I will discuss later, their research suggests that Asian men justify their desires for white men because of 'differences' but these 'differences' are not applied to other Asians or other non-white people. Instead, Asian men ascribe to the idea that all Asians are a homogenous group and all non-white people are also homogenous (Poon \& Ho 2008: 257-8). This then confirms the centrality of whiteness in the gay marketplace of desire, suggested earlier by McBride. Finally, Barnard focuses on a critique of these intraracial discourses by discussing the idea of 'black men loving black men', which McBride seems to celebrate but argues that it does not carry the same amount of weight as white-on-white relationships. While Barnard does not deny the positive political implications of this discourse to counter racist representations and fantasies of interracial desire, he argues that it is also problematic because they rely on nationalistic paradigms of "community and unitary models of subjectivity" (Barnard 2004: 51).

One of the most important contributions made by Barnard in the conceptualization of racialized desire is that he provides a critical analysis of discourses of interracial desire (between white and non-white men) that seem to be 'non-racist'. He offers an important framework to analyze these discourses, by suggesting that in the context of racist social structures interracial desires cannot escape racist power relations. What is problematic about this formulation, however, is that it reduces all desires to one power relation, i.e., race, without necessarily understanding that race always intersects with class, gender, age, and the body. It is also problematic because it essentializes all interracial relationships, without necessarily examining their dynamics. Barnard and McBride fail to adequately address the intersection between race and other relations of power and oppressions. I argue that desires and desirabilities should also be understood as intersec- 
tional, wherein, race, sexuality, gender, class, age, and body types reflect and reinforce the social structural forces that inform the dynamics of gay communities. ${ }^{10}$

A study done by Phua and Kaufman (2003) on personal ads by men on the internet confirms the importance of race in date selection by gay men, which presents a critical model to understand racialized desire. In their analysis, they found that among racialized gay men, white men appear to be a common preference. While this study confirms the existence of racialized desires, it does not tell us a lot about the dynamics of these desires. For example, what roles do masculinity, class, age, and the body play in the construction of these desires? Further, what do these desires for white men by racialized gay men confirm about the social structural forces that are present in gay communities? What about the preferences of white men?

\section{Gender and Desire in Gay Communities}

In mainstream media, gay men are often portrayed as being effeminate. Consequently, some gay men resist these stereotypes by embracing notions of gender and gender conformity. This might be related to the fact that most of us are socialized to adhere to gender norms. These portrayal and resistance are further exacerbated by the fact that our desires are directed towards men and masculinity. However, most scholars studying sexuality often overlook the complicated relationship between sexuality and gender. As Edwards (2006) argues, "to assert [...] that sexuality is a thing apart from gender for anything other than heuristic purposes is not only theoretically inadequate but empirically inaccurate and politically naive" (Edwards 2006: 89). Thus, in studying

\footnotetext{
${ }^{10}$ Intersectionality is a feminist theory and methodology used to understand that, "biological sex, the social construction of gender, and sexual orientation constitute distinct yet interconnected phenomena that, in turn, interconnect with race". Sexuality can be seen as a site of intersectionality, wherein various social divisions intermesh to create concrete experiences of oppression (Collins 2005: 11). Feminists debate the interpretation of intersectionality, specifically, whether it should be interpreted as 'additive' or 'constitutive'. According to Yuval-Davis (2006), the additive model sees working-class Black women as 'triply oppressed': as Blacks, women, and members of the working-class. Yuval-Davis, however, argues that understanding intersectionality as 'constitutive' is more helpful because, in concrete experiences of oppression, being oppressed as a 'Black person' is always intermeshed with other social divisions (Yuval-Davis 2006: 195).
} 
gay men's desires, it is necessary to analyze the role that gender plays in addition to other sites of analysis such as sexuality, race, class, age, and body types. This section focuses on the review of literature about masculinity (or masculinities) and gay men, and the role that gender plays in the analysis of gay desires.

Let me first concentrate on how gay sexuality is gendered. Connell (1995), Edwards (1994, 2006), Nardi (2000), Taywaditep (2001), and Ward (2000), all agree that homosexuality amongst men and women has always been gendered, i.e., gay men are oppressed for being effeminate or being the wrong kind of men and lesbians are oppressed because they are seen to be exhibiting masculinity instead of femininity. However, with the rise of the gay liberation in the 1970's came what Edwards describes as 'the clone culture', which rejected this association of effeminacy with homosexuality as gay men began to adopt the hyper-masculine and hypersexualized clone culture (Edwards 2006: 79). The rise of the clone culture emphasized masculinity as a gender affect and 'masculine bodies' (i.e., strong, muscular, toned, lean, atheletic) are idealized, desired, and obtained. The rejection of the 'sissy-nellie' by the clone culture resulted to what Taywaditep (2001) calls 'anti-effeminacy attitudes' amongst gay men. He also links these anti-effeminacy attitudes with clone culture. Prior to the rise of the clone, the gay community celebrated gender non-conformity.

The clone culture has real consequences for effeminate gay men, as they began to be less desired through repeated sexual and romantic rejections (Taywaditep 2001: 11). Thus, not only did effeminacy begin to be rejected but it also became less desirable. Taywaditep argues that these anti-effeminacy attitudes may be derived from the dominant hegemonic masculine ideology, adopted from mainstream society. Hegemonic masculine ideology means that masculinity is considered to be an asset, and it also stratifies and hierarchizes power. Those men who already 
have this power (i.e., hegemonic masculinity) retain their advantage by subordinating the disadvantaged. In the case of masculine gay men, they subordinate effeminate gay men. Further, since masculinity is considered to be an asset, it is often defended fervently by asserting masculinity through anti-effeminacy (Taywaditep 2001: 16). I wish to argue that anti-effeminacy attitudes have become not only desirable, but some gay men have also used it to describe their desirability. Clone culture radically changed the dynamics of gay desires, wherein masculinity in gay men became desirable and femininity was rejected. Taywaditep links this to the hegemonic masculine ideology evident in the larger social milieu which, I claim, is related to patriarchal social structures. However, Taywaditep does not go into too much detail about how the clone culture becomes manifested in our desires. It is arguable that this has been internalized by gay men, informing their desires and desirability. Clone culture, therefore, is an historical process, which triggered a change in the behaviours and sexual tastes of gay men. This is evident in the proliferation and obsession by a number of gay men with gym and body image. Possessing a lean and muscular body is a 'valuable' quality in the 'gay marketplace of desire'.

Indeed, clone culture largely affects how gay men desire and how they understand and articulate their desirability. Certainly, Taywaditep alludes to the fact that anti-effeminacy attitudes amongst gay men are the manifestation of masculinity in our desires and desirability. Edwards confirms this by suggesting that, "gay male desire often remains chained to limited models of masculinity" (Edwards 2006: 98). These models of masculinity being described is patterned on the gay clone, the hypermasculine male valorizing having multiple anonymous sex as the ultimate masculine performance, together with masculine features and muscular bodies. A major gap in these analyses, however, is how the hypermasculine gay clone is linked to race, class, ability, and the body. 


\section{The Body and Desire in Gay Communities}

In the previous section, I show how desires in gay communities are strongly linked with gender, especially how masculinity is considered to be the most desirable. What is missing in the literature reviewed above is a strong linkage between gender, race, class, age, and the body. In this section, I concentrate on the body because it is through it that masculinity can be visibly seen. The clone culture is strongly related with the proliferation of the gym for gay men. As I demonstrate, for gay men, being lean and muscular is the embodiment of masculinity often understood as white, middle-class, abled, and young.

As aforementioned, Edwards is critical of the very raison d'être of gay male desire because of its valorization of the limited definitions of masculinity. This problematic and limited definition of masculinity is further exacerbated by the very strong relationship of masculinity with muscularity. As Alvarez (2008) discusses in his chapter, 'Muscle Boys', "certain activities are associated with masculinity: weight training and body building. [Indeed], [w]eight training results in increased muscularity, which is typically seen as increased masculinity" (Alvarez 2008: 122). In his book, Muscle Boys: Gay Gym Culture, Alvarez discusses and celebrates (as a personal gym trainer) the proliferation of gay gyms, as he links it to health and positive body image for gay men. He differentiates between positive (or healthy) body image, which is wanting and desiring to be fitter, versus negative (or unhealthy or 'pathological') body image, which is obsession. However, the process of conforming to the desirable body must be problematised because this can be theorized as internalizing and embodying the social structures that are present in gay communities. Although Alvarez celebrates the proliferation of gay gyms and links it to positive body image, he does not critically examine the limitations of who is able to acquire these bodies. Indeed, he is chained to the limited definition of masculinity in gay communities. 
Nonetheless, his chapter on 'Muscle Boys' provides us with a point of discussion and criticism of the relationship of masculinity and muscularity with gay desires.

What role does the association of muscularity with masculinity play in the desires and desirability of gay men? For most gay men, masculinity and muscularity are relational and conflated: masculinity is muscularity and muscularity is masculinity. Alvarez also suggests that the most desirable males (as is often seen in gay porn and gay magazines) are muscular and masculine. This can be related to what Edwards laments earlier as the limited definition of masculinity that is valorized and considered as the most desirable by gay men. As Alvarez confirms, "for gay and bisexual men today, masculinity is, for the most part, a nonnegotiable demand whether from potential partners or from ourselves" (Alvarez 2008: 124). In his discussion of personal ads, Alvarez finds that so much importance is placed on muscularity that pecs, triceps, and abs are becoming crucial statistics used by young gay men to describe themselves (Alvarez 2008: 138). Alvarez, however, ignores the fact that bodies are not just gendered, but are also racialized, abled, and classed.

However, there are some issues with Alvarez's analysis of the body. To illustrate, I focus on two quotations offered by this author.

1. while one can't help one's height or skin color, one can keep oneself fit (Alvarez 2008: 135)

2. [o]n an intellectual level, we can compare the building of a beautiful body to that of getting an education. Education is something that takes time, energy, and dedication. One is not simply granted a college degree-one has to earn it. Similarly, most of us do not have naturally sculpted muscular bodies-we have to build them (Alvarez 2008: 137).

In the first quote, Alvarez seems to be suggesting that the body itself is the basis from which gay desires come from. He acknowledges that while 'race' cannot be changed, the body can be changed and so someone's desirability increases because they acquire masculinity. However, he 
seems to forget that the body itself is racialized, classed, gendered, abled, and aged. Indeed, as demonstrated by McBride and Phua and Kaufman in their treatment of racialized desire, whiteness is the central force that informs the desires of gay men. Alvarez's comparison of educational attainment and the sculpting of the body is, on many levels, problematic. He implies that in order for one to be desirable, they must have a sculpted, muscular, and desirable body. He also seems to suggest that every gay man has access or can afford to get an education; therefore, every gay man can also afford to go to the gym. Gym memberships are also costly and are often not accessible. In this case, one must have disposable income to actually afford it. Therefore, it seems that Alvarez's valorization of the gay gym culture is limited to gay men (mostly white) who are middle-class. This goes to further suggest that the desirable body is always classed, gendered, and also raced.

\section{Race, Gender, the Body, Class, and Age: the Desires and Desirability of Gay Asian Men}

In my discussion above, I provide a review of how racialized desires and desirability in the gay community are conceptualized by various scholars. Notably, Barnard suggests that within racialized social structures, the objectification of non-white people by white men is racist because it is based on exoticization and fetishization. Further, McBride and Phua and Kaufman suggest that whiteness is the main factor which informs the desires and desirability in gay communities. In this section, these themes will be recurrent in my discussion on Asian men's desires and desirability. However, while I strongly agree with the arguments put forward by these scholars, further analysis is needed to provide an intersectional perspective.

Certainly, race, class, gender, age, the body and sexuality cannot be separated in the analysis of desires and desirability in gay communities. In this section, I focus on gay Asian men and how all of these factors intersect to inform their desires and desirability. First, I discuss how 
various authors conceptualize gay Asian men's representation in various cultural forms. In Fung's (1991) celebrated work, "Looking for My Penis: The Eroticized Asian in Gay Video Porn," gay Asian men are portrayed as passive and taking on the role of the 'bottom' in gay pornography. Being a top and bottom entails a relationship of power because bottoming is associated with powerlessness, submissiveness, and passiveness (Han 2000: 218). ${ }^{11}$ Furthermore, Fung observes that Asians in pom rarely fuck a white man, but they are always seen as being fucked (Fung 1991: 152-3). Clearly, some representations of Asian men in porn are informed by ideas about Asian men's sexuality, often connected to gender, the body, and class. Although these representations do not illuminate our understanding of Asian men's desires, they do give us a sense as to how desirability of Asian male bodies are constructed in the porn industry.

Why do Asian men in gay porn produced for gay white consumption often take on the role of the 'bottom'? Why are gay Asian men objectified and fetishized for having feminine features? These questions are central to tracing the historical construction of Asian 'masculinity' in the West. Han (2008) argues that the feminization of Asian men is connected to Orientalism, which aimed to exercise domination and superiority to anything that is considered the 'Other' or the 'East' (Said 1978 in Han 2008: 10). Orientalism essentializes and aggregates vastly different cultural groups under the umbrella of 'Oriental' and constructs an image that is based on Western expectations, perpetually considering the 'East' as inferior and exotic (Leshkowich and Jones 2003: 282).

The construction of Asianness in Orientalist imagination is distinctively gendered, wherein Asian bodies (both male and female) are seen as feminine in opposition to the masculine (white) Western body. This is also evident in the construction of black bodies by Western co-

\footnotetext{
"It should be acknowledged that $\mathrm{s} / \mathrm{m}$ practitioners do not interpret the dynamics of top/bottom with being dominant/submissive. In fact, as Califia (2000) argues, "S/M relationships are usually egalitarian" (Califia 2000: 172).
} 
lonial powers, wherein, the black male body is turned into a penis, coupled with animalistic sexuality. In contrast to the Asian body, the black body is dangerous and hypersexualized; Asian bodies are feminine, delicate, and asexual. What is important to note, however, is that much like the black body, Orientalism also objectifies Asians as foreign, exotic, and different (Han 2008; Fung 1991; Hagland 1998). Orientalism then is a conflation of ideas that are constructed around gay Asian men: not only are they racialized and exoticized (i.e., objectified for being different from white Westerners) but this racialization also involves gendering (i.e., being seen as feminine, thus taking the 'feminine' role of the bottom).

The construction of Asianness is also classed. As Fung argues, most Asians in gay porn are younger men, and "[s]ince youth generally implies less economic power, class-race hierarchies appear in most of the work" (Fung 1991: 162). Not only is this classed, but this is also about age. For instance, Asians in gay pom are always portrayed as youthful. Further, “Asian men have routinely been portrayed as meek houseboys, asexual deviants, or domestic servants who fill 'female' roles when women are scarce," mirroring one prominent style of stereotyping of Asian men in Western popular culture (Hamamatoa in Han 2008: 233). Indeed, the racialization of Asians in general and gay Asian men in particular is conflated with class, gender, age, and the body.

These stereotypes about gay Asian men have negative consequences in their own desires and desirability. In Han's (2007) discussion on the centrality of whiteness (much in agreement with $\mathrm{McBride}$ ) in the desires of gay men, he claims that Asian men become desirable for white men because they are seen as submissive and exotic. Therefore, Asian men become vassals of white men's fantasies of domination (Han 2007: 54-57). However, within the context of gay desires, where white men are portrayed as desirable, white men who are actually attracted to Asian 
men are scarce. Further, as McBride contends and confirmed by Phua and Kaufman, images of white masculine and muscular men as the most desirable is also manifested in the desires of gay Asian men. Indeed, Han further indicates, the sexual day dreams of Asian men are populated by white men. He calls this phenomenon 'internalized racism', wherein the primacy of white images in the gay community negatively impact non-white gay men because they see other non-white gay men as undesirable (Han 2007: 60). Phua (2007) punctuates this finding in his analysis of the relationship of gay Asian with hegemonic masculinity. As he suggests:

some gay Asian American men's preference for masculinity relates only to [w]hite American men but rarely other racial groups [...]. Some gay Asian Americans will not even include someone in their mate consideration set if that man is not [w]hite, no matter how virile or masculine he is (Phua 2007: 915).

Unfortunately, these scholars do not provide a framework to explain Asian men's desires for white men. Albeit the claim of internalized racism or racial self-hatred is very strong, why these become manifested in the desires and desirability of gay Asian men is not addressed. Indeed, this relationship is taken simplistically by these authors.

Racial self-hatred is, in fact, contradicted by Asians who have only dated white men in a study done by Poon and Ho (2008). These authors found that, "almost all of [their] participants who dated only white men did not consider their erotic desire for white men as a sign of self hatred". Neither did they see Asians dating other Asians as self-love. Rather, "they saw their erotic desire for a white man as arising from a personal preference: there is no politics". Often, these men invoke the discourse of difference or opposite attraction; however, their talk of opposite attraction refers only to whites (Poon \& Ho 2008: 257-258). It must be acknowledged first that this study is thus far the only research done on the desires of gay Asian men. While these findings have important implications to how gay Asian men articulate and understand their desires, there are gaps that need further explanation. First, they do not problematize the idea of 'personal prefe- 
rence' or 'personal taste' by Asian men who are only attracted to white men. Indeed, it is impossible to determine the multiplicity of desires often expressed by Asian men for white gay men. By invoking these discourses, these Asian men 'naturalize' their tastes; however, since this is a group phenomenon, the authors should have explored this further and provided a sociologically informed explanation. How can we explain these desires as the manifestation of the social structural forces that are present in gay communities and how can we conceive these as the reproduction of these social structural forces in our desires?

The answer to this question lies in Bourdieu's concept of 'habitus' giving us the framework to study this 'naturalized' taste. In Bourdieu's study, he attempts to understand how culture becomes central to class domination to explain how 'tastes' for luxury or austerity are developed. According to Bourdieu, culture reproduces class domination because the dominant class imposes their tastes, standards, and values (i.e., their habitus) as central to organizing society. The dominant class mystifies or obscures their domination by promoting the ideology that the most desired and valued cultural forms are a product of gifted individuals. In this sense, instead of seeing specific lifestyles and cultural patterns as a reflection of class inequality, most people see these things as natural to the person (Seidman, 2004: 149). Thus, invoking the discourse of 'personal preference' or 'personal taste' can be argued to be obscuring the inequalities that are present in gay communities. Asian men's exclusive desire for white men reflects how the social structural forces in the gay community are embodied in their 'erotic habitus' (this will be clearer later on when I discuss my theoretical framework). As such, this discourse of 'personal preference' must be problematized. The fact that the discourse of 'opposite attraction' only refers to white men might also allude to the larger phenomenon of desires in the gay community (i.e., the centrality of whiteness which intersects with masculinity, muscularity, and middle-class lifestyle). These 
authors fail to explain how these desires in the context of racialized society reflect the social structural forces manifested in our desires.

Largely absent from my discussions thus far is the conceptualization of white men's desires for Asian men in particular. Barnard suggests that within the context of racialized social structures, the objectification (via exoticization and fetishization) of non-white people by white men is particularly racist. The objectification by white men of non-white men is based on the construction of a 'normal' Westerm sexuality in opposition to the 'abnormal Other'. As discussed earlier, part of 'Orientalist' discourse is based on the feminization of Asian sexuality as meek, delicate, innocent, and submissive. This feminized, even infantalized, Asian sexuality is used to describe interracial desires between white men and Asian men. Indeed, in the gay community, Asian-white relationships are described through racist discourses, wherein the white man who is usually older, is called a 'Rice queen' while the Asian man is called a 'Potato queen'. As Han (2000) argues, "[i]n this relationship, the Asian man is placed in the role of the 'woman', whereas the Rice queen, culturally and sexually, is defined as the "man" (Han 2000: 219). Rice queens fetishize Potato queens. Notably, this discourse is not only racialized but it is also paralleled with gender connotations. What is particularly interesting about this discourse and other terms that are used to describe interracial relationships in the gay community (e.g., 'Dinge queen' for white men who desire black men, 'Bean queen' for white men who desire Latino men) is the absence of a term to describe a relationship between two white men. This tells us that whiteness in the gay community remains unmarked and therefore, white-on-white relationships are normalized. Since white-on-white relationships are unmarked, these relationships are always seen as equal, whereas Asian-white relationships are always seen to be gendered and racialized therefore, unequal. 
It is interesting to note, however, that not all Asians who desire white men see themselves to be 'desperate' Asians who would just 'settle' for anyone who is white, no matter if he is attractive or not. As Poon and Ho (2008) describe:

[b]y differentiating themselves [i.e., Asian men who do not identity as 'potato queens'] from those who date rice queens [who are described as 'predators' and 'fetishists' by these men], they consider their erotic desire for white men fundamentally different: Asian men who date rice queens signify a form of sexual colonization and self-hatred but they don't. It is clear for them that dating white men is fine as long as they are not rice queens-in spite of that they may end up dating someone who is characterized as a 'rice queen' by their peers (Poon \& Ho 2008: 259).

Clearly, divisions are created within the gay Asian community. There are those who see themselves as 'normal' Asians who have 'normal' desires for white men and there are 'other' Asians who are seen as 'potato queens', dating white men considered as 'rice queens'. What is crucial to note is that so-called 'normal' Asians have the same desires as potato queens. Their desires are a reproduction of the 'habitus' found within the gay community itself, i.e., that white men are desirable. Despite the differentiations created by these 'normal' Asians from 'potato queens', in the end, they are still caught within the chain of racist power relations, as Barnard would argue. Sudarto (2008) would also agree with this analysis in his study of an Asian/white couple who describe their relationship as 'equal'. He uses Giddens' concept of 'pure relationship' to prove that not all Asian/white interracial relationships are unequal, much like how the research subjects in Poon and Ho's study conceptualize their desires for white men. However, Sudarto argues that while these couples differentiate themselves from the stereotype of the unequal Rice queen/Potato queen relationships, they still follow the dominant discourse regarding Asian/white relationships. Indeed, "[i]t creates a duality between 'good' Asian/White couples from 'undesirable' Asian/White relationships" (Sudarto 2008: 31). I argue that Barnard's critique of the 'nonracist' discourses used to describe interracial desires between white and non-white men actually 
reproduce racist power relations because they are still caught within the web of racialized desires. Within the 'known' scholarship of racialized desires as presented in this chapter, the centrality of whiteness is emphasized and confirmed. Sudarto argues that, while it is largely unknown whether inequality within white/Asian relationships exists, it is nonetheless ingrained in the discourses used by the gay community and it is widely presented as being 'real'. As a result, interracial relationships between Asian/white and white/non-white men are de-legitimized.

\section{Summary}

This chapter provided a review of the literature on gay desires and desirability, specifically on racialized desires. I offered an overview of how 'racialized desire' is conceptualized by authors such as McBride (2005), Barnard (2004), and Phua and Kaufman (2003) who place emphasis on the centrality of whiteness which informs the dynamics of desires and desirability in the gay community. However, I argued that this conceptualization does not provide a complete analysis of 'whiteness'. I then focused on the discussion of masculinity being desired by gay men. Specifically, I have drawn on the works of Edwards (2006) and Taywaditep (2001) in their discussion on the clone culture which promoted masculinity as something that is to be desired, manifested in the anti-effeminacy attitudes that are prevalent amongst gay men. This means that gay men prefer to date masculine men and shun effeminate men as undesirable. However, in this discussion, these authors failed to discuss how masculinity is racialized, classed, aged, and bodied. Alvarez's work is important because he has shown that, for gay men, masculinity and muscularity are conflated which they consider to be the most desirable. Largely absent from this, however, is a critique of the gay gym culture, accessible only to gay men who are able-bodied, have disposable time and income. Thus, what can be drawn out from this review of the literature is that 
whiteness, masculinity, muscularity, youthfulness, and middle-class lifestyles intersect to inform gay desires and desirability.

The question of how do Asian men's experiences come into play, however, needs addressing. In the final part of this chapter, I have provided a review of the 'Orientalism', which feminizes Asian men and considers them fundamentally different. This feminization is fetishized and objectified by white men who desire Asian men, as shown by Fung (1991), Han, C. (2007, 2008), and Han, S. (2000). I focused on scholarship which described Asian men's desires for white men. This scholarship is drawn from the absence of Asian men in popular media in the gay community. However, some Asian men, as demonstrated by Poon and Ho's (2008) research, do not see these desires as being racialized; rather, they conceptualize their desires as a 'personal taste'. I critique this by suggesting that if this is a group phenomenon (among Asian men who desire white men), this 'naturalized' discourse can be explained sociologically through Bourdieu's concept of 'habitus'. The next chapter focuses on the concept of 'erotic habitus', derived from Green (2008a) to sociologically explain desires and desirability. 


\section{Chapter 2:}

\section{Theorizing Erotic Desires and Desirability}

Acknowledging ways the desire for pleasure, and that includes erotic longings, inform our politics, our understanding of difference, we may know better how desire disrupts, subverts, and makes resistance possible (hooks 1992: 39)

For bell hooks, erotic desires should be politicized by critically reflecting on how we can use them to resist, disrupt, or subvert especially in the context where the desire for the 'Other' is unquestioned. However, she warns us that we should not accept the desire for the 'Other' uncritically. My aim in this thesis is to explore the politics of erotic desires. Politicizing desires could result to the policing of desires and may even create a dichotomy between what could be considered as 'bad' and 'good' desires. Conversely, I will demonstrate that erotic desires can be sociologically explained by illustrating that social structural forces influence erotic desires in gay communities (but of course, this could be applied outside of gay communities). I argue that desires and desirability are sociological phenomena by linking them to C. Wright Mills' (1959) concept of 'sociological imagination'. According to Mills, the first fruit of sociological imagination, "is the idea that the individual can understand his own experience and gauge his own fate by locating himself within his period, that he can know his own chances in life only by becoming aware of those of all individuals in his circumstances" (Mills 1959: 5). Thus, by locating the individual within his/her own socio-historical place, we may be able to discern specific patterns of erotic desires and desirability, which are largely shared by those who are in the same social circumstances. This particular pattern shows that desires and desirability are produced and reproduced by social structures. The sociological contribution is not to be deterministic about the direct correlation between social structures and erotic desires; but rather show that structural forces contribute, but are not reducible, to the production and reproduction of desires and desirability. 
This chapter outlines the theoretical framework of this thesis. I begin with a discussion of the market-analogy to examine collective sexual life and specifically, the commodification and consumption of 'Otherness' by white men. The most important contribution of the marketanalysis is that it provides a framework to understand that individuals have exchange-value accrued to them, which they use to participate in the 'field of gay desire'. This analysis offers a context to analyze how the consumption of the 'Other' is based upon the 'value' believed to be intrinsic in the bodies of the 'Other'. It enables me to understand, on the one hand, the 'erotic capital' of 'Others' as fundamentally linked to racialized imaginings. On the other hand, it also provides a framework to understand the erotic capital of white men as the most valued commodity.

Proponents of the market analysis, however, do not shed light on how we come to develop desires and desirability. To address this, I map out what is considered to be the most widely used sociological theory in understanding desires and desirability, namely, Gagnon and Simon's (2005) sexual script theory (SST). On the one hand, Gagnon and Simon and others who are influenced by their work offer a framework to study the relationship between social structures and how we practice sex and sexuality. On the other, SST only goes so far as mentioning the role of social structures, which in turn gives us the 'scripts' and guidelines on how we practice sex and sexuality. SST fails to explain how and why these social structures exist in the first place (at the level of macro-structures). At the micro-level, SST fails to account for how we come to objectify certain persons as desirable and the related intersubjective processes that goes with it. Thus, following Green, I adopt the concept of 'erotic habitus' in order to provide a better analysis.

'Erotic habitus' is a concept derived by Green from Bourdieu's habitus, i.e., a theory that explains how the macro-structures penetrate the unconscious, which ultimately forms and in- 
forms our desires and desirability. Since habitus is both subjective and objective, our desires reproduce the social structures at the macro-level, which in turn shape our desires and how we come to see and objectify ourselves as desirable. Green fails to adopt Bourdieu's 'field' and 'capital', concepts which are essential to the understanding of habitus. In my thesis, I use these terms in relation to Green's erotic habitus since they are relevant in explicating the field of gay desire as a social field, the main location of gay desires and desirability.

\section{Market Analogy and the Commodification and Consumption of 'Otherness'}

In this section, I provide an overview of the market-analogy, which conceptualizes desires as a marketplace, based on competition and consumption. I discuss the market analogy framework as a background to critique Green. Specifically, I argue that Green's rejection of this framework is ineffective because this is essential in conceptualizing one's 'value' or erotic capital. Neoliberal capitalist economy plays a major role in gay communities. Conceiving collective sexual life as 'markets' is not new nor surprising given that most areas of our lives are caught in the web of the economy. For instance, Peñaloza (1996) describes the importance of the market economy in defining the political incorporation of subaltern groups, such as LGBTQ individuals. In fact, she argues that, "the marketplace may be viewed as an important domain of social contestation whereby disenfranchised groups engage in ongoing struggles for social and political incorporation". Indeed, the capitalist market becomes the channel from which the political, social, economic, and cultural enfranchisement of LGBTQ individuals and groups are legitimized. Further, the market targets LGBTQ identity, through advertisement, in turn, shaping gay subjectivities and agency. This is due to the fact that through advertisement, gay subjectivities are defined and through consumption, gay agency becomes possible (Peñaloza 1996: 16-17). In this context, LGBTQ identi- 
ties are commodified ${ }^{12}$ and are available for consumption. Through the marketization of gay identities, the market gives a space for LGBTQ individuals to feel accepted. This is evidenced in the normalization of gays and lesbians in advertisements, but the main reason for this commodification is linked to the survival of capitalist economy. It must be noted that the neo-liberal capitalist market tends to commodify white, middle class gay and lesbian identities because they are believed to be fuelling the 'pink economy' ${ }^{13}$ Consequently, they are perceived as the universal representation of all LGBTQ individuals and their status as 'good' citizens is solidified. Indeed, as Bérubé (2001) points out, in order for the LGBTQ community to gain recognition and credibility, "some gay organizations and media began to aggressively promote the so-called positive image of a generic gay community that is an upscale, mostly male, and mostly white consumer market with mainstream, even traditional, values" (Bérubé 2001: 235). The promotion of the 'positive gay image' fuels the whiteness ${ }^{14}$ of LGBTQ communities and ensures that these communities remain white. This type of whiteness is also what could be considered as the most desirable in the gay community (which is of course, always gendered, classed, and embodied, as I have discussed in the previous chapter), which leads to the 'economy' of desires.

While the 'pink economy' perpetuates the myth that the commodification of LGBTQ identities is a form of liberation, on another level, the conceptualization of erotic desires as 'markets' gives erotic desires the characteristics of capitalist economy. It is helpful to conceptualize desires in gay communities as marketplace because, as McCaskell (1998) argues, "the gay com-

\footnotetext{
${ }^{12}$ Commodification in Marxist theory is the idea that goods and services, which are not normally as such, are turned into commodities. In this particular example, gay identities are turned into commodities by advertising, thus appealing to gays and lesbians to spend their money to, say, gay-friendly establishments and corporations.

${ }^{13}$ The term 'pink economy' is used to describe a market that targets rich or middle-class LGBTQ individuals, which is often mistaken for liberation. For further discussion, see Floyd (2009) and Hennessy (2000).

${ }^{14}$ In this case, whiteness means that being 'gay' remains 'white' by excluding non-white gay men in representations and establishments in the gay community. As I have discussed, this type of whiteness is a conflation of youthfulness, whiteness, masculinity, muscularity, and middle-class lifestyles. See previous chapter for a detailed discussion.
} 
munity is a sexual marketplace where people aren't so likely to get frozen with one partner" (McCaskell 1998: 46). This marketplace of desires is based on competition, for the coveted 'price,' i.e., what is considered the most erotically desirable. In this case, white, masculine, muscular, young, and middle-class men. The conceptualization of desires and desirability as having market-like processes offers an idea of how individuals compete against each other through the accumulation of capital ${ }^{15}$ (in this case, 'erotic capital'), intrinsic in Bourdieu's concept of habitus and the foundation of Green's erotic habitus. This concept of the capital-accumulating individual highlights an important element in the conceptualization of the 'self' in the West. As Skeggs (2004) argues, the different formations of the self in contemporary Western cultural and social theory "are premised upon the accrual of property and value in the self via various technologies" (Skeggs 2004: 75). This accruing individual is a product of the capitalist economy, which is oriented towards the exchange-value of things without consideration to its historical formation. Further, the accruing individual is, "a self that can conceive of a future in which value can be realised" (orig. it., Skeggs 2004: 77). In the context of desires, the self is conceived on the notion that individuals accrue different values (i.e., erotic capitals) and these can be exchanged in the form of sexual and/or romantic relationships by effectively marketing (by objectifying) the self as a sexual commodity. ${ }^{16} \mathrm{I}$ demonstrate below that desires and desirability are theorized based

\footnotetext{
${ }^{15}$ The notion of capital is intrinsic in Boundieu's theory of habitus. Capital plays an important role because agents and institutions struggle to maintain or overturn the existing distribution of capital. According to Wacquant (2006), there are three principal forms of capital: economic (wealth), cultural (titles, knowledges), and social (membership in a group, social ties). A fourth one, symbolic capital, are forms of capital which people do not necessarily perceive as such (such as when we attribute good moral qualities to billionaires who 'donate' their money to charities) (Wacquant 2006: 7; Seidman 2004: 149).

${ }^{16}$ In this thesis, marketing the self or commodifying the self is synonymous to self-objectification (i.e., highlighting what individuals come to think and see as their most desirable desirable attributes as erotic capital). This process is done for various purposes and gains, particularly to attract their objects of desire. Thus, this process can also be understood as a form of agency, informed by the erotic habitus.
} 
upon the assumption that someone has a value and these values are accumulated and advertised as commodities to inform others of their desirability.

In a study conducted by Thorne and Coupland (1998) on personal ads by gays and lesbians, they argue that it is important to interpret these ads "more specifically as commodified and marketised discourses" (Thorne and Coupland 1998: 234). In these marketised and commodified 'dating markets', the personal ads "are modelled on the 'small ads' paradigm, which principally serves to sell second-hand consumer goods" (Coupland, 1996 in Thome and Coupland 1998: 235). Here, we can see the market-like characteristics of the dating market, where the accruing individual focuses on the exchange-value of the self. These market-like characteristics can also be transposed to the sexual market using personal ads on the internet. The self is commodified in personal ads to become desirable and consumed as a sexual object. Further, the objectification and commodification of oneself as sexually desirable is based upon the understanding of one's value in the marketplace of desire. The commodification of one's desirability through personal ads only features marketable attributes, which McBride (2005) suggests to be centered around whiteness (Thome and Coupland 1998; McBride 2005). By featuring only marketable attributes of the self, one's desirability is understood through the paradigm of exchange-value, wherein whiteness and other attributes (such as one's masculinity and body) are highlighted to place oneself in the hierarchy of desires and be sought after as desirable by other gay men. This can be seen in the following example of an online personal advertisement, extracted from McBride:

Edgewsxyguy [...]

Hot Euroguy looking ...

29/5'11"/160/slim-defined/abs/great shape/gdlking and masculine, uncut :-) Looking for a hottie for safe play, possible LTR. Caucasians only, be D/D free and in shape, no fems pls... (McBride 2005: 113). 
In this example, this gay man's age, body, race, and gender-affect are highlighted and objectified as valuable and understood as having exchange-value. Further, his 'value' or 'capital' is only exchangeable for a Caucasian male (must be white), who is in shape (must have body capital) and masculine ('no fems' i.e., read: masculine). This tells us that desires and desirability are intersectional. McBride elaborates on this with conceptualizations of erotic desires in gay communities as having market-like characteristics.

The market-based analysis of erotic desires is explicit in McBride's concept of the 'gay marketplace of desire'. In his description of this 'marketplace', McBride suggests that different variables constitute someone's 'value' which are largely based on "race, gender-affect ('butch'/'femme'), body type (muscle queen, gym bunny, swimmer's build, fat, slim), age, penis size, style" (McBride 2005:88). However, as I have discussed in the literature review, while McBride mentions that these variables determine one's value in the marketplace, he only concentrates on race as a salient factor, without necessarily linking it as to how race intersects with other variables, which constitutes and affects one's value. Although this is a limited analysis, it is helpful in the discussion of the centrality of race in the gay marketplace of desire.

How does race accrue its exchange-value in the gay marketplace of desire warrants a revisit of McBride's discussion of gay pornography. As he argues, the currency (or exchangevalue) of black male bodies is that, "Black men $[\ldots]$ are presented as fetish objects for the "white gaze' (i.e., the racially inflected demands and expectations consumers of these imagesregardless of biological race-bring to them)" (McBride 2005: 104). This suggests that the exchange-value of black male bodies is based on racial imaginings (as it exists in the white mind). McCaskell (1998) also argues that non-white men accrue value through exoticization and fetishization by positing that, "[t]hose of us who have assigned other 'racial' categories live with vari- 
ous kinds of stereotypes of otherness projected on our bodies that determine our value in the sexual marketplace, as marginal or exotic" (McCaskell 1998: 46). The role of the racialized body then plays a major part in the fetishization of racialized men. Black male bodies accumulate exchange-value because of its perceived 'dangerousness'. This 'dangerous' sexuality is rooted on the racialized imaginings of the large black penis. Indeed, as Friedman (2001) discusses, whether the penis is actually large or not, what is important is that this notion enjoys wide currency and is a mainstay of social discourse. More importantly, Friedman suggests, "many of those white people believe that 'larger' black penis has a major-read: 'dangerous'-cultural meaning" (Friedman 2001: 125).

The commodification of black male sexuality in gay pornography through racialized imaginings is also echoed by Barnard. In his analysis, non-white men are commodified for white consumption through invocating racial stereotypes, wherein, "white desire for black or 'latin' men is paralleled with 'orgies' and 'shaved sex' in a seemingly infinite shopping list [...] of white sexual tastes and practices" (Barnard 2004: 38). Black male sexuality only becomes 'valuable' for white consumption because of what is seen as its dangerous sexuality materialized through the big black phallus, without any consideration of other factors. Skeggs' (2004) discussion of the exchange-value of things which is a legacy of the colonial formation of personhood underlines this notion. Indeed, "the European colonial self, [is] premised on understanding only the exchange-value of things and not imbuing things with meaning, memory, and history" (Skeggs 2004: 77). The 'value' of black male sexuality is entrenched on the exchange-value of the big black penis, imagined to have dangerous qualities, without seeing its meaning, memory, and history as having been informed by racial ideologies. 
What is further interesting in this marketplace of desire is that non-white men are commodified characterized by the ideas of their fetishized differences with the dominant (i.e., white men). Non-white men are reduced to fetishistic objects, literally listed as objects on a catalogue, waiting to be 'picked' and consumed by white men. The desirability (and indeed, the exchangevalue) of non-white gay men are based on the imaginings of white men. The objectification and commodification of non-white men are then advertised to satisfy the palates of white men as consumers and not for other non-white men. In this marketplace, 'Otherness' becomes something that is marked to be consumed by white men, to the exclusion of others. The questions, however, on how and why this consumption of 'Otherness' is popular needs to be addressed.

The consumption of 'otherness' as discussed by bell hooks (1992) in "Eating the Other: Desire and Resistance" is linked to commodity culture. hooks argues that the obsession with the 'Other' within this commodity culture is that, "ethnicity becomes spice seasoning that can liven up the dull dish that is mainstream white culture" (hooks 1992: 21). In this sense, non-white people's ethnicities are fetishized to have some properties that could and would potentially change the lives of white people. As she further argues, commodity culture in the US exploits the idea that "racial difference marks one as Other and the assumption that sexual agency expressed within the context of racialized sexual encounter is a conversion experience that alters one's place and participation in contemporary cultural politics" (hooks 1992: 22). Here, we can see the important role of commodity culture in the construction of the 'Other'. By marking racially different people from white people, whiteness becomes normalized, concurrently constructing racialized people as 'Other'. Furthermore, commodity culture promotes the idea that a sexual encounter with the 'Other' is a conversion experience, potentially giving someone 'cultural capital', especially to a white person. By highlighting the fact that their sexual tastes are 'multicul- 
tural', they might be seen as not being racist or even colour-blind. By legitimizing their 'consumption' of the 'Other', they are welcomed by racialized minorities as being 'positive'.

Racial differences are no longer detested. Barnard's discussion of 'non-racist' or 'colourblind' discourses on interracial gay relationships echoes hooks' idea of the conversion experience. These discourses are dependent on the claim that, "the preference is personal rather than political", invoking discourses of compatibility. In this context, the non-white person might desire the white person openly, without necessarily articulating this desire in terms of the desire to have or be associated with white privilege. On the other hand, the white man could claim that his attraction for black men is rooted from 'black beauty' or culture without necessarily invoking racist stereotypical discourses (Barnard 2004: 42).

Barnard is also a sceptic of the 'colour-blind' discourses, wherein race and racism are completely ignored, by invoking discourses of humanism, "that all people are really the same and the bourgeois construction of romantic love" (Bernard 2004: 44). However, these discourses must be examined deeper. Albeit fethishism is not always racist or objectionable, "in the context of racist social structures [...], the objectification of men of colour is racist, especially when whiteness is normalized" (Barnard 2004: 38). hooks would agree with Barnard because she argues that the desire of white men for 'Otherized' women and men is part of what she calls, 'imperialist nostalgia' within commodity culture. As defined by Renato Rosaldo, "nostalgia, often found under imperialism, where people moum the passing of what they themselves have transformed" (Rosaldo in hooks 1992: 25). In this sense, nostalgia is a longing for the 'primitive' which Western imperialists transformed. In contemporary commodity culture, however, this nostalgia found its way into the bodies of the 'Other'. As hooks suggests:

[t]his longing [imperialist nostalgia] is rooted in the atavistic belief that the spirit of the 'primitive' resides in the bodies of dark Others whose cultures, traditions, and lifestyles 
may indeed be irrevocably changed by imperialism, colonization and cultural domination (hooks 1992: 25).

Clearly, the ideas of 'primitiveness' materialize in the bodies of the 'Other'. The bodies of the 'Other' then become an important site because they not only embody the primitive spirit, but they also become the very sites which are to be consumed by white men. However, this longing or desire to make contact with the Other is rooted in the guilt of the past (hooks 1992: 25). Not only is this desire for the Other fuelled by guilt, but this nostalgia is also directly linked with post-modern crises in identity which features "alienation, no sense of grounding, no redemptive identity" but it could be appeased by the commodification of the Other. This is due to the belief that through the consumption of the Other, mainstream white youth culture can have access to the life-sustaining alternative culture of the 'primitive Other', which the contemporary American culture cannot offer (hooks 1992: 25). There are numerous connections to be made, however, I wish to concentrate on the sexual consumption of the primitive Other, believed to have some fetishistic connection with nature (with what is 'natural' or 'organic'). This is arguably part and parcel of contemporary identity crises in the postmodern era, wherein white youth have become sceptical about the promise of a better life through technologies and science. Instead, they want to be closer to the 'primitive' for the belief that they are saving themselves and the world from destruction. This imperialist nostalgia relates to Orientalism. Orientalists aggregate and essentialize all Asian cultures. Concurrently, they are seen as being exotic, delicate, and feminine, as opposed to the strong and dominant West. Orientalism is arguably intersectional because it does not only mark Asians as fundamentally different (read: racialized); but they are also feminized. Asian men then become vassals of white men's fantasies of domination (Han 2008: 54-57).

The relationship between Orientalism and the imperialist nostalgia is demonstrated by Joseph Massad (2007) in Desiring Arabs, wherein he discusses how the Orientalist notion of 
sexuality by the West is based on difference. In this context, however, 'Orientalism' is specific to the Arab world. As Said argues, "in the twentieth century one thinks of Gide, Conrad, Maughan, and dozens of others. What they looked for often-correctly, I think-was a different type of sexuality, perhaps more libertine and less guilt-ridden" (Said in Massad 2007: 11). This phenomenon, however, did not stop in the twentieth century. As Massad argues, "[t]he ambivalent gay representation of the Muslim world as 'homosexual paradise' has led some European gay men to convert to Islam," which led to the influx of white gay men to Morocco (Massad 2007: 176). This represents the fetishization of gay Muslim sexuality, which is related to hooks' notion of imperialist nostalgia. First, it aggregates all Muslim gay men to be the same and secondly, it essentializes gay Muslim sexuality as fundamentally different from the 'West'. In this sense, white gay men are attracted to the belief that Muslims are more tolerant about homosexuality than the West. Indeed, while this cannot be directly linked to nature, it can be connected to the belief of the so-called primitive sexuality of Muslim gay men, who are freer and less guilt-ridden.

This is also related to sexual tourism in general wherein, "[non-white men and women] are often portrayed as being wildly sexual, comparable to animals, which welcome sex at any time" (Brock and Thistlethwaite, 1995 and Harrison, 1997 in Hargrove 2005: 130). This sexual commodification is directly linked with imperialist nostalgia, to rediscover what once was lost by colonialism and imperialism. To have sex with the Other is to celebrate the naturalistic and primitive sexuality of the Other. It must be noted, however, as hooks argues, that this celebration "is linked to white western conceptions of the dark Other, not a radical questioning of these representations" (hooks 1992: 26). These representations aggregate non-white people and justifying these differences through a naturalistic discourse. 
To summarize, the market-analysis, wherein the 'Other' is commodified and consumed by white people, offers an analytical framework to understand racialized desires in general, and in gay communities in particular. Indeed, McBride alludes that the 'value' of black male sexuality is solidified through racialized imaginings, which are premised on the idea of 'dangerous' and 'primitive' sexuality embodied through the black penis. Barnard echoes by discussing the commodification of black sexuality as fetishization, consumable by white men. hooks also demonstrates that commodity culture allows white youth to consume the Other because of the belief that they can have access to primitive sexuality. The commodification of Otherness becomes a symbol of legitimization of the enfranchisement of racial minorities. In this sense, the value of racialized minorities is appropriated by commodity culture, where they are marketized as commodities because of their exotic qualities and sexual availability, free to be consumed by white men.

However, Green rejects this market-analysis, in favour of 'sexual fields' (which is adopted from Bourdieu's 'fields'), because he believes that bodies are not linked to sexual currency. A sexual fields approach is not reducible to a payment for an object because, "human beings actively confront status structures", which gives agency to individuals (Green 2008b: 28). His critique of the market-analogy ultimately rejects the concepts of 'value' that are accrued to individuals, which determines their participation in the marketplace. This is due to the fact that he does not believe that the logic of interaction is based on utility maximization (Green 2008b: 28). His answer to this is to hook his analysis to a Bourdieusian analytic of fields. However, as I will show later, the concepts of field, capital, and habitus, as originally intended by Bourdieu, is fundamentally linked to commodity culture. 


\section{Sexual Script Theory}

In this section, I explore the major sociological theory used to analyze erotic desires. I focus on Simon and Gagnon's sexual script theory (SST), the main theory used by sociologists in analyzing the sociology of desires and discuss its advancements and limitations. Green does not necessarily reject this theory, but he uses it to complement his notion of 'erotic habitus'. Gagnon and Simon's most important contribution to the sociological study of sexuality is the social construction of sexual identities and behaviours (Kimmel 2007: xii). Kimmel suggests that Gagnon and Simon's notion of sexual scripts is that, "[s]cripts provide a cognitive map to the domain of the sexual - through scripts we learned how to have sex, what was sexy and what was not, even how to experience pleasure" (Kimmel 2007: xi). Here, we can see how SST is focused on scripts as the basis to which everything that is sexual is explained. According to Gagnon and Simon (2005), there is no such thing as 'spontaneous' sexual behaviour because each spontaneity is guided by scripts. As they argue, "[w]ithout the proper elements of a script that defines the situation, names the actors, and plots the behaviour, nothing sexual is likely to happen" (Gagnon and Simon 2005: 13). For example, if a young gay man is in a hotel room and sees a naked man in the room, he would not automatically assume that the naked man is there for sex. Rather, he would check if he is in the right room and might not automatically assume that sex would follow, unless the naked man makes a sexual move (such as touching and kissing), which would initiate a sexual act. This kind of initiation would define the situation as being sexual. (This example is similar to the instance Gagnon and Simon provide, see Gagnon and Simon 2005: 13).

Their use of the term 'scripts' has three major dimensions: cultural scenarios, interpersonal scripts, and intrapsychic scripts. Cultural scenarios are the larger cultural frameworks and roles in which sex is experienced. These are "culturally specific 'instructions' for sexual con- 
duct" (Laumann and Gagnon in Green 2008a: 601). In the example I provided above, these "instructions' are the actions that the naked man in the hotel room does to initiate sex (e.g., touching and kissing) and determine that the encounter is sexual and not something else. This initiation also acts as 'instruction' for the main actor who was unsure if the encounter was sexual or not in the first place. Interpersonal scripts are the social interactions between people, providing the instructions to guide people through these interactions. In the example above, the 'how' of this sexual exchange happens when the actors determine that the situation is sexual. They can then begin to negotiate what other sexual actions they might want to engage in. Finally, intrapsychic scripts refer to the intemalization of the levels of the cultural scripts into the psyche, which also informs desires and desirability. In our example above, their previous sexual encounters would 'guide' them through this situation, wherein they would know how to take turns, who gets to 'top' and 'bottom', etc. (Green 2008a; Kimmel 2007).

Gagnon and Simon's important work arguably provides us with a framework to study the relationship of social structures with how we practice sex and sexuality. In this context, I demonstrate how one may be able to use SST by itself to explicate the relationship of cultural scenarios, interpersonal, and intrapsychic scripts with what we come to deem as sexually arousing. For instance, 'hegemonic masculine ideology' (a concept which I have discussed in the literature review) as a cultural scenario in gay communities becomes the basis of the 'instructions' on how to behave properly around another man who is an object of someone's desire and how to negotiate and initiate sexual encounter with this person. This 'hegemonic masculine ideology' is internalized by gay men, which affects what and how they come to know and acknowledge that someone is sexually arousing or not. 
For example, in a study done by Whittier and Melendez (2007) on gay men's subjectivity and gender preferences, they posit that gender expression was a way for some men to feel sexually attractive to other men. Quoting a participant named Robin about going out with his boyfriend, he recounts, "I dressed like...I haven't done it in years but I dressed like cowboy hat, boots and stuff. I think that made me feel really uh... really masculine. You know, that really turned me on" (qtd. from Whitter and Melendez 2007: 199). In this particular example, masculinity as a cultural scenario informs the interpersonal scripts of gay men. According to Gagnon and Simon, interpersonal scripts are, "the script as the organization of mutually shared conventions that allows two or more actors to participate in a complex act involving mutual dependence" (Gagnon and Simon 2005: 14). In this sense, Robin's masculinity is read by him and other gay men as being sexually attractive, according to the logics of 'hegemonic masculine ideology'. In this particular example, the intersubjective process between Robin and other gay men is highlighted, because his perception of his masculinity becomes a point of his desirability.

Concurrently, this is also read by other gay men as desirable. The authors argue that hegemonic masculinity frames the sexual scripts of gay men, as shown in this example. In another example, Ramon says he wants to be in control because for him, being in control is "being the man". This means that he tops his sexual partners in anal intercourse. He says, "I carry myself well. And my fantasy is to be with a guy that is equally that way or bigger that I could have control of" (Whittier and Melendez, 2007: 200). His sexual fantasy comes from the larger cultural scripts of images and representations of masculinity. Hegemonic masculine ideology becomes an 'intrapsychic script' to how sexual encounters are managed, especially in Ramon's case whose idea of masculinity is to take control of his sexual partner by 'topping' him. Intrapsychic scripts according to Gagnon and Simon, "suggest that social action is always conducted with an ongoing 
internal dialog about internalized cultural expectations" (Kimmel 2007: xii). Ramon's masculinity is informed by dominating his 'bottom', as internalized cultural expectation wherein masculinity dominates femininity. In this particular case, the 'bottom' becomes emasculated by the 'topper'; thus legitimizing Ramon's masculinity.

However, scripting theorists do not provide an explanation of how and why these men acquire and enact these desires for masculinity or how race complicates SST even further. Rather, they only offer a framework to describe the effects of social experiences with particular desires (Green 2008a: 604). For instance, in the examples, hegemonic masculine ideology is only able to explicate the particular desires of gay men who see themselves as masculine and gay men who are erotically aroused by masculinity. It does not explain how and why some gay men are attracted to other gay men who may not be masculine. Sexual scripting theorists also do not offer an understanding of how other variables intersect with what is conceived to be desirable masculinity, such as how this masculinity is always related to muscularity and whiteness. As Green argues, "scripting theory provides a conceptual apparatus for describing some of the effects of more decisive factors including, most importantly, one's social structural standpoint and attendant life experiences" (Green 2008a: 604). In the examples, masculinity becomes the most important factor which determines the desires and desirability of the two men. However, in search of an explanation of sexual conduct and desire, "scripting theorists must set aside intersubjective scripting processes in search of their social structural determinants". In short, for this to work, scripting theorists must abandon "what individuals thought others thought of them" (Whittier and Melendez in Green 2008a: 603), by turning towards 'master status ${ }^{\text {'7 }}$ (in these examples, gender) to explain the social structural determinants of sexual desires.

\footnotetext{
${ }^{17}$ Master status is a term used by scripting theorists to describe the social position (e.g., race, gender, sexuality, ethnicity, age, etc), as the primary identity of the individual. For instance, being 'gay' is a master status for a
} 
Proponents of SST go only so far as mentioning the role of social structures (via 'master status'-in the example above, masculinity) which affect sexual fantasies and practices, but it does not fully provide an account of how they are developed and how they come to be manifested in our desires. SST's 'master status' concept, offered as an account of the macro-level social structures are only a gesture, without properly analyzing and explaining how and why these social structures exist in the first place. Indeed, the individual in SST is like a sponge that internalizes the social structures and takes it as a full explanation of why individuals find some as erotically pleasing and some are not. This can only provide an explanation of the experience of masculinity and nothing else. Thus, scripting theory cannot provide an intersectional account of how we experience "race, class, gender, sexuality, ethnicity, and age [...] as mutually constructing systems of power" (Collins 2005: 11). In effect, not only is the individual not given agency to account for his/her desires and therefore desirability, but the analysis is limited to only one experience. This explanation also does not encompass how and why the objective structures become manifested in our desires (i.e., the unconscious) and the processes that come with it.

This takes me to the limitation of SST at the micro-level. SST lacks an explanation of how one's desires are produced and the related inter-subjective processes. As Green argues, "scripting theory lacks a psychodynamic mechanism to link the world of objects to the formation of 'eroticized types' and associated intersubjective processes" (Green 2008: 605). As aforementioned, at the micro-level, the individual acts like a sponge who internalizes the cultural scenarios and inter-personal subjectivities but it does not provide an account of the process of how an individual comes to desire certain types and how an individual comes to subjectively understand $\mathrm{him} /$ herself as desirable. Thus, in order to address these limitations, Green introduces the concept

white gay man, superseding his other identifiers such as being 'white'. In this sense, being 'gay' means that an individual can identify with other individuals who label themselves as 'gay'. 
of 'erotic habitus', derived from Bourdieu's concept of 'habitus'. Despite the limitations of SST, it is still relevant if they are conceived as conscious (original italicized) intersubjective and interpersonal processes, rather than stretching it to a one-size fits all model. Indeed, by conceptualizing it this way, we can explain how scripting processes, "bear on what we do sexually and with whom" (Green 2008a: 605-606).

\section{Bourdieu and Green's Erotic Habitus}

Before going into a discussion of Green's erotic habitus, it is imperative that I contextualize this concept by providing a discussion of habitus, from which Green derived the term 'erotic habitus'. One of Bourdieu's most important contribution to sociology is the introduction of the concept of habitus in order to address the sociological debate between 'structure' and 'agency' or the relationship between macro- and micro-levels of social relations. This dualism is important because it is constantly debated by sociologists in an attempt to properly theorize social phenomena: whether to seek out an explanation that roots out from the level of social structures (for example, a Marxian analysis of class) or find an explanation that comes from the level of individuals (e.g., symbolic interactionism). For Bourdieu, both of these approaches are significant. Webb, Schirato, and Danaher (2002) argue that Bourdieu accepts that subjectivism is useful because, "it draws attention to the ways in which agents, at a practical, everyday level, negotiate various attempts $[\ldots]$ to tell them what to do, how to behave, and how to think" (Webb, et al. 2002: 32). However, Bourdieu is also critical of subjectivism because, "it fails to take into account the close connection between the objective structures of a culture [...] and dispositions of individuals" (Webb, et al. 2002: 33).

On the other hand, objectivism (through structuralism), also has both strengths and weaknesses for Bourdieu. Structuralism is used to explain how "objective structures produce 
people, their subjectivities, their world view" and as a consequence, they also inform people what they come to know as 'reality' (Webb, et al. 2002: 34). Hence, this deterministic aspect of structuralism is useful but it only sees practices as the reproduction of structures and nothing else. In his attempt to marry both subjectivism and objectivism, Bourdieu insists that, "practice is always informed by a sense of agency [...], but that the possibilities of agency must be understood and contextualised in terms of its relation to the objective structures of a culture", which he refers to as cultural fields. Thus, while Bourdieu accepts that practices are always informed by agency, these practices are limited by the habitus located in a specific field. Although habitus is always located within a field, this relationship does not completely determine people's actions and thoughts. However, practice is inexplicable without reference to them (Webb, et al. 2002: 36). Subjectivism is the main approach which influenced Gagnon and Simon's SST. They believe that sexual scripts give instructions to people on what, where, when and how to do sex. Therefore, SST's agents are almost sponge-like. A clarification on SST's position on agency and structures must be discussed first before going any further.

Individual agency in SST is conceived as following cultural scripts, which arguably could be understood to be coming from the level of macro-structures. But, it does not give an explanation as to how individuals interpret and re-create these scripts. As Green (2008) argues, "sexual actors [in the tripartite model of SST] are less agents who actually build sexual lives than wooden puppets who mechanically follow the puppet master-i.e., "cultural instructions"' (Green 2008a: 602). In some sense, there is a conceptual problem in its linkage of structures and agency because it supposes that the relationship between these two is linear and one-dimensional rather than complex. By following cultural scripts in their inter-subjective and intra-psychic scripts, individuals in SST replicate the structural forces of the cultural script. However, SST does not 
and cannot see sexual practices as always being informed by agency like Bourdieu, as I have discussed earlier. Thus, Bourdieu's concepts of habitus, capital, and field is more useful because its explanation of the relationship between structures and agency are more complex.

What then is habitus? According to Wacquant (2006), "[h]abitus designates the system of durable and transposable dispositions through which we perceive, judge, and act in the world" (orig. it. Wacquant 2006: 6). Habitus is largely unconscious which provides us with guidelines of how the world works and how to do certain actions (Seidman 2004: 148). Moreover, these unconscious schemas are "acquired through lasting exposure to particular social conditions and conditionings, via the internalization of external constraints and possibilities" (Wacquant 2006: 6). The habitus, according to Bourdieu, "is not only a structuring structure, which organizes practices and the perception of practices, but also a structured structure" (Bourdieu 2005: 503). Habitus is a result or product of the structural conditions in which an individual is located but at the same time, it also informs individual practices which reproduce the objective reality of social structures (Seidman 2004: 148). Therein lies the beauty of the concept of habitus. It represents both the subjective, which are the unconscious interpretive frameworks, and the objective, because these frameworks reflect the social conditions in which an individual was, is, and will be located (habitus is, after all, malleable and transposable). The objective reality of habitus can also be seen via shared dispositions, likes, tastes of individuals, who share the same experience, even though there are some varying degrees of differences amongst them. Thus, individuals sharing the same nationality, class, gender, sexuality, race, occupation, significant experience such as migration, etc. feel 'at home' with one another at some levels (Seidman 2004; Wacquant 2006: 6-7). 
Perhaps the most important characteristic of habitus which is helpful in studying desires sociologically is Bourdieu's study on tastes to explain class domination and hierarchy through culture. Tastes are often perceived as 'natural' to a person; such as a taste for the arts or for luxury, versus a taste for what is practical. This is also evident in sexual desires, wherein 'taste' for someone is seen as 'natural'. People often say, "he or she is not my type" when they refer to a person who is not erotically pleasing to them. But these 'types' are often taken for granted, as something that is essential to the individual. While tastes are often seen as natural, Bourdieu dispels this through the habitus. As he argues:

refined aesthetic tastes and sensibilities of the 'cultural nobility' were not an evidence of cultural superiority, but rather, 'the deep, dispositional workings of social structure inculcated in the taste, sensibilities, and appreciations of a given class' (Bourdieu in Green 2008a: 607).

Here, we can see how Bourdieu demystifies the notion of tastes, by arguing that what are considered as tastes for 'luxury' are not an evidence of cultural superiority, but rather, these are inculcated in the individuals' habitus as a result of their long-term exposure to a particular socioeconomic status. Tastes then, for Bourdieu, are acquired "through lasting exposure to particular social conditions." While tastes can change because habitus is malleable, these changes are limited by primary experiences (Wacquant 2006: 6-7). Thus, in this context, tastes are a reflection of class. But how are tastes, or rather, habitus in general developed?

In his study of how 'gender habitus' is acquired, Bourdieu proposes a 'two-fold operation', which starts first with internalization "in the form of habitual perceptual schemata" (Green 2008a: 610). This means that through long-term exposure in the social order, male and female individuals acquire the concept of gender as binary, which informs the individual (through the unconscious) the possibilities of human form. Here, "the social order is literally embodied", which is the second moment of Bourdieu's two-fold operation (Green 2008a: 610). We can 
transpose this 'two-fold operation' to theorize how we come to recognize something or someone as desirable and how we project and understand our desirability, i.e., erotic habitus. First, through a long-term exposure to a specific social order, we acquire concepts of what are erotically desirable and undesirable, which in turn inform us (through the unconscious), the possibilities of erotic desires and practices. Thus, our 'bodily desires' come into being, in which the social order is embodied. The embodiment of desires not only literally talks about bodies, but also how we use and see our bodies erotically. This might be informed by conscious use of scripts, which I have discussed earlier. Arguably, erotic habitus is developed in the same way as the gender habitus.

What does Green mean by erotic habitus? According to Green, erotic habitus is where, "the social order and one's place within it have a somatic relationship to the unconscious, supplying a cosmology of eroticized objects and attendant thematics [...] that orients the undifferentiated biological libido towards particular social forms" (Green 2008a: 614). In order to clarify what Green means by this, it is important to concentrate on what he means by 'the social order having a somatic relationship to the unconscious'. Here, Green adopts Bourdieu's notion of the habitus, wherein interpretive schemas are internalized and somatised in the unconscious via 'symbolic force'. This concept implies that classifications and relations are inscribed in the mind (via internalization) and becomes physical at the level of the body. Not only is the social order internalized, but this social order is historically specific. The social order basically provides us with cues which, "differentially invest particular objects with erotic meaning, while rendering other objects neuter" (Green 2008a: 614).

Through the internalization of these cues, we come to recognize what are erotically pleasing or displeasing to us. This informs the latter part of the quote, "that orients the undifferen- 
tiated biological libido toward particular social forms". Internalization of the social order, which is then somatised in the unconscious, organizes the biological libido, to discern which are erotically arousing and not. Therefore, he says that, "the self makes an imaginary encounter with the social through an erotic mediation on particular objects-i.e., object choices". However, this is actually not an imaginary encounter because we have a physical encounter to our objects of desire. How do we then make a (physical) encounter with the social? He argues that, first, when object choices (i.e., whom and what we identify as erotically arousing) are eroticized, they reflect the internalized differentiation in the erotic habitus. Hence, these encounters are not imaginary because the unconscious (i.e., sexual tastes) are materialized through the choices we make with whom we want to have sex. Our choices of sexual partners then are the reflection of the stratifications in the social milieu of whom and what is desirable and undesirable. Secondly, all object choices reflect the subjective sense of an individual's location in the social order.

In an example of how racial domination is eroticized, he cites the works of Gary Fisher, wherein, "racialized social structures occupied a position in the unconscious", which resurfaces in his erotic thoughts. Fisher's encounter with the social order produced desires and practices that are drawn from racial inequalities and dispositions. As Green argues, "[f]or Fisher, being African-American was more than just a 'master status' as scripting theory might suggest", but, "it was also a somatic relation to the social order reworked and made conscious in sexual fantasy" (Green 2008a: 616). Through this example, we can see how racialized social structures are internalized by Fisher and materialized through his desires, particularly, his sexual desire of being dominated by white men. I would also suggest that his subjective sense is evident in how he sees himself in relation to white men: as subordinate vis-à-vis white men, whom he sees to be dominant. This might mean that he is replicating racial ideologies. It might also mean that he is 
agreeing with the racialized social structures. Another possibility is that he is trying to take control through fantasy. However, what is missing from this analysis is how this intersects with other complexities. While Green acknowledges that erotic habitus provides us with an analysis of how sexual desires, "implicate the subjects' unconscious sense of self as a social object (e.g., racialized, gendered, classed self)", in his analysis of Fisher, he does not explicitly discuss how Fisher's race intersects with how he sees himself as a gendered individual, how his class plays into his sexual fantasies, etc. Consequently, I develop an intersectional approach to augment erotic habitus as a sociological tool. As Collins suggests, "biological sex, the social construction of gender, and sexual orientation constitute distinct yet interconnected phenomena, in turn, interconnect with race" (Collins 2005: 11). Thus, it is imperative to understand how desires and desirability represent the intersections of race, sexuality, gender, and body types, with reflect and reinforce oppressions.

Green also fails to conceptualize how this type of desire is shared by other gay black men who may have the same experiences as Fisher. One of the problems in his examples is that Green only focuses on individual experiences, but he does not link how particular types of erotic habitus are shared by people who have similar experiences. I argue that Green cannot make this connection because he fails to mention the importance of the concept of 'fields' and 'capital' in his formulation of erotic habitus. In another article, however, Green mentions 'sexual fields' and 'erotic capital' as analytical concepts in his study of gay black men's collective sexual life in New York; but he only glosses over the concept of erotic habitus, without fully developing these concepts in tandem with each other.

Green's failure to adopt the concept of 'field' in his development of erotic habitus in "Towards a Sociology of Desire: Erotic Habitus", needs to be problematised because, as Thorpe 
(2009) argues, "habitus develops in response to field" (Thorpe 2009: 501). Not only is habitus developed in response to a field, but, "different fields value different types of capital or resources" (Seidman 2004: 149). Linking these concepts together is crucial to explain social practices if one is to use Bourdieu's analytical framework. As Wacquant argues, "to explain any social event or pattern, one must inseparably dissect both the social constitution of the agent and the makeup of the particular social universe within which she operates as well as the particular conditions under which they come to encounter and impinge upon each other" (Wacquant 2006: 8). Therefore, in order to fully develop a sociological analysis of desires, it is imperative to emphasize the social constitution of an individual, which involves her race, class, sexuality, gender, age, ability, etc. In particular, we need to analyze her habitus because this would not only inform us about her social constitution, but also her location within a particular field (i.e., the 'social universe', which forms the second part of a Bourdieusian analysis). Finally, consideration should be afforded to the amount of erotic capital which one has in order to analyze how an individual compete against other individuals and impinge upon each other.

To summarize, applying the concept of habitus to desires, we can see how desires (what and who we deem to be erotically pleasing and arousing) reflect the social structures (i.e., these social structures are embodied in the unconscious) and at the same time, these desires reproduce these social structural conditions. Habitus exists within social fields. Therefore, erotic habitus exists within 'sexual fields'. Green defines sexual fields as:

[a]t these sites, participants with more or less shared erotic appetites congregate in ways that put in high relief structured relations of social and sexual exchange constitutive of a sexual field. Indeed, the more specialized a given erotic world becomes, the more standardized its erotic prize, the more predictably ordered the relational patterns, and the more institutionalized the currency of a given form of erotic capital (Green 2008b: 29). 
Here, we can see that in a specialized sexual field, there are patterns that are more standardized, which I aim to discern in the 'field of gay desire', a more specific 'field' than Green's 'sexual fields'. I intend to use the term 'field of gay desire' in my analysis because it is more characteristic of the social field in which gay men 'play', experience, act out, and live out their sexual fantasies. Since each field has its own autonomous logic, such that, "[f]ields such as academia, the economy, sports [...etc], are not reducible to one another or to some broader system logic," using the concept of 'field of gay desire' will enable me to pursue specific erotic capital and erotic habitus for this particular field (Seidman 2004: 149). Using the term 'sexual fields' is very general because there are different kinds of sexual fields (a heterosexual sexual field is different from a homosexual sexual field, etc), with different forms of erotic capital and erotic habitus. Consequently, the dynamics of the field of gay desire are different from the field of lesbian desire, but these fields are part of a larger sexual field of desire.

The field of gay desire then should be understood as a social sphere in which social interactions occur between gay men in their search for a sexual and/or romantic partner(s). This sphere may include bars, clubs, personal ads, coffee shops, sex toy stores, gay-oriented stores, 'gay villages', gay popular culture, gay events, or anywhere and anyhow gay men in general find each other. In this particular field, I discern particular patterns or 'codes' or 'scripts', which gay men use to interact with each other. This particular field has its own internal logic that is recognized and enacted by those who participate in it. Within each field, agents have different forms of capital, enabling them to take part in it. The manner in which one makes use of his/her capital however, is based on the habitus. Capital plays an important role because agents and institutions struggle to maintain or overturn the existing distribution of capital. 
Within Green's 'sexual field' and my field of gay desire, the most important form of capital which determines a person's ability to compete is 'erotic capital'. I adopt Green's conceptualization of erotic capital, "as the quality and quantity of attributes that an individual possesses, which elicit an erotic response in another." Furthermore, this capital takes many forms, including physical traits, affective presentations, and socio-cultural styles (Green 2008b: 29). 1 argue and demonstrate, however, that the characteristics which constitute the dominant form of erotic capital within the field of certain experiences of gay desire is the intersection of whiteness, youthfulness, masculinity, muscularity, and middle-class lifestyles, which inform the dominant erotic habitus within the field.

It follows that within the field of gay desire, different types of gay men acquire and possess different types of social, economic, cultural, or symbolic capital, which they sometimes convert into erotic capital. For instance, economic capital (wealth) may be converted into physical capital (such as going to the gym, to gain muscularity). It must be noted that habitus and capital create social hierarchies and domination within a specific field, which I wish to discern in this thesis. Bourdieu's study attempts to understand how culture becomes central to class domination. According to him, culture reproduces class domination because the dominant class imposes their tastes, standards, and values (i.e., their habitus) to the whole society, as the standard of what is best, highest, and most legitimate in the national culture. Their class domination is achieved in so far as their habitus is legitimized and dominant. I would argue that within the field of gay desire, the dominant (i.e., young, white, upper- and middle-class, masculine, and muscular men) impose their standards of what is desirable and undesirable (i.e., their erotic habitus) to all gay men who participate in this field as the standard of what is the most desirable within the gay culture. The dominant, however, mystifies and obscures their power by promoting the ideology 
that the most desired and valued are a product of gifted individuals, rather than a product of their class (Seidman 2004: 149). This mystification and obfuscation of power also materialize in the discourse non-white gay men use to describe their erotic tastes for gay white men as being 'natural', and vice-versa. This is what Bourdieu calls misrecognition as the key to 'symbolic violence', which he defines as, 'the violence which is exercised upon a social agent with his or her complicity" (Bourdieu in Webb et al. 2002: 25). In other words, agents are subjected to different forms of violence such as being treated as inferior and being denied access to resources, but they fail to recognize it as violence. Rather, they see them as the natural order of things (Webb, et al. 2000: 25). In this sense, instead of considering specific erotic desires and practices as a reflection of inequality in the field of gay desire, most gay men see that these things are simply natural.

Just as different fields value different capital, in the field of gay desire, erotic capital is the most valued. I wish to argue that the erotic capital in this field consists of an intersection of body capital (muscularity), gender capital (masculinity), racial capital (whiteness), age capital (youthfulness) and class, which are resources or qualities possessed by individual gay men. In this section, I wish to briefly discuss the importance of the body and embodiment in Bourdieu's analysis. The concept of embodiment is one of the important contributions of Bourdieu in feminist thought because it mediates between the Cartesian dualism. ${ }^{18}$ The body plays an important role in Bourdieu's analysis of class and tastes. As he argues, "the body is the most indisputable materialization of class taste" (Bourdieu 2005: 515). It is helpful to argue that the body is the indisputable materialization of erotic desires. Thus, echoing Bourdieu, the most indisputable materialization of what is considered to be the most desirable is in the body. The body plays an im-

\footnotetext{
${ }^{18}$ Catesian dualism understands body to be separate from the mind or emotions. It is important for feminists to dispel this myth because it supposes that the mind is the domain of the 'masculine' and the body is the domain of the 'feminine'. Embodiment, therefore, is a theory which connects these two and understands them as inseparable.
} 
portant role in the rice queens' desire for Asians. As McCaskell asks, "[d]oes the rice queen lust after [Asian] culture?". He continues, "[i]n spite of a tendency toward trappings of jade and apartments decorated with Chinese paintings, I think not. It is primarily the Asian body, not Asian culture which is being fetishized" (1998: 45). This is an important analysis because the desirability of black males in the white imagination is based on the idea that the big black phallus is 'dangerous', thus, its value lies in the racialized body.

In the field of gay desire, the possession of the 'right body' (i.e., young, white, masculine, muscular, and middle-class) gives an individual erotic capital, which puts him at the top of the hierarchy of gay desires. The dominant group produces and reproduces ideas, values, standards, tastes, and practices of desire and desirability (i.e., erotic habitus) through cultural production. They exercise their domination (via 'symbolic force') by imposing their erotic habitus to all gay men who participate in the field of gay desire, as the standard of what is desirable and undesirable.

Why then does Green reject the market-analysis in favour of what he calls the 'sexual fields' approach, when the notion of 'capital' follows the principle of exchange-value? In his description of the 'structures of desire', Green actually hints upon the 'market-like' properties of erotic capital, but he does not go as far as exploiting its potential. While it is true that his notion of 'sexual field', "draws attention to important nonmarket dimensions associated with sexual sociality" (original italicized, Green 2008b: 28), the idea of capital in Bourdieusian terms however, has some market-like behaviour, based on competition and value. Indeed, as McBride argues, and I would agree with him, there is a parallel between "the gift of capital and gift of whiteness", both of which define the rules of engagement in the gay marketplace of desire. Whiteness then is just like capital because it is a valuable commodity (McBride 2005: 118). 
While McBride's analysis is limited to whiteness, I will focus on how the dominant erotic capital within the field of gay desire is composed of the intersection of whiteness, masculinity, muscularity, age, and class, which produces the dominant erotic habitus. Green pursues the same idea which he calls, 'structure of desire', "that made hegemonic a currency of erotic capital revolving around hypermasculinity [to describe the 'collective erotic disposition' of a clone subculture]" (Green 2008b: 31). However, he does not make an explicit connection between capital and habitus, which I will do here. Erotic capital is related to erotic habitus. As Skeggs (2004) argues, Bourdieu's habitus, “is also a very explicit model of accumulation, based on knowledge of the game and how to play it". Further, "[t]he objective forces somehow shape a logic based on exchange-value in which the habitus always works with a perception of future value". As such, "practice never ceases to conform to economic calculation" (Skeggs 2004: 85). Green seems to have missed this point in his study of black gay men's desires and desirability, in which the black gay men playing in the field would 'do race', "as a technique to increase erotic capital and improve their standing in the field's tiers of desirability" (Green 2008b: 37).

Green also fails to mention how 'doing race' also involves doing gender, doing sexuality, doing class, doing age, etc. These black men actually 'do race', together with other factors, to attract white men, a process Green does not put into question. In increasing their erotic capital to attract white men, it is possible to theorize this as the general erotic habitus of black men playing in the field of gay desire, conforming to the dominant erotic habitus of white gay men. By adopting white middle-class lifestyles, these black men imitate the erotic habitus of white men to increase their erotic capital and therefore, legitimizing the dominance of white men's erotic habitus. Green also fails to address, why is it that these black men's erotic desires are targeted towards white men and not to other black men. Further, why and how do some white men find 
black men erotically desirable, if the dominant erotic habitus is targeted towards other white men. These are important questions which Green failed to address, thus, not fully developing the potential of his theories.

\section{Summary}

This chapter set out the theoretical basis of the current investigation in this project, i.e., a sociological analysis of desires. I began with a discussion of the market-analogy to examine collective sexual life and specifically, the commodification and consumption of 'Otherness' by white men. The most important contribution provided by a market-analysis is a framework to understand that individuals have exchange-value accrued to them, which they use to participate in the 'gay marketplace of desire'. This analysis also provides a framework to analyze how the consumption of the 'Other' is based upon the 'value' believed to be intrinsic in their bodies. Market-analysis enables me to understand, on the one hand, the 'erotic capital' of 'Others' in the field of gay desire, as fundamentally linked to racialized imaginings. On the other hand, it also offers a framework to understand the erotic capital of white men as the most valued commodity.

Conversely, SST theorists do not give us insight into how we develop desires and desirability. I mapped out what is considered to be the most widely used sociological theory in understanding desires and desirability, through Gagnon and Simon's SST. One of its advantages is that SST offers a framework to study the relationship of social structures with how we practice sex and sexuality. Unfortunately, SST only goes in so far as mentioning the role of social structures, giving us the 'scripts' or guidelines on how we practice sex and sexuality. But, it fails to explain how and why these social structures exist in the first place (this is at the level of macrostructures). At the micro-level, SST fails to account for how we come to objectify certain persons as desirable and the related intersubjective processes that goes with it. Thus, following Green, I 
adopt the concept of 'erotic habitus' in order to address these problems in SST to provide a better analysis of the sociology of desire. Erotic habitus is derived from Bourdieu to explain how the macro-structures penetrate in the level of the unconscious, ultimately forming and informing our desires and desirability.

While Green acknowledges that erotic habitus provides us with an analysis of how sexual desires “implicate the subjects' unconscious sense of self as a social object (e.g., racialized, gendered, classed self)", he does not explicitly claim that he is using an intersectional approach to analyze erotic habitus (Green 2008a: 622). An analysis of erotic habitus with an intersectional approach then would be crucial. Thus, in this project, the desires and desirability of gay men represent the intersections of race, sexuality, gender expression, and body types which reflect and reinforce the oppressions in the gay community. Building upon these theoretical frameworks, the following chapter presents the methodological and analytical frameworks, which I use in this project. As a methodology, I am particularly interested discerning how the social structures are literally embodied in the erotic habitus of gay men, and specifically, the erotic habitus of gay white men whose desires are specifically directed towards gay Asian men in personal ads and vice versa. In order to show the social structural forces that creates domination and hierarchies in the field of gay desire. 


\section{Chapter 3:}

\section{Methodological Framework and Data Analysis Strategies}

Not only will you confess to acts contravening the law, but you will seek to transform your desire, your every desire into discourse (Foucault 1978: 21).

One possible explanation for the proliferation of online spaces dedicated to erotic discussions may be a general dissatisfaction with how sex is apprehended in the discourse of daily life [...]. Although I would hold that sex is far from hidden in daily life [...], I agree there is something unsatisfying and profoundly dishonest, or perhaps artificial, underlying mundane discussions of sex (Campbell 2004: 16).

The juxtaposition of these two quotes is intended to highlight the important role of the proliferation of discourses of erotic desires online, specifically through personal ads, which is one of the main sources of my data. These quotes demonstrate that the more sex is considered taboo, the more people talk about it. Thus, I want to highlight the proliferation of the accessibility of the internet, paving the way for people to talk about the 'secret' (i.e., sex) which is not so secret after all. The rise of personal ads on the internet, from print ads, enables people to talk about sex, desires, and fantasies anonymously with fewer prohibitions. The result is a freer exchange of thoughts about desires, fantasies, and sex.

This chapter outlines the approaches used to conduct my research, namely critical discourse analysis and feminist methodologies. It also provides a thorough description of the collection of data through Craigslist and Fab Magazine. I highlight the analytical procedure(s) which I utilized to draw conclusions based on the information 1 collected. Before beginning this section, I wish to reiterate the problem which I am attempting to address through this methodology: how do discourses of desire constructed by and for gay men in general and gay Asian men in particular-as found in particular cultural vehicles in gay communities such as Craigslist, Fab Magazine, and Rice Queen Diaries - help us understand the relationship of social structural forces of 
race, gender, body types, and class in the production and reproduction of desires and desirability? In my analysis, the focus is on the following aspects of the embodiment of desire through gay men in general and gay Asian men in particular. Firstly, I explore the characteristics of the dominant 'erotic habitus' found in the gay community. Secondly, I investigate the erotic habitus of gay Asian men and compare and contrast it with the dominant erotic habitus. Thirdly, I examine the discourses made by gay white men who are particularly attracted to Asian men (i.e., rice queens) in order to explore their erotic habitus vis-à-vis the dominant's.

\section{Critical Discourse Analysis (CDA): A Discussion}

My research methodology is informed by CDA. According to Van Dijk (2001), “(CDA) is a type of discourse analytical research that primarily studies the way social power abuse, dominance, and inequality are enacted, reproduced, and resisted by text and talk in the social and political context" (Van Dijk 2001: 352). By analyzing personal ads on the internet (particularly on Craigslist), I attempt to show how social inequalities based on race, class, gender, and body types are produced and reproduced in our erotic desires. Not only does CDA enable researchers to discern power relations through discourses of desires and desirability, but it also emphasizes that meaning is not intrinsic in the words used by authors, but rather, they are found in the choices that authors have made in the presentation of their narratives (Han 2008: 825). However, I did not restrict myself to analyzing the text of personal ads alone because I was also interested in the front covers of Fab Magazine and the images presented in the personal ads as forms of semiosis. Discourse is used by CDA practitioners in many ways such as studying language and also visual images. Therefore, I adopt Fairclough's (2001) notion of semiosis to encompass all forms of meaning-making, not only through language but also, "body language, visual images, or any other way of signifying" (Fairclough 2001: 229). Semiosis and CDA are intrinsically linked be- 
cause, "CDA is analysis of the dialectical relationships between semiosis (including language) and other elements of social practices" (Fairclough 2001: 234). Semiosis figures into social practices in two ways: through social activity and representations. It appears in social activities within practices through the use of language in specific ways. For instance, political rhetoric in governing or the language used in personal ads to signify erotic desires, desirabilities, practices, and fantasies. Semiosis is also present in representations. According to Fairclough, "[s]ocial actors within any practice produce representations of other practices, as well as ('reflexive') representations of their own practices" (Fairclough 2001: 234). To summarize, semiosis is any form of meaning-making, which does not only include language through texts and talk, but also visual images and body language. CDA is the study of semiosis that figures into social activities through language and representation. Through the analysis of semiosis, CDA practitioners are able to discern power relations. Thus, it is understood that personal ads (the text and pictures included) and the front covers of Fab Magazine are forms of semiosis which were studied and analyzed through CDA to discern how power relations are produced and reproduced through our desires and desirabilities. I now highlight the relationship between CDA and erotic habitus.

\section{$C D A$ and Erotic Habitus}

Adopting CDA is central to my project because, as Green argues, "erotic habitus is an unconscious psychic structure [therefore] it cannot be studied through empirical methods" (Green 2008a: 615). Through this approach, I am able to discern, identify, and describe the parameters of erotic habitus through 'erotic work', i.e., discourses constructed about desires and desirability. Adopting CDA to analyze discourses of desires and desirability is important because, "the structure of the erotic habitus reveals itself in the patterning of sexual desires, brought to consciousness via the erotic work" (italics original). Erotic work is, "the process whereby internalized 
schemes and dispositions of erotic habitus are transformed into sexual scripts" (Green 2008a: 615). In this context, personal ads and images found in the gay male community's cultural vehicles are considered as sexual scripts, therefore understood as erotic works. The analysis of these texts and images enables me to show how erotic habitus is intrinsically linked with social structural inequalities. However, the origins of these sexual fantasies cannot be explained in each individual case because of its highly subjective and subconscious character. As Green suggests, individuals are generally unaware and unable to describe where their sexual fantasies come from and cannot alter these fantasies. Erotic habitus is only able to show general patterns but not individual desires themselves (Ibid). By closely analysing the personal ads and images produced by gay white and Asian men, I am able to show the patterns of how social structural forces affect and effect desires and desirability.

CDA functions in two ways: as an analysis of the erotic works of gay men to discern the patterns of their erotic habitus, and as an attempt to link the macro- and micro-social structures, much like the habitus. As discussed, habitus is an attempt by Bourdieu to marry the divide between the macro- and micro-levels, which is also fundamental to this project. Adopting the concept of habitus enables me to explicate how desires are shaped by social structures. At the same time, desires are also informed by agency but limited by the habitus. This is because habitus is both a structured structure and structuring structure. Habitus is both internalized and externalized. As Seidman argues, "[t]he habitus is both a product of social structure and itself a structure generative of social practices that reproduces social structures" (Seidman 2004: 148). Therefore, erotic habitus is a product of social structures and it also informs the choices of individuals. These choices, however, are limited by the habitus itself. Through our erotic desires and practices, we reproduce the very social structures that inform our erotic habitus. 
On the other hand, CDA also theoretically bridges the gap between macro and microlevel structures, thus suitable for my analysis informed by the notion of habitus. As Van Dijk argues, language use and communication exist in the micro-level, while power, domination, and inequalities belong to the macro-level. For example, "a racist speech in parliament is a discourse at the microlevel of social interaction $[\ldots]$ but at the same time may enact or be a constituent part of legislation or the reproduction of racism at the macro-level" (Van Dijk 2001: 354). We can consider the personal ad as a discourse at the micro-level of social interaction between gay men (and also inter-subjective processes). ${ }^{19}$ Similarly, they reproduce not only the racist social structures in the field of gay desire, but also discriminations based on gender, body, and class. Thus, in order to discern the erotic habitus of gay men, it will be helpful to adopt CDA as a methodological framework.

In addition to personal ads and Fab Magazine, I also closely analyzed a book called The Rice Queen Diaries by Daniel Gawthrop (2005) in order to understand how patterns of erotic habitus of 'rice queens' emerge vis-à-vis social structures. The choice of this book is informed by the fact that it is the only book of its kind, written specifically by someone who identifies himself as a 'rice queen'. McCaskell (1998) argues that 'rice queen', “[is] not a nice category. It's not said with pride. Not a badge to be worn proudly" (McCaskell 1998: 45). There is a lot of stigma attached to this label. Therefore, this book is relevant and problematic at the same time. Relevant because it is written by a white man who writes from a privileged perspective, who is 'aware' of the politics behind his erotic desires for Asian men. On the other hand, it is problematic because, while he claims that his book is inspired by 'Orientalism', he does not critically engage with it. Rather, he reproduces the very Orientalist discourses he claims to be central to his

\footnotetext{
${ }^{19}$ Whittier and Melendez (2007) argue that intersubjectivity is important in the conceptualization of desires and desirability. In their research on intersubjectivity among gay men, their participants' attraction to some other men only began after they perceived an interest from the other (Whittier \& Melendez 2007: 195).
} 
analysis. Although this book is only one example, I am not using it to explain every experience of rice queens; rather, I use it as a way to illustrate some of the ways a rice queen conceptualizes racialized desires. By examining this text, I explore the erotic habitus of a self-identified rice queen and critically analyze his desires. Through the analysis of this book, personal ads from Craigslist, and images from Fab Magazine, some sociohistorical patterns can be extrapolated. Through closely analyzing these forms of meaning making-i.e,, semiosis-I attempt to unite them with discursive practices involved in creating these images and texts with the larger social context (Fairclough in Han 2008: 835).

\section{Feminist Methodologies: Standpoint Theory and Reflexivity}

As a methodology, CDA emphasizes the analysis of semiotics to identify power relations and bridge the gap between micro and macro-level social structures via discourse analysis, but it also stresses the role of the researcher in the research and in the society. This is also evident and emphasized by Bourdieu's social theory. Bourdieu insists that in order to create a rigorous sociology, "we need to know what constraints bear upon the sociologist and how the specific interests

they pursue [...] affect the knowledge they produce" (Wacquant 2006: 11). Methodologically, CDA also insists that the researcher cannot separate herself from the research. As Van Dijk argues, "[c]rucial for critical discourse analysts is the explicit awareness of their role in the society." Indeed, critical discourse analysts reject the idea of 'value-free' science. They argue that science and intellectual discourse are part of and influenced by social structures (Van Dijk 2001: 353). Thus, they insist (as well as Bourdieu) on reflexivity, which suggests that the identity of the researcher will have implications in his/her research (Wetherell, Taylor, and Yates 2001: 16). I then wish to emphasize the important role of feminist methodologies in my project, specifically standpoint theory and reflexivity. 
Standpoint theory and reflexivity are two interrelated concepts. Standpoint theory arose from Marxist epistemology, which suggests that, "the standpoint of an oppressed social group has epistemic privilege". Marxist standpoint is centered around class as the social division to which different standpoints are generated, whereas feminist standpoint theorists emphasize that gender creates different standpoints (Bubeck 2000: 187). Feminist standpoint theory aims to develop a feminist epistemology that is centered on women's experiences and knowledge production. One of the feminist theorists who pioneered feminist standpoint theory is Dorothy Smith (1999). Smith's conceptualization of standpoint theory is as follows: “[d]eveloping a sociological inquiry grounded on women's standpoint entails making a sociology that is in dialogue with the actualities of people's lives as they experience them" (Smith 1999: 69). From this perspective, a sociological inquiry grounded on feminist standpoint theory puts an emphasis on the experiences of individuals as an object of inquiry. Standpoint theory suggests that social relations-such as our sexual relations - are constituted in and through our everyday experiences and not by outside forces (Weeks in Naples 2003: 38). Locating the experiences of desire and desirability of gay men through the everyday form of interaction (via personal ads) is a legitimate object of inquiry because it is through these ads that I will be able to discern the dynamics of racialized desires and desirability.

Standpoint theory becomes more relevant for researchers of and by individuals who are members of a marginalized or oppressed groups. For example, the marginalization of gay men not being able to fulfill ideal masculinity, we come to experience masculinity differently; therefore, we have access to specialized knowledge about masculinity (Ward 2000: 153). This is where reflexivity comes into play vis-à-vis standpoint theory because my subjectivities are very closely linked to the research I am doing. As a self-identified queer Asian man, I experience and 
am continually caught within the web of racialized social structures in gay communities. Specifically, racialized desire has and is always a part of my everyday experience. Being romantically involved with a white man, there is no doubt that the collection, interpretation, and composition of the data is informed by my familiarity with racialized desires. Thus, the question of how far I can separate myself from my research needs to be addressed. According to Wetherell, et al., reflexivity suggests that the separation between the researcher from the research is impossible and that the implications of the identity of the researcher for data collection and analysis must be considered (Wetherell, et al. 2001: 16). This reflexive exercise also emphasizes the fact that knowledge production is inherently a reflection of my location in time and social space (Bryman 2004: 500).

\section{Data Collection and Analysis}

In order for me to effectively answer the questions I posit above, I critically analyzed the front cover of a popular gay magazine in Canada, Fab Magazine, dubbed as the 'gay scene magazine'. This magazine is published bi-monthly, free, and widely distributed in Toronto, Hamilton, London, and Ottawa, while those in other cities could buy it for $\$ 4.50$ per issue. Previous (from the very first issue) and current issues are archived online, which can be easily accessed by anyone who has internet. Since it is easier for me to get copies online, I gathered the front page covers from the Fab Magazine website (fabmagazine.com). Following Alexander's (2003) sampling of Men's Health magazine, wherein she took a random sample of ten issues in a span of 4 years to take into account of any changes that might have occurred in a monthly magazine, I chose to cover issues published between January 2000 to January 2010. Since this is a bi-monthly magazine, these ten random samples would take into account any changes that might have occurred for ten years, covering about one issue for each of the years represented. From these 271 , I chose 
every thirtieth issue so that I have a random sample, to cover ten (10) issues for my discourse analysis (i.e., issues $\# 129,159,189,219,249,279,309,339,369$, and 399). In addition to these issues, I have included seven issues which specifically feature Asian men (issues \# 146, 202, $216,239,325,328$, and 367$)$. The aim of this discourse analysis is to discern the representations of desires and desirability in these front covers. By doing this, I describe how the dominant attitudes towards Asian men in the field of gay desire are produced and reproduced. I also show how Asian men's desirability are represented in these images.

The reproduction of these desires was the next step of my data collection, notably to discern how these dominant desires are internalized, reproduced, and externalized through the language gay men use in personal ads. According to McBride (2005), the transition from print and phone-line ads to the proliferation of gay male personal ads on the internet is significant because it enables posters to use photos and also simplified and privatized the placing of ads (McBride 2005: 110). Studying personal ads has further advantages and implications for research. According to Phua and Kaufman (2003), one of the advantages is that, "those who are being studied do not know they are being studied" (Phua and Kaufman 2003: 985). This is significant because it avoids the 'reactive effect', which is likely to occur in a research in which subjects know that they are being researched and thus compromise the validity of the data (Bryman, 2004: 175).

Another advantage of analyzing personal ads on the internet is that users and posters can be totally anonymous. No actual e-mail addresses have to be exchanged, they can choose what kind of information they offer and they have the choice to put pictures or not. This anonymity is significant because, as McBride argues, "it becomes possible to be far clearer, more honest, and unapologetically (even if at time brutally) discriminating about what it is we want", which is not possible in gay bars where everyone can see you (McBride 2005: 112). Finally, according to 
Phua and Kaufman, "those who place and respond to personal ads are more representative of the general population than those involved in experiments" (Phua and Kaufman 2003: 985).

Thus, I looked specifically at personal ads on a popular website called Craigslist.org. Craigslist is a website which features free online classified advertisements: such as selling new and used items, renting apartments and houses, looking for jobs, forums to exchange ideas, and personals. As a geographically-specific service, I focused my research on Toronto's Craigslist and Montreal's Craigslist. I chose these two cities because they are considered two of the three most populated cities in Canada (the other being Vancouver), and they both have a large multiracial and multicultural population. They also have a bigger and more established gay culture and communities. I focused on the personals section. This section is divided into: strictly platonic, women seeking women, women seeking men, men seeking men, miscellaneous romance, casual encounters, missed connections, and rants and raves. My analysis concentrated on the men seeking men section because my main concern was discerning the erotic habitus of gay men. Most of these posts are short and some of them have pictures.

The first step was to go to the MSM (Men Seeking Men) section of Toronto's and Montreal's Craigslist. This section only keeps posts for two months, so all sampled posts were published in 2010. Data were collected between June, 2010 and December, 2010. Toronto's MSM section lists 100 posts per page and goes up to 20,000 pages (a total of two million posts). Montreal's posts are significantly smaller in that it only goes up to 4, 500 pages, with 100 posts per page (a total of 450, 000 posts). In Phua and Kaufman's (2003) research on personal ads on the internet, they used systematic sampling ${ }^{20}$ to collect their sample, wherein every ten ads were collected for a total of 300 , in each of the categories they have specified. Since my aim in this first batch of samples is to get a 'general' sample of personal ads, without specifically narrowing it

${ }^{20}$ Systematic sampling is based on an ordered sampling frame, wherein every nth element is chosen. 
down to any variable, I chose every fifth post from 5 pages, for a total of 100 posts. I have noted, however, Bryman's (2004) suggestion that, "[i]t is important to ensure [...] that there is no inherent ordering in the sampling frame, since this may bias the resulting sample" (Bryman 2004: 92). Thus, I employed the following systematic sampling. For Toronto's listings, I started from page 1 of the listings, then $100^{\text {th }}, 1000^{\text {th }}, 10000^{\text {th }}$, and the last page, $20000^{\text {th }}$ (a total of 5 pages) and chose every fifth post from these pages, for a total of 100 posts. For Montreal's section, I started from page 1 , then $100^{\text {th }}, 1000$ th, $3000^{\text {th }}$, and $4500^{\text {th }}$, for a total of 5 pages and also chose every fifth listing for a total of 100 posts. These data produced a good random sample in discerning the dominant erotic habitus of gay men. Next, I conducted an analysis of posts that are specifically made for and by Asian men. In the MSM section, there is a search box option where someone could type in whatever they are looking for. I typed the word "Asian" in order to slim down the posts that contain the word "Asian" in them. Toronto's Craigslist showed ten pages when I did this search, containing 100 posts each page for a total of 1000 posts out of 2 million. Montreal's Craigslist showed a total of 200 posts out of 450,000 with "Asian" in them. For the Toronto listings, I chose every $10^{\text {th }}$ post out of the 1000 to have a random sample of 100 . For Montreal, I chose every second post out of the 200 for a total of 100 samples. In total, I had 400 data samples collected. As I explain below, I did not use all of these ads. Albeit Wetherell, et al. (2001) argue that, "[d]iscourse data are 'rich', which means that it is probably impossible to reach a point where the data are exhausted, with nothing more to find in them because the analysis is complete," I focused on some patterns at the expense of others for later exploration due to time constraints (Wetherell, et al. 2001: 39).

In order to analyze the data I gathered, I employed coding by reading through the personal ads, search for particular patterns by labeling items which I think have a theoretical significance 
and/or to be particularly interesting in describing the erotic desires and desirabilities of gay men (Bryman and Teevan, 2005: 285). In particular, I separated the ads which I collected as 'general sample' and 'Asian samples'. I separated each by 'race': white men as posters, Asian men as posters, and white men who are particularly interested in Asian men. I narrowed these samples down by dissecting them into two parts: self-description, in order to delineate how these men describe themselves as desirable, and what they look for as their 'erotic choice'. I also discarded ads which did not contain any of these information I delineated. In total, I coded 120 ads. To analyze the visual images from Fab Magazine and the pictures which the research subjects attach with their personal ads, I turned to Pauwels' (2010) emphasis on analysing what is/are being depicted and how it is being depicted (Pauwels 2010: 557). These visual data is important because it enabled me to "acquire insight into the social functions of the cultural product itself $[\ldots]$ but also gain access to broader and more profound aspects of society [...]" (Pauwels 2010: 552). This means that these images have particular functions in depicting what is desirable, but at the same time, they also inform us of the social context from which these images are produced and reproduced. Utilizing CDA also entails that I analyzed the personal ads, front covers of Fab Magazine, and Rice Queen Diaries by:

- Examining how the text is framed, how the text is presented, and what particular 'angle' the author is taking. This will also apply to the images: examining how the picture is framed, how it is presented, and what particular 'angle' the photographer is taking.

- Discerning what concepts are given prominence in the text;

- Examining what presuppositions the writer makes;

- Examining who is the subject and the object;

- Discerning what is and is not included; 
- And finally, how visual aids are used (Huckin 1995 in Han 2008: 835).

Thus, special attention will be paid to the language used in personal ads, specifically how gay white men describe themselves and their desires; how gay Asian men describe themselves and their desires; and how 'rice queens' describe themselves and their desires.

As I aforementioned, critical to CDA and feminist methodologies is the emphasis placed on standpoint theory and reflexivity in the research, analytical, and writing process. Thus, reflexivity played an important role in the analysis of the data. How to translate these into actual practice in the analysis of the data is explained by Mauthner and Doucet (2005). According to these authors, an effective way of being reflexive in the analysis of data is through a 'reader-response' element wherein the "researcher reads for herself in the text". This means that the researcher places herself, her history, and experiences vis-à-vis the respondent or data. By locating ourselves socially, emotionally, and intellectually, we are able to "retain some grasp over the blurred boundary between the respondent's narrative and our interpretation" (Mauthner and Doucet 2005: 419). I employed such reflexive strategies in my data analysis in order for me to see how and where my subjectivities, background, and biography affect the interpretation of the data. One of the strengths and challenges of having similar characteristics and experiences with my research is that I interpreted the data based on my own background. The 'reader-response' element was one way of doing this reflexive exercise.

\section{Summary}

Through these research methodology and data analysis strategies I outlined above, I hope to discern the following: first, the dominant erotic habitus of gay men; second, how this dominant erotic habitus is racialized and gendered and how this is imposed on all gay men; third, how this dominant erotic habitus affects the erotic habitus of gay Asian men (or are they different? the 
same?); finally, how the erotic habitus of 'rice queens' is produced and reproduced, what social structures influence these desires, and how are they the same or different from the dominant erotic habitus that is found in the field of gay desire.

In this chapter, I outlined the methodological frameworks based on CDA and feminist methodologies, which I utilized in the gathering of the data and analysis. CDA is central in this project because of its particular emphasis on how power, dominance, and inequalities are reproduced through texts, talk, and images as semiosis, i.e., any form of meaning-making which includes language, visual images, and body language. I discussed that CDA is the analysis of the dialectical relationship between semiosis and social practices. Thus, through the analysis of personal ads on Craigslist, the front covers of Fab Magazine and Rice Queen Diaries, I was able to analyze how social inequalities are produced and reproduced in our erotic desires, through the erotic habitus. CDA and erotic habitus are intrinsically linked because they both aim to bridge the gap between the macro and micro-social structures. In essence, erotic habitus is the theory and CDA is the methodology. The use of CDA in analyzing erotic works (which are manifestations of the erotic habitus via sexual scripts) is essential because the main sources of my data can be considered as discourses of sexual scripts. CDA and Bourdieu, from which the theory of 'habitus' came from, are also intrinsically linked because critical discourse analysts and Bourdieu insists on reflexivity. Thus, feminist methodologies are also central in my project, specifically standpoint theory and reflexivity. Feminist standpoint theory places emphasis on experiences of those marginalized or oppressed groups (such as women) as knowledge-production. Thus, due to my identity as queer Asian, I have to acknowledge that my interest in this particular research is influenced by my own identity and experiences, which have implications on the analysis of my data. 


\section{Chapter 4:}

\section{Erotic Habitus and the Production and Reproduction of Desires and Desirability in Gay \\ Cultural Products}

This chapter presents a critical discourse analysis of how erotic desires are produced and reproduced through Fab Magazine. Fab is a cultural product used to exhibit what are considered desirable in the field of gay desire. Although this is only one example, it is the characteristics of erotic habitus being reproduced in these front covers that are significant because the same representations can also be found in other gay magazines, pornography, websites, literature, posters, etc. $^{21}$ Thus, Fab Magazine signifies the dominant erotic habitus which are also present in these other cultural vehicles. I argue that through a long-term exposure in the field of gay desire, where representations of what are considered to be erotically desirable are produced through cultural products, our erotic tastes are shaped. Our understanding of erotic capital is formed in the process. These erotic tastes and erotic capital become embodied in the erotic habitus, materialized through personal ads. Further, through Fab Magazine and personal ads, a hierarchy of desires is maintained wherein whiteness, youthfulness, muscularity, masculinity, and middle-class lifestyles are considered to be the most valuable erotic capital. These cultural vehicles also produce Orientalist discourses eroticizing Asian men through exoticization and fetishization. Orientalist discourses become manifested in the desires of 'rice queens'. Their desires are both hegemonic and counter-hegemonic. This is because, if whiteness is seen as the most desirable, thenon some level - the desire for Asian men is a disruption of white supremacy even if that desire manifests through the exoticization of Asian men.

\footnotetext{
${ }^{21}$ While other cultural products such as pom are not studied here, the representations that are present in $F a b$ Magazine can also be found in other cultural vehicles (See Bamard 2004; Edwards 1994; Fung 1991; Han 2008; and McBride 2005).
} 
This chapter provides a critical discourse analysis of Fab Magazine to illustrate that the erotic habitus of the dominant (i.e., gay white men) ${ }^{22}$ is reproduced through culture which, in turn, is used to legitimize and normalize their hegemony. Fab issues 146 (Figure A5), 202 (Figure A8), and 239 (Figure A3) also reproduce Orientalism based on the ideas of exoticism, passiveness, and femininity of Asian men, giving them a particular mode/set of 'value' in the field of gay desire.

In Chapter 2, I showned how culture is fundamental to Bourdieu's analysis of class domination because it is through culture that the dominant class imposes their tastes (i.e., their habitus) to the whole society as the standard of what is best, superior, and most legitimate (Seidman 2004: 149). Culture plays an important role in the development of 'tastes'. According to Bourdieu, tastes are acquired through the 'cultural arbitrary', wherein, "things (whether practices, products, or values) are made to seem universally significant because they are important to dominant people and institutions". These become inscribed in the habitus, supported by values and discourses in the social field (Webb, et al. 2002: 153-4). Erotic tastes are also acquired through the 'cultural arbitrary'. Following this logic, cultural products, such as Fab Magazine, are used by the dominant to make their erotic tastes and fantasies universally significant, which become inscribed in the erotic habitus.

In fact, the people who sit in Fab's editorial board are all white men. It is owned by Pink Triangle Press (PTP), a non-profit publishing organization specializing in LGBTQ media which

\footnotetext{
${ }^{22}$ In this thesis, I refer to the 'dominant' group as gay white men, based on the discussion in Chapter 1 by Bérubé (2001) and Seidman (2004). The 'gay community', according to Bérubé, is constructed according to the image and issues that are important to white men. As he argues, the structure of "everyday life and politics in what is often called the 'gay community' [...] [mirrors] the whiteness of men who run powerful institutions as a strategy for winning credibility, acceptance, and integration" (Bérubé 2001: 236). This gay whiteness also intersects with homonormative ideals. As Seidman (2004) argues, "the normal gay is expected to be gender conventional, links sex to love and a marriage-like relationship, defend family values, personify economic individualism, and display national pride" (Seidman 2002: 133). Thus, the 'dominant group' is understood as being white and homonormative.
} 
owns Xtra!. In 2008, Fab was bought by PTP whose owner is Brandon Matheson. Matheson acts as publisher and editor-in-chief of Fab and Xtra!. Currently, Drew Rowsome and Matt Thomas work as associate editors, while Matt Mills is the associate publisher and editorial director. Fab's target audience are the 'mainstream' white gay male who are upper- and middle-class in their 30's and 40's. In 2008, Erin Tandy, a writer for the Ryerson Review of Journalism interviewed both Rowsome and Thomas about the aims of $F a b$ after PPT's take over. Thomas claims that he wants to focus more on issues outside of the "gay mainstream," 23 defining it as "middle to upper class gay white males between the ages 30 and 40" (qtd. in Tandy 2008). Fab is also criticized for not including lesbian and trans issues, but Thomas claims that he has no plans of changing it into a 'women's magazine' arguing that, "[n]o one's going to accuse GQ [Gentelemen's Quar$t e r l y]$ of being gender-phobic - it's a men's magazine. But sometimes in men's magazines there are places for women and for trans people, too." (Ibid). Since Fab is a gay men's magazine, women's and trans issues are often excluded, but are granted 'places' if the editors choose to. Obviously, Fab targets the dominant group in the gay community whose erotic tastes are considered universal and acceptable to all. Furthermore, a survey of the issues from the first issue published in June 1994 to June $2010,74.25 \%$ (297 out of 400 ) of the covers feature white men, either alone or in groups. Only $7.25 \%$ of these covers feature non-white men (a total of 29 ) and out of these, only 7 (a mere $1.75 \%$ ) feature Asian men. $7.25 \%$ ( 29 out of 400 ) also feature white men and non-white men together (see Table 3, Appendix C). It is important to note, however, that while tastes are distinctive to each social class, Bourdieu insists that the aesthetics of the working-class is a dominated aesthetic, "which is constantly obliged to define itself in terms of the dominant aesthetics" (Bourdieu 1984: 41). Although each class develops their own 'taste', it is

\footnotetext{
${ }^{23}$ Currently, this is the main focus of Fab and the editors want to move away from it.
} 
attained in relation to the dominant. The dominant's erotic habitus is always present in the habitus of the dominated.

According to Fairclough (2001), semiosis figures into social practices via social activity by the use of language and representations (Fairclough 2001: 234). Bourdieu maintains that representations play an important role because, "[t]he representations that individuals and groups inevitably engage in their practices is part and parcel of their social reality" (orig. it., qtd. in Wacquant 2006: 11). This means that representations of desires and desirability become real through Fab Magazine and personal ads. Since CDA aims to analyze power relations through semiosis (Fairclough 2001), Bourdieu's understanding of 'culture' can be viewed as a form of semiosis which is about the struggle for power. As he suggests, since social classifications become instruments of social domination, each class, "tries to gain control over the classificatory schemata that command the power to conserve or change reality by preserving or altering the representation of reality" (Bourdieu in Wacquant 2006: 11). What this means is that the field of cultural production is a constant struggle for individuals to control 'culture', to change or preserve power relations via representations of reality (i.e., meanings, symbols, cultural products). Extending this analysis of social domination via culture, Fab Magazine and personal ads are understood as sites of power contention, wherein desires and desirability are produced, reproduced, and contested by the dominant and dominated groups in the field of gay desire.

\section{The Production and Reproduction of Erotic Desires and Desirability in Fab Magazine}

In this first part of my analysis, I concentrate on Fab Magazine as a cultural product in the field of gay desire. Fab is used as a vehicle by the dominant to produce and reproduce erotic habitus. The cover pages are forms of semiosis used to represent what is erotically desirable in the field. They also show the form of erotic capital considered to be the most valuable, stratifying the field 
into a hierarchy of desire based on the 'value' of desirability and the social structures in the field of gay desire internalized by gay men.

Within gay communities, white men who are young, masculine, muscular, and middleclass are considered to be the most desirable because they are the ones who are mostly represented in these images. However, although these representations delineate only these white men as desirable, 'other' white men who are non-masculine, non-muscular, non-middle-class, and older who are not necessarily represented can still claim certain amount of privileges based on whiteness. As Han (2008) argues:

these images of young, attractive white men-while problematic for other reasons-do not relegate other white men to the margins of the gay community nor actively construct them as being outside of the gay community. Rather, it works to highlight their privileged racial status allowing non-young, non-muscular, and non-successful [i.e., non-middleclass] gay white men to racially identify with the privileged position within the gay community (Connel in Han 2008: 847).

Thus, even though these 'other' white men are not represented to be as 'desirable', they still have the important erotic capital of whiteness, enabling them to claim to be as powerful as their more 'dominant' counterparts. As Seidman (2004) suggests, “[w]hiteness confers a generalized social privilege. Everyone who can successfully claim [w]hiteness can claim something of its benefits and social advantages" (Seidman 2004: 242).

Of the ten samples I gathered, eight of them feature white men. With the exception of issue 399 (Figure A6), all of the subjects on the cover of these eight issues are shirtless or fully naked, featuring their slim, toned, muscular, or gym-built bodies. The fact that the majority of these issues are represented by young, masculine, muscular, middle-class, white men already inform us about the dominant erotic habitus and erotic capital in the field of gay desire. Attention is always drawn towards the body as a key object of desire. This suggests that the body is an im- 
portant site of the materiality of desirability. However, only certain types of bodies are featured in these covers representing not only the desirable body, but also desirable masculinity. These covers suggest that gay white men are politically invested in maintaining and reproducing a certain kind of masculinity, largely based on aesthetics. Therefore, as Whitehead argues, "the body symbolizes or at least encapsulates the very 'materiality of masculinities' or the sense that masculinity is embodied" (qtd. in Edwards 2006: 153). Neither Edwards nor Whitehead provide empirical evidence to this claim.

Turning towards Alexander's (2003) analysis of Men's Health Magazine, muscularity in the postmodern era is often linked with masculinity. She suggests, "the most significant message about masculinity [in Men's Health] is that men should build and maintain a hard body" (Alexander 2003: 542). Thus, for gay men, muscularity and aesthetic masculinity are conflated. Alvarez argues, "certain activities are associated with masculinity: weight training and body building. [Indeed], [w]eight training results in increased muscularity, which is typically seen as increased masculinity" (Alvarez 2008: 122). Therefore, "for gay and bisexual men today, masculinity, is for the most part, a non-negotiable demand whether from potential partners or from ourselves" (Alvarez 2008: 124). Certainly, the fusion of masculinity and muscularity with whiteness, youthfulness, and middle-class lifestyles become manifested in the erotic habitus represented in Fab Magazine. This highlights the characteristics of the erotic habitus of the dominant in the field, which is informed by the social structural forces of race, gender, age, class, and the body.

\section{The Issues: Fab Magazine}

In this section, I provide a preliminary discussion of $F a b$ 's covers. I grouped these covers into the following themes: Dominant/Submissive Roles; Asian Men as Feminine through the 'Orientalist gaze'; Issues of Insider/Outsider; Exoticization, and Fetishization of the 'Other' through 
Sexual Tourism; and, White Men as Consumers and Consumable. I chose to group the covers into these themes in order to allude to the erotic habitus being produced and reproduced in $F a b$, maintaining that white men are the dominant and the most desirable. This points to Dyer's (1997) argument that, "white people create the dominant images of the world, and don't quite see that they thus construct the world in their own image" (Dyer 1997: 9). I argue that through these front covers, the dominant's erotic habitus is presented as natural, legitimate, superior, and universal imposed on all gay men.

In fact, although I argue that dominant-submissive fantasies are represented in these covers, 'race' plays an important role in these depictions. While white men are shown as 'submissive', their submission is ambiguously represented; meaning that they could both be read as either dominant or submissive. The 'Others', however, are almost always represented as 'submissive' particularly because Asian men's portrayal is informed by 'Orientalist gaze'.

Issues of insider/outsider are also prominent in this magazine, wherein white men are the 'gate-keepers' of the gay community while constructing 'Others' as outsiders. The ideologies that are used to 'keep out' racialized minorities are based on the 'Orientalist gaze'. The issue of insider/outsider is also manifested through the construction of non-white men as fundamentally foreign in and outside of Western geographical areas. By delineating them as such, they are exoticized and fetishized as essentially different from the 'norm'. Sexual tourism becomes an important mechanism from which the desirability of the 'Other' is recognized and consumed. These covers portray white men as consumers not only of racialized bodies but also of the consumable white body. Through Fab, the market-like characteristics of the field of gay desire is reproduced. 


\section{Dominant/Submissive Roles}

I start this analysis with a comparison of issues 339 (Figure A1) and 189 (Figure A2) because these issues represent a sharp contrast of how white men's desirability is represented and how the 'Other' is portrayed. One way of reading these images is that they represent the fantasy of BDSM and both of these men are in a submissive role, but they are implied differently. On the one hand, the 'brown' man's submission is more obvious because he is tied up. On the other hand, the white man can also be read to be in a submissive role because he is riding on a sling, traditionally used by gay men to suspend the 'bottom' while being penetrated by the 'top'. However, the caption that accompanies the photo ('caught in his web') says otherwise. This is because the reader is being invoked to be 'caught' by this white man's 'web'. In this case, the white man can even be read to be in the role of the 'dominant'.

Dominant-submissive fantasies are prominent amongst gay men, which are reproduced through these covers and personal ads. ${ }^{24}$ These fantasies are not surprising given that, "the animating dynamics of eroticism-including dominance and submission, humiliation, merger, and transformation-are likely universal features of human sexual life" (Bataille 1962; Chodorow 1994; Stoller 1995 in Green 2008a: 615). I also suggest that in the field of gay desire, power relationships are sexualized, much like in the society at large. Green links desires of domination based on gender to the larger phenomenon of gender domination, which becomes, "embodied in the structure of the erotic habitus, into consciousness, despite its political and personal implication" (Green 2008a: 618). While this is helpful, it only provides a framework to explain desires and fantasies that are based on gender domination. hooks' (2000) concept of 'culture of domina-

\footnotetext{
${ }^{24}$ In Erotics and Politics, Edwards (1994) suggests that in most gay pornography, the eroticization of inequality or dominance is almost always present (Edwards 1994: 86). Thus, if gay pomography is considered as erotic work, dominant-submissive fantasies can be considered as prominent amongst gay men who are both producers and consumers of gay pomography.
} 
tion' provides another understanding of this dominant-submissive fantasies, that are not only based on gender, but also other factors such as race and age. Although hooks' original concept of 'culture of domination' is used to explicate violence perpetrated by both men and women by arguing that, "[i]n a culture of domination everyone is socialized to see violence as an acceptable means of social control" (hooks 2000: 64), this concept helps to explain desires based on power relations, domination, and control exercised through violence in a physical sense and also through 'symbolic violence' in a Bourdieusian sense. The culture of domination becomes embodied in the erotic habitus despite its political and personal consequences.

These covers show the eroticization of the culture of domination becomes manifested through BDSM fantasies. However, while these fantasies may be universal, 'race' plays an important role in how the fantasy of domination/submission is portrayed. Beginning with issue 339 (Figure A1) entitled, "The love and sex issue", the desirability of a young, white, masculine, muscular man with brown hair, blue eyes, facial and chest hairs is highlighted. He represents the most desirable because he is featured in the issue on love and sex. He is suspended on a plastic sling, with the caption, "caught in his web". The sling is used by gay men in BDSM sexual practices, where the 'bottom' is suspended and swung by the sling while being penetrated by the 'top'. This particular fantasy and sexual practice is about domination and submission because the 'bottom' is in a total submissive position by spreading his legs up, ready to be penetrated. In this case, the white man can be read to be in a submissive position, inviting readers to penetrate him. However, the caption says otherwise: it is the readers who are 'caught in his web'. In the larger social context, being 'caught in a person's web' invokes a person being lured into someone's 'web', in which case, the person who is 'caught' has no means of escaping. In this cover, the 
readers are the ones who are being invoked and invited to be in the position of submission and the vulnerability of the trapped because they are the ones who are being 'caught'.

The image also underscores the desirability of white men as universal, which is concurrently imposed on all gay men in the field. Being 'caught in his web' signifies that gay men have no other way of desiring but to look at his body and submit to or be unable to resist his desirability. As a result, he is not only being portrayed as the most desirable, but he also represents everyone's fantasy. Through this imagery, whiteness is given meaning as the most valuable erotic capital, simultaneously de-valuing the erotic capital of non-white men. At the level of representation, we can see that sexual fantasies of domination and submission are reproduced. However, white men are not put in the position of submission and vulnerability as evident in this cover. Often, the 'Other' is put in this position, such as in issue 189 , wherein the 'Other' is literally trapped and tied up.

In issue 189 (Figure A2), we see a non-white (brown?) man who is toned and muscular, tied up with exposed film on an actor's chair. His crotch is covered by his hands. His mouth is taped up with the caption, "exposed film". His brownness is almost demystified because, in many ways, he can pass as 'white' with his muscular and toned body; however, brownness does not and cannot escape exoticization. Perez (2005) suggests that brownness oscillates between whiteness, blackness, and Asianness but the most important thing to note is that, "[t]he ambiguities of brownness function to unburden fantasies of black sexuality from their troubling histories; those same fantasies, and new ones, may be revisited on the brown body" (Perez 2005: 185). The desirability of the 'brown' body then is enmeshed in its difference. It is being commodified for being ambiguous and submissive. 
The model's submissiveness is evident because he is tied up and muffled. In fact, his arms are crunched because they are covering his crotch, meaning that he does not occupy the same space as white men. I suggest that what is being invoked in this representation is Orientalism, wherein the desirability of this 'brown' model is informed by his submissiveness (by being tied) in order to legitimize the domination of his body to compliment the fantasy of domination by white men. As Said (2007) argues, "Orientalism is fundamentally a political doctrine willed over the Orient because the Orient was weaker than the West" (Said 2007: 46). Further, "[a]s a cultural apparatus, Orientalism is all aggression, activity, judgement, will-to-truth, and knowledge" (Ibid). I argue that the desire that is being 'exposed' here (the issue is called, "Desire Exposed: Inside Out Preview") is the desire to know and understand the racialized 'Other'. By tying him up, he becomes subjected to scrutiny and examination of the primitiveness of his body. The 'differences' that they find through this 'exposure' becomes the basis of his exoticness and fetishization. This idea is taken from feminist theorist Susan Bartky's analysis of Foucault's disciplinary gaze. Bartky argues that patriarchy produces beauty ideas about women which, in turn, are internalized by women (Malacrida and Low 2008: 5).

I define 'Orientalist gaze' as a mechanism from which the 'Other' (in this case, Arab and Asian men) are portrayed and objectified through the perspective of white men, informed by Orientalist ideas. I will develop this analysis further in my discussion on personal ads. Meanwhile, I want to suggest that the portrayal of the desirability of this model is informed by an 'Orientalist gaze' because the ideas being invoked in this representation are informed by the submissiveness of his racialized and fetishized body. This is evident because that is how white men understand and want him to be. His body serves as a function to differentiate it from the norm. I argue that this Orientalist gaze also informs the portrayal of Asian men. 


\section{The Portrayal of Asian Men as Feminine through the 'Orientalist gaze'}

In this section, I analyze how the Orientalist gaze is used to feminize Asian men. Asian men are portrayed as the 'Other' by invoking notions of Orientalism, rendering them as fundamentally different from white men. Asian men become desirable to white men because of their fetishized difference from the norm, i.e., their 'Otherness'. In this following analysis, I argue that Asian men are portrayed as essentially feminine and racialized based on the Orientalist gaze to compliment the dominant fantasies of white men. On the other hand, while white men may not possess a muscular (therefore, masculine) body, they do not experience the same level of 'gendering' and exoticization that non-muscular Asian bodies do. Indeed, their white privilege continues to inform a position of socio-cultural power.

Said argues that the portrayal of non-white men as 'Other', as fundamentally different from white men helps to solidify whiteness. As he suggests, "[t]hrough the reproduction of Orientalism, non-white subjects are characterized as a function of the white subject and are allowed no autonomy, and purpose except as a means of knowing the white self" (Said 1978 in Gosine 2007: 139). This Orientalist gaze homogenizes and essentializes all Asian cultures. Asians are seen as exotic, delicate, and feminine, as opposed to the strong and dominant West. Orientalism is intersectional because it does not only racialize Asians as fundamentally different from the West, but this racialization also includes ascribing gender and constructing the body of the 'Other'. This is due to the fact that Asians are designated as more feminine and therefore, they are seen to have delicate features and smaller body frames. Thus, they are constructed as being submissive and passive. In this formulation, Asian men become vassals of white man's fantasies of domination (Han 2008: 54-57). 
The feminization of Asian men is evident in issue 239 (Figure A3), "The Bridal Issue," which portrays an Asian man covered in body paint, resembling a tuxedo in purple, covering his whole body. The model's body is toned, muscular, and fit usually signifying a hypermasculinity. This portrayal might even suggest that this Asian man is being portrayed as a "hybrid', both a bride and a groom. However, there are two considerations that may trouble this interpretation. First, while this might be true, the fact that the issue is called 'The Bridal Issue' not the "Wedding Issue" or the "Happy Groom Issue" may entail the feminization of Asian men. Second, the feminization of Asian men (even muscular ones) focuses our attention to the possibility that once again this body is gendered in particular ways because it is not white. While the painting on his body emphasizes his muscular torso, this 'masculine' body is covered by paint instead of exposing it. This might suggest that his masculinity is being 'hidden' or toned down in order for him to effectively portray what a gay (Asian) 'bride' is supposed to be. This portrayal confirms Han's (2006) assertion that, "Asian bodies, both male and female, [are] painted with feminine brushstrokes" (Han 2006: 10) because, instead of showcasing his muscular body which is often the case for white men featured in these front covers, this Asian model's body is painted over to focus attention away from his muscular body and therefore, his masculinity.

In contrast, the white man in issue 249 (Figure A4) is topless, but not as muscular as the Asian model in the issue discussed above. In the previous cover, the Asian man is fully 'clothed' without exposing his muscularity; therefore, his masculinity is devoid. Although this man has a significantly smaller body frame, the fact that it is not hidden highlights his white privilege. In this cover, the model is also being ambiguously sexualized as either being a student or a teacher to represent a teacher-student fantasy. However, his positionality is not clearly demarcated. He can be read as both: as a student because he is wearing a school uniform (kilt) and as a teacher 
(because he is holding a ruler). This echoes the portrayal of the white man in issue 339 (Figure Al), wherein he can both be read as dominant and submissive, allowing a certain kind of fluidity.

\section{Issues of Insider/Outsider}

The Orientalist gaze is also used to depict groups who are outside and inside of the 'gay community'. This is evident in issues 399 and 146, wherein gay Asian men are represented as outsiders while gay white men are insiders. In issue 146 (Figure A5) entitled, “Asian Pride: How gay Asians have created a community of their own" demonstrates how Asian men are portrayed as a group that exists outside of the (white) gay community. This serves as a reminder that Asian men are excluded from the mainstream gay community and are creating a community of their own. Indeed, a certain line is drawn where white men are 'inside' and Asian men are 'outside'.

The cover is accompanied by a photo of a young Asian man, featuring his smooth and slim body underneath the unbuttoned shirt. The Asian man in this cover may be understood to represent how Asian men are fetishized through the Orientalist gaze, rendering them as fundamentally different from white men. For instance, the model is fetishized for having slim and smooth body. Furthermore, much like the feminization of Asian men in issue 239, this issue also 'hides' the Asian men's body to soften his masculinity. This may inform us that Asian men's fetishization is also linked to perceived cultural traits of what it means to be an 'Asian' such as being feminine.

The theme of outsider/insider is very explicit in issue 399 (Figure A6) titled, "Onward "mo: Exploring the neighbourhoods gay men call home," accentuates who gets to be included in the gay community and who does not. In this context, 'gay neighbourhoods' exclude women, non-white men, and other groups and individuals under the LGBTQ umbrella who are not young, 
white, and middle-class men. This cover features a young white man, dressed very fashionably, pointing towards somewhere, directing 'mo's (i.e., homos) to visit certain neighbourhoods. The background is plain blue, forcing our attention towards the model. Although he is fully-clothed, the top buttons of his shirt are open, emphasizing a V-shaped torso, meaning that underneath his clothes is a toned body. This suggests that 'homos' who populate 'gay neighbourhoods' are young, white, middle-class, muscular, masculine, and fashionable men to the exclusion of 'Others'.

This theme of inclusion/exclusion is also implicated by citizenship. In issue 129 (Figure A7), "Jorge Flores: Escape from persecution", Flores is already rendered as 'foreign' because he comes from a county where persecution of LGBTQ individuals is rampant. While he is being 'granted' a 'safe space', his portrayal is patronizing because his desirability (and to some extent, his existence) is managed by the dominant. Granting him a 'space' in the (white) gay community comes with concessions which are to be directed by the dominant. This relates to the idea of citizenship. According to Phelan (2001), 'citizenship' in the form of political membership does not require the elimination of stigma attached to certain groups. As such, "[i]n order to carry the day, the presumption must conform with pre-existing stigma or exclusion that marks the targeted group as not part of 'us,' but a 'them' to be managed by us" (italics added, Phelan 2001: 19-20). In the context of this cover, homonormative citizenship within the white gay male community means that racial ideologies about 'Others' are maintained by granting political membership to them (such as Flores), but their sexual expression and the stigma attached to their racialized bodies, informed by ideologies such as Orientalism, must be managed by the dominant.

In this issue and the previous issue on 'Asian Pride', racialized gay men are standing for political issues as opposed to the love, sex, and fun issues. Keeping in mind Phelan's argument, 
it seems that homonormative citizenship is being granted to 'outsiders', i.e. those who are excluded from the mainstream. However, this citizenship should be managed by the dominant by clearly demarcating who is the group who is not part of 'us'. Furthermore, in issue 129, there is such an intense close-up between Jorge and the reader. This creates an immediacy and intimacy with the image. This might point to notions of citizenship, wherein the 'Other' is considered very child-like, who needs help from those who are more 'mature' or 'civilized'. This might also point to notions of colonialism and imperialism, wherein Western imperial powers saw themselves to be helping and taking-care of the 'savages'.

\section{Exoticization and Fetishization of the 'Other' through Sexual Tourism}

Managing racialized 'Other' through the Orientalist gaze is also suggested in issue 202 (Figure A8), "The Travel Issue", wherein non-white men are exoticized and simultaneously relegated outside the confines of the white gay male community. In this cover, the men are all topless, wearing swimming trunks, and wearing little flags on their chests possibly to identify where they are from. The only Canadian flag is painted on a white body. Although the Asian male sports a Swedish flag, the most important feature to note from this image is that 'traveling' entails that the gay male tourist is able to consume many different types of bodies, specifically the exotic 'Other' in different geographical spaces. While the particular Asian man is located within a Western space, his Asianness still makes him a racialized 'Other' because his desirability and the desirability of these men (majority of whom are non-white: 3 white men and 7 are non-white men) only exist in the context of traveling. The bodies of the 'Others' here are being commodified through sexual tourism. As Perez (2005) argues, "[t]he development of an Anglo-American tourism industry to service a growing leisure class contributed to the formation of a cosmopolitan gay male identity, making available for consumption both spaces and bodies imagined as precivi- 
lized" (Perez 2005: 177). I suggest that the 'leisure class' who are the potential consumers of this particular issue consist of white middle-class men who have disposable incomes who are also able to consume these bodies through traveling.

On the other hand, white men who are not able to travel can still have an access to these bodies without even leaving their backyards. Due to the fact that non-white men are simultaneously inside and outside of the white gay male community, white men can have the option of exercising sexual tourism within the confines of the city or the country. As long as racialized bodies are understood through the Orientalist gaze as essentially different, they will always be fetishized for being exotic regardless of their geographical location. This idea of sexual tourism will be important in the discussion of rice queens later on.

Sexual tourism becomes a means for white middle-class men to act out their desires for the 'Other'. This is related to imperialist nostalgia which I discussed in Chapter 2. Imperialist nostalgia is based on the belief that the spirit of primitiveness is embodied by racialized 'Others'. This nostalgia is also related to Orientalism, wherein, "[s]ex was always an important feature" (Massad 2007:9). Indeed, sex was and is exercised through sexual tourism. As Said says, "[j]ust as the various colonial possessions... were useful as places to send wayward sons, superfluous populations of delinquents, poor people and other undesirables, so the Orient was a place where one could look for sexual experience unattainable in Europe" (qtd. in Massad 2007:9). I argue, however, that sexual tourism can also be exercised within Western countries itself, without necessarily traveling to 'exotic' places. The desirability of Asians, blacks, and other non-white men only exists in the erotic habitus of white men in the context of sexual tourism. For them, to be a sexual tourist in and outside of the 'West', is to explore and fuck the precivilized, the primitive, which resides in the bodies of the 'Other'. 
The desirability of white men, however, is not based on any essential qualities about their 'race' because, as Dyer (1997) argues, "[a]t the level of racial representation [...] whites are not of a certain race, they're just the human race" (Dyer 1997:3). This assertion can be extrapolated from issue 159 (Figure A9), "Pride Down Under". Although this is not explicitly about sexual tourism, 'Down Under' (i.e., Australia) is not presented as a place where the consumption of 'Others' can be exercised. Rather, it is portrayed as a place where white men gather together, party, and have sex. Although there is a group of men, much like "The Travel Issue", the white men in this cover are not marked as a 'race'. They are presented as gay men having fun in Sydney's Gay and Lesbian Mardi Gras. Their desirability is not based on any exotic or fetishized qualities. Their erotic appeal is based on their well-toned and muscular bodies, accentuated by swimming trunks that also emphasize their bulging crotches, which points to the importance of aesthetic white masculinity.

The invisibility of gay racialized citizens is very telling because not only does it suggest that only white, masculine, young, muscular men who have disposable income are desirable, but they are the only ones who can represent what 'Pride' is about. This can be related to Bérube's (2001) discussion on how gay stays white, especially in this context, where 'Pride' can only be represented by white men. By constructing white men as the 'norm', who can represent what 'Pride' is all about, points to the issue of insider/outsider. Through the exclusion of 'Others' by rendering non-white men as 'foreign', the idea that gay citizenship is white and well-to-do is maintained and solidified. By being portrayed as the 'norm' of what it means to be a gay citizen is also related to white privilege. As Seidman (2004) argues, "whiteness serves as a standard, a baseline of what is considered natural and normal" (Seidman 2004: 242). To be a white gay man means that they can claim a 'normal' gay citizenship, while excluding 'Others'. 
This portrayal relates to what Bourdieu calls the 'cultural arbitrary' wherein whiteness, masculinity, muscularity, youthfulness, and middle-class lifestyles are portrayed as universally significant. In turn, cultural arbitrary develops erotic tastes, which become embodied in the erotic habitus. Through the construction of desirability in the image of white men, they set the standards of desirability, "by which they are bound to succeed and others bound to fail" (Dyer 1997: 7). The rules of the 'game' in the field are put in place informed by the standards of desirability produced in this cultural vehicle, enabling white men to succeed while 'Others' have to play harder. The centrality of whiteness then, following McBride (2005), is evident in this cover. This whiteness, however, is always represented as masculine, muscular, young, and middle-class.

\section{White men as consumers and consumable}

The construction of white men having the most valuable erotic capital also highlights the marketplace-like characteristics of the field of gay desire. This is manifested through issue 249 (Figure Al0), wherein white men are simultaneously represented as both consumer and consumable. The Halloween issue titled, "How to get boned on Halloween," features a vampire in leather suit with blood dripping out of his mouth. He holds a blond and boyish-looking man's wrist lying down below him, shirtless with a red blanket covering him from waist down. 'To get boned' means to have sex, and both of these models are being sexualized. They are also representing a vampire fantasy, eroticized in popular culture with films such as the Vampire Diaries and the Twilight Saga. The vampire represents the 'consumer' of the 'consumable' blond, white guy with a slim body. Indeed, the desirability of both men in this cover is being underscored, especially that of the blond man, who 'got boned' by the vampire. Since the vampire in popular culture is always represented as the 'consumer' of humans, this image encourages readers to identify with the 'victim'. Consequently, both the agent of desire (i.e., the one who consumes) and the 
object of desire (the one being consumed) are both represented by white men. What is being implicated here is that the reader is supposed to relate with either the vampire as a consumer or the victim as consumed. The erotic habitus of the dominant white men is reproduced, wherein 'getting boned' is only applied to white men, making non-white men absent and invisible from their desires.

\section{Summary}

Through the analysis of Fab Magazine, the role of semiotic elements, via culture, are highlighted in the reproduction of the erotic tastes of the dominant group, which inform us of the social structural forcers present in the field. $F a b$ is an example of a cultural product wherein desires and desirabilities are produced and hierarchies of desire take shape. Through these representations, the erotic tastes and fantasies of the dominant are depicted as the most legitimate and universal, which plays an important role in the maintenance of white privilege. This is because white men are unmarked, presenting them as 'normal' which do not need to be explained or be 'exposed'. Indeed, this is evident not only in the depiction of white men as the most desirable, but most importantly, in the representation of non-white men. Specifically, Asian men who are characterized as fundamentally 'different' from the 'norm'. These images also inform us of the most valuable erotic capital in the field, which is the intersection of whiteness, youthfulness, masculinity, muscularity, and middle-class lifestyles. How gay men use their erotic capital is the issue that I will discuss in the next chapter. 


\section{Chapter 5:}

\section{The Erotic Habitus in Craigslist's Personal Ads and Rice Queen Diaries}

This chapter builds upon the analysis of Fab. It focuses on the personal ads of gay men found in Craigslist in order to delineate how the social structural forces of whiteness, youthfulness, masculinity, muscularity, and middle-class lifestyles become embodied in the erotic habitus of gay men. Keeping in line with Bourdieu's concept of habitus, 1 extrapolate how the erotic habitus inform the practices of gay men. Specifically, how they express their desires and desirability. I argue that the erotic tastes found in $F a b$ (as a cultural product) become manifested and embodied in the erotic habitus of white men, Asian men, and rice queens through their erotic works (i.e., personal ads). Due to the market-like characteristics in the field of gay desire, gay men's personal ads highlight what they come to think as their 'value' in order to attract their erotic choices. Through the 'Orientalist gaze', Asian men 'self-Orientalize' (Kondo 1997; Leshkowich and Jones 2003) themselves as a form of commodifying and objectifying themselves to become desirable to 'rice queens'. Orientalism also includes ideas of colonialism, control, and domination, also manifested in the rice queens' erotic habitus demonstrated by Gawthorp in his memoirs.

The choice of personal ads to explicate some of the characteristics of the erotic habitus of gay men in the field of gay desire is helpful because personal ads are increasingly replacing print ads and they are also becoming extensions of chat rooms. According to McBride (2005), the transition from print to the proliferation of gay male personal ads on the internet (such as on Craigslist) is significant because it enables posters to use photos and also simplified and privatized the placing of ads (McBride 2005: 110). Personal ads also have important implications especially because, "the structure of the erotic habitus reveals itself in the patterning of sexual de- 
sires brought to consciousness via the erotic work" (orig. it., Green 2008a: 615). It must be noted, however, that these personal ads not only inform us of the erotic habitus but also erotic capital. The erotic capital in these personal ads (i.e., how the poster subjectively sees himself as desirable) can be read as a form of self-commodification in order to 'market' the self as desirable to get the most response from the poster's erotic choices (read: a form of agency, informed by the erotic habitus). Since these personal ads are constructed by pairing erotic choice and erotic capital, sexual desires within the context of Craigslist have market-like characteristics based on the 'value' of erotic capital exchangeable for equal or greater value. Thus, a relationship can be discerned between erotic habitus and erotic capital, i.e., the use of erotic capital is informed by the erotic habitus.

\section{The Erotic Habitus of Gay White Men}

My analysis starts with the personal ads posted by white men from the general samples. Majority of the ads from both Toronto and Montreal are posted by self-identified white men between the ages of $20-50$, with the majority posted by men in their 20 's. ${ }^{25}$ In fact, $48 \%$ (52 out of 108 ) from Toronto and $46 \%$ (47 out of 101 ) from Montreal are posted by self-identified white men. $32 \%$ of the ads from Toronto and $45 \%$ of the ads from Montreal are not-specified (see Table 1 and Table 2, Appendix C). These unspecified ads with no racial identifiers may be posted by white men because, as Dyer (1997) points out, "[t]he sense of whites as non-raced is most evident in the absence of reference to whiteness in the habitual speech and writing of white people in the West" (Dyer 1997: 2). In sharp contrast, Asians, blacks, Latinos and other non-white people always feel obliged to identify themselves as racialized. Therefore, these ads generally reflect the erotic habi-

\footnotetext{
${ }^{25}$ In analyzing my data, I separate the ads gathered as 'general sample' and 'Asian samples'. I separate each by 'race': white men as posters, Asian men as posters, and white men who are particularly interested in Asian men. I code these posts by dissecting them into two parts: self-description, in order to delineate how these men describe themselves as desirable and what they look for as their 'erotic choice'.
} 
tus of the dominant. These ads consist of their erotic choice(s), erotic capital, and the reasons for posting the ad, which is to find sex. My analysis focuses mainly on erotic choice(s) and erotic capital because, by focusing on these factors, I am able to explicate how these ads reproduce some of the social and sexual stratifications present in the field. This erotic habitus does not only replicate racial stratification but also stratifications based on gender, age, body type, and class. Furthermore, these ads inform us of the market-like characteristics of the field of gay desire. The culture of domination, via fantasies of domination/submission, is also embodied in these ads. It must be acknowledged that this analysis only describes some but not all of the characteristics of the erotic habitus of gay men. This is because, in order to describe the erotic habitus in whole, Bourdieu's large-scale and extensive survey data must be employed. What can be extrapolated from these ads, however, is that whiteness, masculinity, muscularity, youthfulness, and middleclass lifestyles all intersect to inform the dominant form of erotic capital.

One of the major stratifications of desirability that are common amongst these ads is masculinity as a non-negotiable demand which they expect from their sexual partner choice. In fact, 'masculine' and 'straight acting' appear in $60 \%$ of their erotic choice. Masculinity is also a characteristic which these men use as one of their erotic capital. $70 \%$ amongst those selfidentified white men consider themselves as 'masculine', 'very masculine', or 'straight acting'. Here, we can see that masculinity is eroticized and embodied in the erotic habitus. Edwards $(1994,2006)$ explores this eroticization of masculinity arguing that, "gay male desire often remains chained to limited models of masculinity" (Edwards 2006: 98), although he does not offer an explanation as to why this is so. One explanation which Whittier and Melendez (2007) offers is that, "[b]y having sex with a particular type of man, they [gay men] can express masculine and feminine traits" (Whittier and Melendez 2007: 199). Indeed, gender is one of the structural forces 
embodied in the erotic habitus of gay men in these ads, which are experienced differently. Most of the men in these ads, however, recognize and delineate masculinity as sexually arousing. Through the exposure of most gay men to the structural forces within the field of gay desire, they have come to consider masculine men as desirable. This particular erotic habitus also informs how they come to objectify themselves as desirable, i.e., to highlight the fact that they are masculine in order to attract other masculine men. This is especially true for some white men and is based on emphasizing hyper-masculinity by the clone culture which Taywaditep (2001) links to explain the anti-effeminacy attitudes amongst gay men. Thus, a link can be made between the 'cultural arbitrary' (i.e., representations of masculinity as the most desirable) and shaping an erotic response towards masculine men.

Fat men, femmes, older men, poor men, disabled men, and non-white men are often excluded from the erotic choices of Craigslist posters who are white. For instance, $46.2 \%$ of selfidentified white men from Toronto and $53 \%$ of self-identified white men from Montreal specifically have white men as their erotic choice. This exclusionary erotic choices correlate to the representations of desires in $F a b$ (and other cultural products) where the idea of masculinity is linked to muscularity and also class. These representations also inform the erotic capital of those who are included as the most sexually arousing and those who are not. Through these personal ads, a hierarchy of desires is reproduced and maintained.

Age as a social stratification is also embodied in the erotic habitus, wherein the majority of posters are young, enabling them to place a cap on who can contact them, i.e., preferably men between 20-35 or younger, but certainly not older. Those who are over 40 highlight the fact that they do not look their age or that they have a 'baby face'. Often times, these men would also highlight their other desirable attributes, especially their whiteness, masculinity, and muscularity. 
These men are looking for someone younger, with a preference for younger non-white men, especially Asian men, which I will discuss later. I will argue that, by highlighting their whiteness, masculinity, and muscularity, they attract more Asian men, whose desires are directed towards white men. Due to the hierarchy of desires, both of these populations are relegated below the youthful, masculine, muscular, middle-class, and white men. Specifically, older white men's erotic capital becomes very valuable for Asian men, whose erotic capital is of lesser value. Because the field of gay desire follows the characteristics of capitalist economy, the value of erotic capital is only exchangeable for equal or greater value. Thus, Asian men earn more 'erotic profit' from consuming older white men while older white men 'exchange' their value for the erotic capital of Asian men, whose youthfulness, exoticness, perceived femininity, passiveness, and submissiveness make them consumable and valuable. I offer a detailed analysis of this exchange when I discuss the erotic habitus of 'rice queens'.

Another important aspect that needs to be highlighted is the use of pictures that accompany the ads. These pictures only feature the poster's slim, toned, or muscular torsos and/or their hard and erect penises, which follow the characteristics of commercial print ads. In fact, to be desirable in the field, one must make himself marketable by accentuating their most valuable erotic capital. For white men, these pictures act as proofs of their value and desirability, without necessarily mentioning their race in the text. Pictures of their erect penises are almost always attached to inform readers of their consumability. Their 'big dicks' however, do not represent the dangerousness that is attached to black dicks.

In the following paragraphs, I provide a closer analysis of two personal ads posted by white men. I suggest that this poster's erotic choices conforms to the erotic habitus of the domi- 
nant being reproduced in Fab Magazine. Further, what he highlights as his erotic capital is also informed by this erotic habitus.

21 year old college guy. horny for a hookup. (davisville) [see picture attached, Figure B1]

like the title says. its [sic] been a while and i'm looking for a hookup. 21 year old, white, gym fit, and have a big cock (actually). i'm [sic] looking for hot guys my age \& i only play safe. prefer white and middle eastern dudes. i prefer someone level headed who can carry a conversation. you be healthy and clean as i am discression [sic] expected, and returned as well. thanks

In the 'world' of personal ads, short-term casual sexual encounters constitute a major part of the 'game'. First, he tells us why he is posting the ad: "it's been a while and i'm [sic] looking for a hookup [sic]", which might suggest that he is homy and needs sex immediately. Next, he highlights his erotic capital to 'sell' himself (via self-objectification) by emphasizing what he thinks are his desirable attributes. These attributes conform to the general erotic habitus in the field, i.e., what are considered as desirable that were extrapolated from the previous analyses: " 21 year old, white, gym fit, and have a big cock (actually)". Here, he emphasizes his young age as an asset, which intersects with his race, body type, and huge dick, casually emphasizing that it is 'actually' big. Big cocks are desirable attributes in the field of gay desire, but it is only desirable for white men. Popular discourses on penis size attribute 'dangerousness' to big black dicks. Big cocks in Asian men simply do not exist because of the stereotypes about Asian men having smaller dicks. Thus, we can see that the conflation of 'normal' masculinity with having big penises are only applied to white men, whose erotic capital includes having a big cock. This capital, however, is denied to black men and Asian men.

The poster's erotic capital, however, is only exchangeable for the same 'value', which reflects the erotic habitus I extrapolated from $F a b$. Looking closely at his erotic choice, we can see cultural ideas shape his sexual tastes and subjectivity. Indeed, some of the stratifications of 
desirability present in the field are embodied in his erotic habitus. First, his erotic habitus reflects the stratification based on age, i.e., "looking for hot guys my age" (read: the 'value' of his age is only exchangeable for same). The standard of 'hotness' is only applicable to 'white and middle eastern dudes'. This tells us that the stratification based on race is embodied in his erotic habitus, which means that the 'value' of his race is only exchangeable for white and Middle Eastern men.

It is difficult to discern why his erotic capital can be exchanged for Middle Eastern men because he does not tell us the reasons why this is so, pointing to the limitations of personal ads. One may argue that he has come to exoticize and fetishize Middle Eastern men based on the exoticization and fetishization. Another argument explicated by McBride (2005), who contends that 'whiteness' sometimes apply to Latino men as long as they are 'light-skinned' and 'clean and safe' (McBride 2005: 117). Perhaps 'whiteness' can also be applied to Middle Eastern men who are 'light-skinned' (therefore, could 'pass' as white) as long as they have the body and gender capital. Thus, in this man's erotic habitus, some Middle Eastern men are erotically desirable who have the same exchange-value as a white man. It is also possible that this individual prefers Middle Eastern men because of accidental encounters-having lived in the Middle East or having had Middle Easten lovers before.

He also prefers someone who is 'level headed who can carry a conversation. This is interesting given that he is looking for sex and not for a date. He also demands them to be 'healthy and clean as i [sic] am", which inform us of class, race, gender, and body dynamics. In this context, to be 'healthy' means that they are drug and disease (read: STI and HIV/AIDS) free and also must be 'fit' which could be achieved by going to the gym. The fact that he is also 'gym fit' informs us that he works out, that he can afford to spend time and money to go to the gym and eat healthy. Indeed, the gym has become a part of the habitus of gay men that it has become one 
of the most valuable erotic capitals. For this poster, being muscular is conflated with masculinity, which increases his value. To be white, 'gym fit' (read: muscular) and therefore, masculine, inevitably makes him valuable in the field of gay desire. This informs us that the way he selfobjectifies to 'market' his value in the field is informed by his erotic habitus which recognizes white, young, masculine, muscular, and middle-class men as the most desirable. These erotic capitals, however, is only exchangeable for the same value.

Finally, he accompanies his ad with a picture of his torso to prove to readers that he is, in fact, muscular, masculine, and white. By showcasing these attributes, his body becomes the site of his desirability. Through the attachment of a photo, we see how the field of gay desire has market-like characteristics. Posting a picture of the body attracts 'consumers' to fight over the coveted piece of meat: young, fit, and white. Most of the time, providing a picture is a must, which tells us that men judge each other based on the pictures that they send and attach with their ads. This idea of a 'proof' (through pictures) then is part of the 'game' in the field. ${ }^{26}$

These same characteristics can also be extrapolated from the following ad from Montreal's Craigslist.

\begin{abstract}
young college prof visiting mcgill - looking for students - 35 (mcgill plateau) [see picture attached, Figure B2] masculine white college prof visiting from nyc and looking for local college guys for discreet fun, never get to play at home because they might be or become my students, but into the older younger dynamic, not silly role play, but chill relaxed fun, love to massage a hot college body, this can be totally discreet and anon if you need that--looking for masc white guys, love uncut but not nec [sic], can help you explore if you need it, or not. if this
\end{abstract}

\footnotetext{
${ }^{26}$ While this is not unique to the field of gay desire, posting naked bodies and erect penises are unique to gay men. Photos are also used by people participating in online dating and personal ads. A quick browse through the Craigslist personals section shows that women (women seeking women and women seeking men) do not post pictures as much as men. Women post pictures of their faces or other body parts (such as lips and cleavages) but not their sexual parts. They do not post any naked photos. Men in the men seeking women section post pictures of their faces and bodies but not erect penises or buttocks. Men in the men seeking men section, however, post pictures of their fully naked bodies including erect penises, butts, and butt holes. However, faces are rarely shown.
} 
sounds fun, send pics and stats and some info--can't host, staying with colleague, but can find a place if we need it

In this ad, a university professor is relaying that he is into younger college students. Unable to fulfill his fantasy in New York City, he feels freer to entertain his sexual appetites while visiting Montreal. He also describes his erotic fantasies by saying that he is "into the older younger dynamic, [but] not silly role play, but chill relaxed fun". Here, he provides a window into his sexual fantasy, i.e., the fantasy of older-younger dynamic (or student-teacher fantasy), wherein an older man fantasizes about having sex with a younger man. This informs us that he has come to eroticize his position as someone in power. This can be related to the dominant/submissive erotic fantasies that are also part of the erotic habitus in Fab. By playing out his fantasy, he legitimizes his power as an older college professor over the younger college student. Power is eroticized based on age, social position, and through gender relations.

In the culture of domination, men are socialized to exercise domination over those who are deemed powerless in order to demonstrate one's masculinity. In Edwards' (1994) study on gay pornography, he suggests that, "there is a significant emphasis placed upon the eroticisation of inequality and dominance" (Edwards 1994: 86). Edwards further argues that, underlying this eroticisation of inequality and dominance is, "the eroticisation and valorisation of masculinity", which can be derived from the culture of domination prevalent in the field evident in popular cultural vehicles such as gay porn and magazines (Ibid). This personal ad demonstrates that gender inequalities become part of this professor's erotic habitus by exercising domination over those whom he deems powerless (i.e., young college students). After all, according to Long (1994), "gay sex is a way for two contemporary gay men to come to know and feel themselves to be men" (Long 1994: 23). Ultimately, gay sex is about the valorisation and eroticisation of masculinity. 
Race also plays a role in this poster's erotic habitus. The poster underscores that he is, "looking for masc white guys". This erotic choice is related to the erotic habitus found in the cultural products in the field such as $F a b$, which is fundamentally racist by excluding non-white men in their desires. This brings me to conclude that social structures impact gay men's erotic tastes and fantasies. However, this does not mean that social structures explain all aspects of sexual desires. Social structures also inform how gay men come to subjectively see themselves as desirable and how they negotiate their desirability. In this poster's picture, he highlights his white penis, informing us of his masculinity and dominance, derived from the dominant erotic habitus in the field of gay desire.

As evident in these analyses, there is a particular pattern of erotic habitus that is present amongst the ads coded and analyzed. In these analyses, gay white men often objectify their whiteness, youthfulness, masculinity, muscularity, and their class position (via professions) as erotic capital, which may be derived from social structures. Older white men's erotic habitus also bears an imprint of these social structures where they highlight their 'baby face', youthful looks, and muscular bodies. They also look for younger men. Due to the market-like characteristics of the field, gay men actively and creatively find ways to boost their exchange-value via posting pictures of their torsos and/or big erect penises to market themselves. The main rule of the 'game' therefore is to increase one's value by objectifying erotic capital which is deemed to be universally desirable in the field. These structural forces also find their way in the erotic habitus of gay Asian men, which is the subject of the next section.

\section{The Erotic Habitus of Gay Asian Men}

'Race' traps the body in real life. It attaches meaning to skin, hair, and bones that have been organized around the ambitions of colonialism/imperialism, capitalist exploitation and psychoanalytical differentiation, and which have proven difficult to destabilize (Gosine 2007: 141). 
In this section, my aim is to provide an analysis of erotic habitus of Asian men and how 'race' traps the Asian body, organized around Orientalism. Gosine (2006) argues that race gives meaning to the body, I focus on how this translates to desires and desirability specifically for Asian men. I argue that based on the personal ads on Craigslist, Asian men's erotic habitus bears some imprint of social structures, wherein their erotic choices are informed by what are considered as desirable by the dominant (i.e., young, white, masculine, muscular, and middle-class men). Their subjective sense of their desirability (i.e., how they objectify themselves) is shaped by the ideologies of race based on Orientalism, produced in the dominant culture. I suggest that by 'selfOrientalization', they creatively and actively play out the stereotypes about them in order to make themselves valuable, desirable, and consumable in the field for certain ends such as attracting their objects of desire, or for their own pleasure. In this instance, the power relations usually associated with submissive positioning is re-defined so that some Asian gay men are able to use position of vulnerability as a possible place of power. In the next section, I begin with the latter (i.e., how they 'self-Orientalize') and move on to the former (i.e., their erotic choices). This is to show that their erotic habitus bears an imprint of social structures and the power of cultural products in shaping desires and desirability.

\section{'Self-Orientalization': Asian Men's Subjectivities and Erotic Capital}

Asian men's masculinity ${ }^{27}$ is embodied in their erotic habitus, which I call 'self-Orientalization' to market themselves as 'valuable' in the field. Indeed, $80 \%$ of the ads posted by self-identified Asian men describe themselves as 'slim', 'smooth', 'bottom', 'submissive', and 'passive'. These may appear alone (e.g. 'I'm 5'10", Asian, one fifty pounds, and slim/athletic') or combined (e.g., 'slim fit cocksucking bottom wants your load now'). I suggest that through the process of self-

${ }^{27}$ Poon \& Ho (2008) describe Asian men's masculinity as, "skinny, effeminate, passive, and submissive" (253). See discussion in Chapter 1. 
Orientalism, Asian men see themselves and others through the 'Orientalist gaze' which tends to render Asian men as passive, submissive, and feminine; therefore, they do not complement each other. 'Orientalist gaze' is based on Bartky's argument that women discipline themselves and other women through the 'disciplinary gaze' in order to conform to the patriarchal beauty ideal so that they do not transgress from the rules attached to the feminine body (Malacrida and Low 2008: 5). Through the 'Orientalist gaze', Asian gay men objectify themselves by adopting their exotic qualities (also known as 'self-Orientalization') to fit into the mould of what the dominant white men want them to be for the purposes of attracting them or for their own ends.

The idea of self-Orientalization is developed by Kondo (1997) and by other fashion studies scholars such as Leshkowich and Jones (2003). Kondo advances this notion to mean 'autoexoticization' (taken from Savigliano 1995), wherein Asians incorporate 'Westem gaze' (in this thesis, 'Orientalist gaze') to reinscribe Orientalism (Kondo 1997: 84). Leshkowich and Jones further argue that, "[s]elf-Orientalizing is $[\ldots]$ a fraught endeavour, a way to internalize stereotypes, to counter them, or to reproduce them, often an uneasy mix of all simultaneously" (Leshkowich and Jones 2003: 285). Self-Orientalization is understood as internalizing Orientalism at the same time, using/exploiting these stereotypes by gay Asian men for gains (i.e., accessing white privilege through sexual encounters with white men). It is more than 'internalized racism', in which case individuals simply passively accept their supposedly inferior position. In selfOrientalization, individuals act on the stereotypes in order to achieve certain ends they desire such as attracting white men. Racist power relations are embedded in self-Orientalization and through this Orientalist gaze, they come to see each other as competitors for the attention of the desirable white men. As Hon and Ma (1993) suggest, "[n]ot only do we not see other API men as desirable; they are almost always perceived as competition because those who are like us under- 
mine our exoticism and 'specialness' in the eyes of the (desirable) white men" (qtd. in Obendorf 2006: 169).

Self-Orientalization, however, does not mean that Asian men identify themselves as 'feminine'. Indeed, some of the ads do not even mention gender. This might be a deliberate move by these men to not identify themselves as either 'masculine' or 'feminine'. Certainly, Orientalist discourses surrounding Asian men's masculinity inform this action. Due to the fact that Asian men's masculinity is virtually erased through these discourses, Asian men do not include any gender identity. On the other hand, they avoid identifying themselves as 'feminine' because of the anti-effeminacy attitudes amongst gay men, which would result to their rejection from other men. ${ }^{28}$ However, there are posters who describe themselves as being 'passive' and 'submissive'. It is not clear however, whether using these identifiers stems from a process of internalization of ideas of Asian desirability or a strategy used by these posters to attract certain white men.

Furthermore, as Han (2000) claims, “Asian American men's bodies are portrayed as small, unattractive, effeminate, and wimpy" (Han 2000: 207), which is ultimately derived from Orientalism. However, the Asian men in this study do not necessarily understand their bodies as unattractive. Rather, they use their small, effeminate, and wimpy bodies as erotic capital. Indeed, for Asian men, being 'slim' is one way of self-objectification. In addition to being 'slim', another characteristic they attach to their bodies is 'smoothness'. Having no hair is ascribed to Asian male bodies to feminize them; however, these Asian men use it to increase their erotic capital. Some Asian men may use this to increase their exchange-value. This is because, according to Mohr (1992), the norm in gay porn is a smooth body, "ascribing it to a focus on the desirability of youth" (Mohr in Campbell 2004: 161). In the absence of 'masculinity', attention is drawn by Asian men to their desirable youthfulness by having a slim and smooth body in order to increase ${ }^{28}$ See Taywaditep (2001) in Chapter 1 for a full discussion. 
their position in the hierarchy of desirability. In the field of gay desire, youthfulness is one of the characteristics that is delineated as desirable.

However, this needs to be problematised. As Hom and Ma (1993) warn:

[o]ur (presumed) racial characteristics are fetishized by non-API [Asian Pacific Islander] gay communities as a frozen form of desirability-one that is derived from Orientalist perspective. In this economy of desire, the trade is almost always unidirectional, where APIs are encouraged to use our 'exotic appeal,' our 'Oriental sensuousness,' to maximise our attractiveness to other-non-Asian and usually white men (qtd. in Obendorf 2006: $165)$.

Thus, within the field of gay desire where Asian men are only valuable because of their presumed exoticness, Asian men self-Orientalize by using their 'exotic appeal' to either become desirable to certain white men or for their own pleasure. Due to the feminization of Asian men in mainstream and gay media, such as Asian men's portrayal as a 'bride' in Fab Magazine, the absence of masculinity influences their erotic habitus. For some white men, the desirability of Asian men is based on a 'frozen' idea of exoticness. Thus, in order for some Asian men to appeal to white men, they have to emphasize their exotic appeal.

Other erotic capitals which Asian men highlight are similar to what white men underscore in their personal ads, including height, weight, hair and eye colour, and penis size. One of the major differences, however, between Asian and white men is how they identify their sexual positions as either top, bottom, or versatile. Whereas white men identify themselves mostly as versatile, Asian men mostly consider themselves as bottoms. This is an interesting difference which is connected to the discussion of 'self-Orientalization' since it accentuates Asian men's subjectivities, especially in relation to masculinity and their marketability.

In order to effectively discuss Asian men's subjectivity vis-à-vis adopting a particular sexual position (i.e., being a bottom), I wish to revisit Fung's (1991) discussion on gay porno- 
graphy's representation of Asian men. In his analysis, Fung argues that Asian men are always assigned the role of the bottom, while white men are always portrayed as the penetrator (i.e., the top). Power relations always implicate these sexual positions. However, we must avoid the tendency to view these positioning as static. As Han (2000) argues, "[t]his position [i.e., being a bottom] has direct association to powerlessness, submissiveness, and passiveness" (Han 2000: 218), which are stereotypes about Asian men prevalent and engrained in gay cultural representations. Some gay men derive gender ideologies from these sexual positions. Whittier and Melendez's (2007) research suggests that being the 'top' in anal intercourse means 'being a man', i.e., exercising one's masculinity to be in control by being the inserter in anal intercourse (Whittier and Melendez 2007: 200). Green (2008) also relates this to gender domination embodied in the erotic habitus. ${ }^{29}$

Since Orientalist discourse delineate Asian men as passive, submissive, and feminine, these ideologies shape their erotic habitus. Indeed, this is evident in the personal ads by using descriptions such as, "submissive Asian looking to service a nice cock" or, "slim fit Asian bttm [bottom]". Thus, since Orientalist discourses are part of the structural forces about 'race', Asian men can be seen to self-Orientalize in these ads. Through the dominant group's cultural production, an image and ideology regarding gay Asian men is created (i.e., Orientalist gaze) which, in turn, inform Asian men about their objectification and position (literally and figuratively) in the field of gay desire. Since the 'value' of being Asian can only be conceived through exoticization and fetishization, Asian men highlight what some white men have eroticized them to be, i.e., being a bottom, having a small and smooth body. This understanding of their 'value' is also related to Bourdieu's 'symbolic violence'.

\footnotetext{
${ }^{29}$ 'Tops' as masculine and 'bottoms' as feminine are discourses already problematised as rooted from heteronormative gender ideologies (see Long 1994). However, the aim in this thesis is to show how these gender ideologies (as social structures) become inscribed and embodied in the erotic habitus.
} 
According to Riger-Ladich (2010), "[s]ymbolic violence characterizes thus those practices through which the dominated are incidentally bound, as it were, to exactly those forms of processing reality in which the interests of the dominant social groups are given expression" (Rieger-Ladich 2010: 114). The embodiment of the racial domination, informed by Orientalism in the erotic habitus of Asian men, can be conceived as a form of symbolic violence. This is because, Orientalism and racial domination are considered the 'natural order of things', wherein Asian men's masculinity is not present in how they self-objectify in these ads (which, of course, could be a calculated move). However, by adopting what white men conceive to be their (i.e., Asian men's) erotic capital, Asian men give expression to the interests of the dominant. By directing their erotic desirability and marketability to white men, the social structures that govern the field of gay desire (i.e., whiteness, masculinity, muscularity, youthfulness, and middle-class lifestyles) are somehow retained and highlighted. Self-Orientalization can function as both hegemonic and counter-hegemonic social strategy for Asian gay men.

The images that Asian men attach to their personal ads provide a window to how they market themselves as desirable. In contrast, the images white men affix with their posts often feature their bodies and erect penises whereas Asian men feature their bodies and their buttocks. The differences between these images are also telling of the masculine identity of Asian men. In Edwards' (1994) study on gay porm and masculinity, the eroticisation and valorisation of masculinity is primarily interjected through "physical and psychological masculinity," which involve, the actor's "muscles, the size of his cock, his physical presence, and his authoritative orders" (Edwards 1994: 86). The size of the penis only becomes meaningful when it is erect and thus, the erect penis can be read as the eroticisation and valorisation of masculinity. Some Asian men, come to conceive themselves as being passive and submissive by being the bottom, the pene- 
trated and not the penetrator, by featuring their buttocks instead of their erect penises. This is not to suggest however, that all Asian men are bottoms and all white men are tops.

\section{Asian Men's Erotic Habitus: Erotic Choices}

In this section, my focus is on the erotic choices of Asian men, which follows the erotic habitus of the dominant. In these ads, most Asian men recognize masculine, muscular, youthful, middleclass white men as their preferred sexual partners. $70 \%$ of those who have preferences desire white men, while $50 \%$ said they look for masculine or top or masculine tops. These erotic choices bring light to the role of culture in the field of gay desire, shaping the erotic habitus. Through cultural production, we come to acquire ideas of what and who are erotically pleasing. Some of our erotic choices can be derived from these representations. This can be demonstrated by looking at the following example.

VGL Asian Hottie looking for Masculine TOP - 27 (Downtown ) [see picture attached, Figure B3].

Swimmers Built Very lean, smooth and toned. 5'6 140 lbs. smooth bubble butt looking for a HOT Masculine Top to play and possibly cuddle after.

Safe sex only. Please reply with stat and pics.

looking for tonite (sic) and tomorrow.

In this example, self-Orientalisation can be extrapolated through underscoring and objectifying his "lean, smooth, and toned" body. Further, while not identifying himself as bottom, he communicates this through his self-description and photos. By choosing to highlight that he has a "smooth bubble butt" and attaching pictures of his ass, he markets and objectifies himself as a bottom, which is exchangeable for a "Hot Masculine Top". However, what is not being said here is that his erotic choice of "Hot Masculine Top" is not applicable to Asian men because Orientalism voids Asian men's masculinity. 
Thus far, I argue that Asian men do not consider other Asian men as masculine because they judge themselves and each other through the Orientalist gaze. From this perspective, masculinity is only attributed to white men, informed by the social structural forces present in the field, reproduced through cultural products. This conflation of masculinity with whiteness can be extrapolated from the following example.

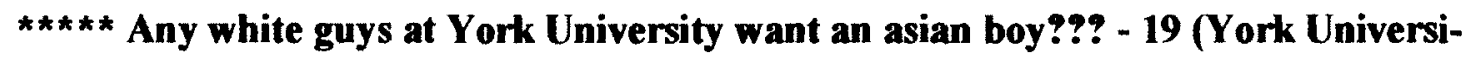
ty) [no picture attached]

I'm a young asian boy. I want to find a white guy (preferably a student at York U) to boss/bully me around on a regular basis. Not looking to do anything sexual right away, but I'm definitely open to it should there be chemistry ;) I'm open to other ideas as well. I'm on campus everyday so I'm pretty flexible. Hope to hear from you!!!

Reply to this ad and I'll tell you more about myself :)

Another thing. I'm around 5'10 so 1 hope you're my height or taller LOL. But I'm slim..

In this particular ad, this poster self-Orientalizes by downplaying his status as a man through his identification as a 'boy'. This plays into the dynamics of age, gender, and race. This selfOrientalization is taken to be a form of agency, informed by his erotic habitus (i.e., he objectifies himself as a boy to attract his object choice). In his erotic habitus, being a boy is conflated with being Asian, which entails submissiveness. To be an "Asian boy" is to be 'bossed' and 'bullied' around by a real 'man' who is, and should be, a white man. Although he is looking for another student, his erotic habitus recognizes white men as masculine - despite of the age. Thus, his erotic habitus legitimizes the hegemony of white men because he has come to internalize the Orientalist gaze and attributing power, domination, control, and masculinity to white men.

However, not all white men are desirable in the erotic habitus of Asian men. This is because, Asian men's desires for white men are restricted by age. This restriction, and taste for younger men, may be shaped by cultural representations which deem older men as undesirable. Under thirty-five years old is the general rule for these Asian men, which goes against the 'rice 
queen' age dynamics. However, older Asian men tend to go for men their age. There is only one case wherein an Asian student is looking for men over forty. What is evident, however, is that the imposition of the erotic tastes of the dominant via cultural vehicles shape the erotic habitus of Asian men, whose preference for masculine white men is obvious in these personal ads. Asian men, however, rarely identify themselves as masculine. Rather, they objectify themselves mostly as passive, submissive, and bottom. ${ }^{30}$ This objectification can be conceived as selfOrientalization wherein they exoticize and fetishized themselves through the Orientalist gaze to make themselves 'valuable' and consumable in the field of gay desire to attract white men or for other purposes such as for their own pleasure. In the next section, I discuss how rice queens' erotic habitus is informed by Orientalism, how they use their power through the Orientalist gaze, and how they exercise symbolic violence through social and sexual practices, which are fundamentally connected to the erotic habitus of Asian men.

\section{The Erotic Habitus of 'Rice Queens'}

In this section, I explore ads posted by white men who are specifically attracted to Asian men in order to describe their erotic habitus. I pursue the argument that rice queens' erotic habitus is informed by Orientalism. It should be noted that not everyone (in fact, not any one) of these posters identify themselves as 'rice queen'. As McCaskell (1998) argues, 'rice queen' "[is] not a nice category. It's not said with pride. Not an honour. Not a badge to be worn proudly" (McCaskell 1998: 45). There is a lot of stigma attached to this label because it is usually stereotyped as, what Gawthorp (2005) calls, 'UFO': ugly, fat, and old (Gawthorp 2005: 11). Thus, this label is used cautiously. While this might be essentialist and controversial, I follow the use in the literature and gay vernacular for the purposes of this thesis. According to Gawthorp (2005), 'rice queen,'

\footnotetext{
${ }^{30}$ I use these qualifiers based on how self-identified Asian posters describe themselves in personal ads.
} 
"refers to a man, usually Caucasian who is sexually attracted to men of Far East-including Southeast-Asian origins" (Gawthorp 2005: 9).

Out of 209 posts in total, $58(28 \%)$ were specified as white men looking for Asian sex partners. The Asian men of interest to white men in these ads range between the ages of 22-50 (or sometimes older), with the majority between the ages of 40-50 years old. Thus, while there are, in fact, younger men in their twenties who can be considered rice queens, rice queens are generally older. In these personal ads, Orientalism bears an imprint in their erotic habitus. Consider the following example.

For boys who prefer older man - 51 (Montreal) [no picture attached] Glk horny mature man searching for cute young bottom boy who is into \& like to please older man. You are from 18 to $30 \mathrm{y} / \mathrm{o}$, cute; [sic] slim; [sic] hairless. Asian; [sic] little format; [sic] effeminate are welcome, [sic] too! Open for regular meetings if we click. No commercial! Serious replies only!

In this example, this rice queen fetishizes Asian men for their slim and smooth bodies: "slim; [sic] hairless. [sic] Asian; [sic] little format". This also suggests that all Asian men, regardless of their differences, are believed to have these characteristics as something that is intrinsic to them. The poster's self-objectification is based on his power of being older, white, top, and masculine who fantasizes about dominating a young, bottom, slim, smooth, and effeminate Asian man. Curiously, this power dynamic is also evident in sexual tourism in Asia based on white men's economic advantage. As Fung (1991) argues, "[w]hite men who for various reasons, especially age, are deemed to be unattractive in their own countries, suddenly find themselves elevated and desired" (Fung 1991: 156). These same dynamics are also present in the field of gay desire; however, power inequalities are based on erotic capital rather than economic capital.

McCaskell (1998) suggests that rice queens are at an advantaged position in the sexual marketplace. This is because: 
[w]hile white guys that like white guys compete with all other white guys and Asians who like white guys, the rice queen only competes against other rice queens, and is therefore in a much better position to get what he wants, especially since Asians are competing for him (McCaskell 1998: 47).

In the hierarchy of desires based on erotic capital, the exchange-value of older white men is greater than that of younger Asian men. As Phua (2007) suggests, the stereotypes that are produced about Asian men, based on Orientalism, as non-manly compromise their location in the hierarchies of desire (Phua 2007: 916). In turn, this limits Asian men's choices of erotic partners. In order to enjoy the privilege of whiteness (as one possible reason for Asian men's desire for white men), Asian men often sacrifice age and go for older rice queens who actually lust over them. This puts the rice queen in a powerful position because Asian men compete against each other for their attention. Thus, older rice queens find themselves elevated and desired by Asian men.

This analysis can further be clarified by invoking the notion of supply and demand, which points to the market-like characteristics of the field. In this field, there is little demand for Asian men from the young, muscular, masculine, middle-class, white men (i.e., the most desirable men in the field of gay desire); however, there is an excess of supply of Asian men who desire white men. The majority of the demand for this supply comes mostly from older rice queens, also considered undesirable by the 'desirables'. Asian men compete against each other to respond to this limited demand. Older rice queens know that there will always be a supply of young and desirable Asian men. Thus, white men turn towards them to fulfill their fetishistic desires for the exotic while Asian men self-Orientalize to access white privilege or for other purposes. This explains why older rice queens do not seek older Asian men as sexual partners. However, this is only one piece of the puzzle.

The other piece of the puzzle can be found in this next ad: 
Looking for Slim Bottom - 41 (u host) [no picture attached]

41 year-old top (5ten, 175 pounds, $6 \mathrm{c}$ ) looking for a slim bottom who can host this afternoon and who is willing to use both his mouth and ass to please me. Smaller the better. Asian or black ++ . Somebody who is willing to drink my cum $+1+$. Please provide stats with your reply. Please remember that you must be able to host (preferably near a metro station).

In this ad, Asian and black men are reduced to a "mouth and ass" to please this rice queen. Part of this man's fantasies is to exercise dominance over those who are weaker (i.e., younger and racialized 'Others') in order to prove his masculinity. Domination also includes treating the 'Other' like 'slaves' who exist only to please the white master by using their mouths and asses. This man's domination over Asian and black men is ended by making them swallow his cum. Johnson (2010) argues that ejaculation and hegemonic masculinity is inseparable. In fact, ejaculation is intrinsically linked with 'masculine performance'. By making Asians and black men drink his cum, he is literally putting them in a submissive position.

The power lies with the rice queen whose disciplinary 'Orientalist gaze' is directed towards Asian men who discipline themselves to conform to the stereotypes. Concurrently, there is also power in self-Orientalization, wherein Asian men deliberately objectify themselves for their own desires and gains. In turn, they get rewarded by granting them access to white privilege via sexual encounters. Asian men's erotic tastes for white men are shaped by the cultural products which reproduce the erotic habitus of the dominant. Through culture, the dominant imposes their erotic tastes based on the delineation of young, muscular, masculine, and middle-class lifestyles as the most desirable. Through cultural products, Asian men's 'value' is produced by invoking Orientalism. These cultural products inform white and Asian men of their erotic capital, which they use to self-objectify and market their desirability to other men. This marketization involves commodifying the body as the most important site wherein desires and desirability materialize. 
McCaskell (1998) argues that, "[i]t is primarily the Asian body, not Asian culture which is being fetishized" (McCaskell 1998: 45). Bodies become the site where 'cultural differences' become 'natural' because they are embodied. This is not evident, however, in the personal ads I presented in the discussion above. The inscription of Orientalist ideas in the Asian body is apparent in Daniel Gawthorp's (2005) memoirs, Rice Queen Diaries, an autobiography about the politics of being self-identified 'rice queen'. Tracing where, how, and why his desires for Asian men started, Gawthorp begins his story in grade nine when he witnessed a 'ritual' done by a group of grade tweleves to an Asian boy named Jackson. Gawthorp recounts, "the purpose of the ritual became clear: the Grade Twelves, all four of them upper-middle class Wasps, wanted to see what hot, dripping candle wax looked like on Chinese balls" (Gawthorp 2005: 37). Upon witnessing this ritual, he begins to acknowledge his desires, not only for men in general, but for Asian men in particular. He writes:

[u]ntil Jackson's hazing, I had never seen ethnicity treated as an alter at which to worship - or, from Jackson's point of view, be worshipped. But that's exactly what happened that night, when the subject of an ostensibly demeaning ritual was transformed from victim into angel. Jackson's difference-his Chinese-ness-had at first been an object of teasing. But that same difference, revealed under candlelight, became so powerful in its naked beauty that not even the prefects—-hot blooded, macho jocks that they were-could deny it (original italicized, Gawthorp 2005: 41).

In this quote, we can see how this ritual of torture, exercised by the "Grade Twelve Wasps" on Jackson, instigated Gawthorp's desires for Asian men. This ritual can be considered as an exercise of power and control over the 'Oriental's' body. Indeed, Said (2007) argues, Orientals are seen as "problems to be solved or confined or-as the colonial powers openly coveted their territory-taken over" (Said 2007: 47). In this context, colonization and control is exercised upon the body. Colonialism and violence are fundamentally linked as demonstrated in this scene of torture. As Said (2007) argues, Orientalism as a cultural apparatus is all about aggression (Said 
2007: 46). Following Fanon, Sharp (2009) argues, "it was colonialism itself that was the real source of violence, firstly in the initial act of conquest, but then in the day-to-day practices of rule which required a power over the body and mind of the native" (Sharp 2009: 127). The colonization of the Asian body then is manifested in this ritual, which involves the dripping of hot candle wax on Jackson's 'Chinese' body as an act of conquest. This very act of colonization also manifest itself in the desires and sexual practices of rice queens over Asian men, wherein Asian men's bodies are literally used as tools to 'please' white men. This can also be interpreted as the subjectification of Asian men. As Said (2007) further suggests, "[s]ince the Oriental was a member of a subject race, he had to be subjected: it was that simple" (Said 2007: 47).

This very act of colonization, through violence, instigated Gawthorp's desires for Asians. For him, Jackson's racialized body is a reification of familiar cultural discourses. His body becomes a mysterious and powerful object which transformed him and his desires. As I discussed in Chapter 2, the bodies of the 'Other' are believed to have power to transform, a conversion experience, informed by a ritualistic act. In this sense, this ritualistic torture has transformed Gawthorp. Upon witnessing this act, Gawthorp fetishizes and exoticizes Asian men's ethnicity and bodies. As he further writes:

[p]ondering the reasons for this [why he ended up with more Asians], I came up with the usual checklist of fetishes: smooth skin, 'almond' eyes, shiny black hair, sleek bodies, and youthfulness. But it was more than just physical. My desires were motivated as much by a need for knowledge as a need for release. I wanted to understand my lovers--if only to learn about myself. What I knew so far was that the factor of youthfulness in East Asian guys awakened memories of Jackson, which in turn reminded me of my own arrested development and how I both resented and worshipped Jackson for his beauty. So all that smooth brown skin, all those firm round buns and boyish faces, had become a potent elixir of nostalgic eroticism and wish fulfillment fantasies. All that other stuff-the stereotypes of passivity, good manners, 'traditional values, inscrutability - was merely a challenge, an invitation to strip away layers (Gawthorp 2005: 56). 
From this quote, we can see the 'transformative' power of Jackson's body in Gawthorp's desires, wherein the 'youthfulness' inscribed in the Asian body is a nostalgic experience for him, bringing him back to the ritualistic torture of Jackson. Thus, his desires are fundamentally informed by the longing to exercise power and control over the bodies of Asian men, to replicate that ritual which had become a fetish.

This theme of transformation is further evident when he writes, "I wanted to understand my lovers-if only to leam about myself". As Said argues, "[t]hrough the production of Orientalism, non-white subjects are characterized as a function of the white subject and are allowed no autonomy, and purpose except as a means of knowing the white self' (Said in Gosine 2007: 139). The 'Other' becomes the basis for self-knowledge regarding his whiteness. By essentializing Asians in his mind, they function to differentiate himself from them; thus Gawthorp's whiteness becomes real.

However, not all Asian men are desirable for him. As he writes, "East Asian men who had integrated into Western ways were often less attractive than those who hadn't [...]. For me, it was far more exciting to watch a Chinese boy strip off his thong if he still regarded queerness as a cultural taboo" (Gawthorp 2005: 56). From this quote, we can see how 'Otherness' is embodied in his erotic habitus. For him, Asians integrated into the Canadian society are no longer 'primitive' or 'authentic', no more transformative power, because they have come to accept their 'queerness'. For Gawthorp, 'queemess' and 'Asianness' cannot and do not exist. For him, 'queer Asians' are no longer 'Asian'. The idea of 'Otherness' which is equated with 'primitiveness' does not apply to 'Canadianized' and 'queered' Asians.

Attention should also be drawn towards his description of his desire: “[f]or me, it was far more exciting to watch a Chinese boy strip off his thong [...]". Here, I argue, his desires are 
based on power relations between him as a white man and the 'Chinese boy'. First, notice how the 'Chinese boy' is a stripper and he identifies himself as the consumer. He recognizes himself to have the power because he is consuming the Asian's body. He also calls him a 'boy' effectively emasculating Asian men. This reinforces particular power dynamics related to race and age. Since, in his erotic imaginings, Asian men are always 'boys', he expects them to submit to him because he considers himself as the 'real man'.

\section{Summary}

In this chapter, I employed critical discourse analysis of personal ads on Craigslist and Rice Queen Diaries. I argued that through a long-term exposure in the field of gay desire, where representations of what are considered to be erotically desirable are produced through cultural products, our erotic tastes are shaped which also gives meaning to our understanding of erotic capital and informs how we self-objectify and market ourselves as desirable. These erotic tastes and erotic capital are embodied in the erotic habitus, materialized through personal ads. Further, through Fab and personal ads, a hierarchy of desires is maintained wherein whiteness, youthfulness, muscularity, masculinity, and middle-class lifestyles are considered to be the most valuable erotic capital. These cultural vehicles also produce Orientalist discourses, which eroticizes Asian men through exoticization and fetishization. Conversely, an 'Orientalist gaze' is produced through which Asian men 'self-Orientalize' themselves, as a form of commodifying and selfobjectifying, to become desirable to 'rice queens'.

Bringing these analyses back to semiosis, the cultural products presented here (Fab, personal ads, and Rice Queen Diaries) are understood as semiotic elements because they are various forms of meaning-making, which do not only involve language, texts, and representations, but also body language. These semiotic elements were all important for these analyses. I employed 
CDA to analyze power relations. Through the use of these cultural products, desires and desirability are produced and reproduced, while erotic capital are sustained and contested in the field of gay desire. The concept of erotic habitus, I described the role of social structures in shaping our erotic tastes, desires, and fantasies. I also illustrated how the dominant maintains a hierarchy of desire, based on what they produce as the most desirable erotic capital. The most desirable erotic capital is an intersection of whiteness, masculinity, muscularity, youthfulness, and middleclass lifestyles. This is evident in the cultural products in the field of gay desire shaping our erotic desires and desirability. Some white men embody this in their erotic habitus by highlighting their erotic capital, which is also only exchangeable for the same value. Asian men's desirability, on the other hand, embody the Orientalist discourses which delineate them as passive, submissive, feminine, and possess a small and smooth body. Because they come to recognize white men as the most desirable, they self-Orientalize by adopting what they believe to be their erotic capital to market themselves to white men. On the other hand, 'rice queens' highlight their whiteness, which is the most valuable commodity in the field of gay desire in order to attract Asian men. 


\section{Conclusion}

This thesis presents a way of thinking sociologically about the roles of desires and desirability in gay men's sexuality. By utilizing a Bourdieusian analysis (adopted from Green), I integrate the concepts of erotic habitus, erotic capital, and field of gay desire (as defined in this thesis) with market-analysis to explain the dynamics of racialized desires in gay communities. Keeping in mind the research question and aims I have laid out in the introduction, I employed CDA of Fab Magazine, personal ads, and Rice Queen Diaries to show that structural forces relate with desires and desirability. In particular, I argued that through a long-term exposure in the field of gay desire, where representations of what are considered to be erotically desirable are produced through cultural products, our erotic tastes are shaped. Our understanding of erotic capital is formed. These erotic tastes and erotic capital are embodied in the erotic habitus, materialized through personal ads. Further, through Fab Magazine and personal ads, a hierarchy of desires is produced wherein whiteness, youthfulness, muscularity, masculinity, and middle-class lifestyles are considered to be the most valuable erotic capital. These cultural vehicles also produce Orientalist discourses, which eroticizes Asian men through exoticization and fetishization. Conversely, an 'Orientalist gaze' is produced through which Asian men 'self-Orientalize' themselves, as a form of commodifying, to become desirable to 'rice queens'.

My analysis of Fab Magazine shows that the dominant (i.e., gay white men) produce and reproduce their erotic habitus. This magazine, understood as one example of cultural product in the field of gay desire, produces and reproduces the idea that the most desirable are white, young, masculine, muscular, and middle-class men. Since erotic habitus has a 'double-life', as a product of social structures and which informs practices, I demonstrated that these representa- 
tions reflect the social structural forces that are present in the field. The erotic habitus also structures the practices of individuals illustrated through personal ads.

Thus, social structures influence our erotic choices and our subjectivities; but this relationship is complex and not unidirectional. This brings us to racialized power (which intersects with gender, class, age, and the body) in our desires and how they affect our sexual practices. This thesis has real implications, especially in the context of gay men's desires. The exclusion of the 'Other' in the desires of white men and the preference for white men by non-white men is often seen as 'just a matter of taste'. However, in a true Bourdieusian sense, these erotic tastes are, in fact, a product of the exposure to a specific social order, wherein white men are delineated as the most desirable. Structural forces inform our erotic habitus. For Asian men and other nonwhite men, the impact is that they are relegated to the margins of desires. Their position in this particular hierarchy of desires affects their sexual health and negotiation and ultimately their self-esteem. For instance, because they are powerless, negotiating whether or not using a condom is necessary can be difficult.

This thesis further shows that gay white men are politically invested in maintaining a particular form of (aesthetic) masculinity which is also connected to Taywaditep's (2001) research on the anti-effeminacy attitudes of some gay men. Asian men and non-white men are discriminated against because of their race, but men who do not fit the desirable such as gay men who are effeminate, disabled, poor, and old, are also excluded.

Further research is needed to explore if and to what extent the standard of desirability is becoming less and less relevant for Asian men and non-white men. One personal ad which stood out during the analysis is that of an Asian man who blatantly rejects white men, specifically looking for Asian men. This might be informed by Bourdieu's notion of reflexivity and explore 
the potential of theorizing this phenomenon as 'reflexive desires'. Another possibility is to research interracial relationships between non-white men and compare and contrast these with interracial white-non-white relationships. This is to explore the differences or similarities in their erotic habitus.

Despite the successful results, CDA certainly have drawbacks. Due to time constraints, I did not conduct interviews. Interviews allow researchers to investigate the nuances that were not readily available through personal ads. Interviews would also offer me a more detailed look into their subjectivities and practices. In particular, I would have interviewed 'rice queens' because research is truly lacking in this area. The only available data about 'rice queens' is through the memoir I presented here and also through personal ads. I would also have analyzed the personal ads that were posted by other non-white men and find out the nuances and differences with the ads analyzed in this research. I especially interested in exploring if self-Orientalization is also present in their subjectivities.

To conclude, desires and desirability are complex sociological phenomena. This study shows this complexity by synthesizing Bourdieu's theories and also point out the importance of market analysis. Despite, however, the sociological contribution to desires and desirability, it must be acknowledged that, in a true Bourdieusian fashion, these are not reducible to social structures. Since erotic habitus is both internalized and externalized, we also cannot ignore the fact that our desires have political consequences. As hooks (1992) argues, “[a]cknowledging ways the desire for pleasure, and that includes erotic longings, informs our politics, our understanding of difference, we may know better how desire disrupts, subverts, and makes resistance possible" (hooks 1992: 39). Thus, acknowledging that our desires are more than just a product of 
our fantasies and tastes and that they do have, in fact, real political implications, we may be able to use desires to make resistance possible. 


\section{Bibliography}

Alexander, Susan. 2003. "Stylish Hard Bodies: Branded Masculinity in Men's Health Magazine." Sociological Perspectives 46 (4): 535-554.

Alvarez, Erick. 2008. Muscle Boys: Gay Gym Culture. New York: Routledge.

—. 2000. "Asian Pride." Fab Magazine (146), August 31-September 132000.

Barnard, Ian. 2004. Queer Race: Cultural Interventions in the Racial Politics of Queer Theory. New York: Peter Lang.

Bérubé, Allan. 2001. ""How Gay Stays White and What Kind of White It Stays." Pp. 234-265 in The Making and Unmaking of Whiteness, edited by B. Rasmussen, E. Klineberg, I. Nexica, and M. Wray. Durham: Duke University Press.

Bryman, Alan. 2004. Social Research Methods. $2^{\text {nd }}$ ed. London: Oxford.

Bryman, Alan and James Teevan. 2005. Social Research Methods: Canadian Edition. $2^{\text {nd }}$ ed. London: Oxford.

Bourdieu, Pierre. 1984. Distinction: A Social Critique of the Judgement of Taste. Cambridge: Harvard University Press.

Bourdieu, Pierre. 2005. "Distinction: A Social Critique of the Judgement of Taste." Pp. 499-525 in Social Stratification: Class, Race, and Gender in Sociological Perspectives, edited by David Grusky. $2^{\text {nd }}$ ed. Boulder, Oxford: Westview Press.

Brym, Robert. 2004. Society in Question: Sociological Readings for the $21^{\text {st }}$ Century. $4^{\text {th }}$ ed. Toronto: Thomson Nelson.

Bubeck, Diemut. 2000. "Feminism in political philosophy: Women's Difference." Pp. 185-204 in The Cambridge Companion to Feminism in Philosophy, edited by M. Fricker and J. Hornsby. Cambridge: Cambridge University Press.

Califia-Rice, Patrick. 2000. Public Sex: The Culture of Radical Sex. $2^{\text {nd }}$ ed. San Francisco: Cleis Press.

Campbell, J.E. 2004. Getting it On Online: Cyberspace, Gay Male Sexuality, and Embodied Identity. New York: Harrington Park Press.

- 2008. "Caught in his web: the love and sex issue." Fab Magazine (339), February 5192008.

Collins, Patricia Hill. 2005. Black Sexual Politics: African Americans, Gender, and the New Racism. New York: Routledge.

Connell, R.W. 1995. Masculinities. Berkeley: University of California Press.

"desirability, n." 2011. Oxford Dictionary Online. Oxford University Press. Retrieved October 1, 2010 (http://oxforddictionaries.com). 
"desire, $n$., and v." 2011. Oxford Dictionary Online. Oxford University Press. Retrieved October 1, 2010 (http://oxforddictionaries.com).

—. 2002. "Desire Exposed: Inside out preview." Fab Magazine (189), July 9-22 2002.

Duggan, Lisa. 2002. "The New Homonormativity: The Sexual Politics in Neoliberalism." Pp. 175-194 in Materializing Democracy: Toward a Revitalized Cultural Politics, edited by R. Castronovo and D. Nelson. Durham: Duke University Press.

Dyer, Richard. 1997. White. London: Routledge.

Edwards, Tim. 1994. Erotics and Politics: Gay Male Sexuality, Masculinity, and Feminism. London: Routledge.

Edwards, Tim. 2006. "Identity and Desire: Gay Male Sexuality and Masculinity." Pp. 79-98 in Cultures of Masculinity. London, New York: Routledge.

Fairclough, Norman. 2001. "The Discourse of New Labour: Critical Discourse Analysis." Pp. 229-266 in Discourse as Data: A Guide for Analysis, edited by S. Yates, S. Taylor, and M. Wetherell. London: Sage.

"fetish, n." 2011. Oxford Dictionary Online. Oxford University Press. Retrieved May 19, 2011 (http://oxforddictionaries.com).

Floyd, Kevin. 2009. The Reification of Desire: Toward a Queer Marxism. Minneapolis: University of Minnesota Press.

Foucault, Michel. 1978. The History of Sexuality, Volume 1. New York: Pantheon Books.

Friedman, David. 2001. A Mind of Its Own: A Cultural History of the Penis. New York: Penguin.

Fung, Richard. 1991. "Looking for My Penis: The Eroticized Asian in Gay Video Porn." Pp. 145-168 in How Do I Look?: Queer Film and Video, edited by Bad Object-Choices. Seattle: Bay Press.

Gagnon, John and William Simon. 2005. Sexual Conduct: The Social Sources of Human Sexuality. New Brunswick: Aldine Transaction.

Gawthorp, Daniel. 2005. Rice Queen Diaries: A Memoir. Vancouver: Arsenal.

Gosine, Andil. 2007. "Blonde to brown at gay.com: Passing white in queer cyberspace." Pp. 139154 in Queer Online, edited by S. Driver. New York: SUNY.

Green, Adam Isaiah. 2008a. "Erotic habitus: towards a sociology of desire." Theoretical Sociology 37: 597-626.

Green, Adam Isaiah. 2008b. "The Social Organization of Desire: The Sexual Fields Approach." Sociological Theory 26 (1): 25-50. 
Hagland, P.E.P. 1998. "Undressing the oriental boy": The gay Asian in the social imagination of the gay white male." Pp. 277-294 in Looking Queer: Body Image and Identity in Lesbian, Bisexual, Gay, and Transgender Communities, edited by D. Atkins. New York: Harrington Park Press.

Han, Chong-Suk. 2006. "Being an Oriental, I could never be completely a man: gay Asian men and the intersection of race, gender, sexuality, and class." Race, Gender and Class 13 $(3 / 4): 82-97$.

Han, Chong-suk. 2007. "They Don't Want To Cruise Your Type: Gay Men of Colour and the Racial Politics of Exclusion." Social Identities 13 (1): 51-67.

Han, Chong-suk. 2008. "Sexy like a Girl and Horny like a Boy: Contemporary Gay 'Western' Narratives about Gay Asian Men." Critical Sociology 34 (6): 829-850.

Han, Shinhee. 2000. “Asian American Gay Men's (Dis) Claim on Masculinity.” Pp. 206-223 in Gay Masculinities, edited by Peter Nardi. Thousand Oaks: Sage.

Hargrove, Melissa. 2005. "Structurally Adjusted Intercourse: Exoticized Sex Workers and Anthropological Agency." Pp. 123-140 in Resisting Racism and Xenophobia: Global Perspectives on Race, Gender, and Human Rights, edited by F. Harrison. Toronto: Altamira.

Hennessy, Rosemary. 2000. Profit and Pleasure: Sexual Identities in Late Capitalism. New York: Routledge.

Henslin, James. 2005. Down to Earth Sociology: Introductory Readings. $13^{\text {th }}$ ed. Toronto: Free Press.

hooks, bell. 1992. "Eating the Other: Desire and Resistance." Pp. 21-39 in Black Looks: Race and Representation. Boston: South End Press.

hooks, bell. 2000. Feminism is for Everybody. Cambridge: South End Press.

2004. "How to get boned on Halloween." Fab Magazine (279), October 20-Nov 2 2004.

Johnson, Michael. 2010. "'Just Getting Off': The Inseparability of Ejaculation and Hegemonic Masculinity." Journal of Men's Studies 18 (3): 238-248.

2000. "Jorge Flores: Escape from persecution." 2000, Jan 6-19. Fab Magazine (129), January 6-19 2000.

Kallen, Evelyn. 2003. Ethnicity and Human Rights in Canada: A Human Rights Perspective on Race, Ethnicity, Racism, and Systematic Inequality. $3^{\text {rd }}$ ed. Oxford: Oxford University Press.

Kimmel, Michael. 2007. The Sexual Self: The Construction of Sexual Scripts. Nashville: Vanderbilt University Press.

Kondo, Dorinne. 1997. About Face: Performing Race in Fashion and Theatre. New York: Routlegde. 
Leshkowich, Ann Marie and Caria Jones. 2003. "What Happened When Asian Chic Becomes Chic in Asia?" Fashion Theory 7 (3/4): 281-300.

Long, Ronald. 1994. "An Affair of Men: Masculinity and the Dynamics of Gay Sex." Journal of Men's Studies 3 (1): 21-48.

Low, Jacqueline and Claudia Malacrida. 2008. Sociology of the Body: A Reader. Toronto: Oxford University Press.

Massad, Joseph. 2007. Desiring Arabs. Chicago: The University of Chicago Press.

Mauther, Natasha and Andrea Doucet. 2003. "Reflexive Accounts and Accounts of Reflexivity In Qualitative Data Analaysis." Sociology 37 (3): 413-431.

McBride, Dwight A. 2005. "It's a White Man's World: Race in the Gay Marketplace of Desire." Pp. 88-131 in Why I Hate Abercrombie and Fitch: Essays on Race and Sexuality. New York, London: New York University Press.

McCaskell, Tim. 1998. "Towards A Sexual Economy of Rice Queenliness Lust, Power and Racism." Pp. 45-48 in Rice: Explorations Into Gay Asian Culture + Politics, edited by S. Cho. Toronto: Queer Press.

McClintock, Anne. 1995. Imperial Leather. New York: Routledge.

Mills, C. Wright. 1959. The Sociological Imagination. Oxford: Oxford University Press.

Naples, Nancy. 2003. "Standpoint Analysis and Reflective Practice." Pp. 37-48 in Feminism and Method: Ethnography, Discourse Analysis, and Activist Research. New York: Routledge.

Nardi, Peter. 2000. Gay Masculinities. Thousand Oaks: Sage Publications.

Obendorf, Simon. 2005. "Reading Racial Gaze: Western Gay Society and Pornographic Depictions of Asian Men." Pp. 153-176 in Gendered Outcasts and Sexual Outlaws; Sexual Oppression and Gender Hierarchies in Queer Men's Lives, edited by C. Kendall and W. Martino. New York: Harrington Park Press.

- 2010. "Onward 'mo: Exploring the neighbourhoods gay men call home." Fab Magazine (399), May 25-June 1.

Pauwels, Luc. 2010. "Visual Sociology Reframed: An Analytical Synthesis and Discussion of Visual Methods in Social and Cultural Research." Sociological Methods and Research 38 (4): 545-581.

Peñaloza, Lisa. 1996. "We're Here, We're Queer and We're Going Shopping! A Critical Perspective on the Accomodation of Gays and Lesbians in the U.S. Marketplace." Journal of Homosexuality 31 (1/2): 9-41.

Perez, Hiram. 2005. "You Can Have My Brown Body and Eat It, Too!" Social Text 23 (3/4): 171-192. 
Phelan, Shane. 2001. Sexual Strangers: Gays, Lesbians, and Dilemmas of Citizenship. Philadelphia: Temple University Press.

Phua, Voon Chin and Gayle Kaufman. 2003. "The Crossroads of Race and Sexuality: Date Selection Among Men in Internet 'Personal' Ads." Journal of Family Issues 24 (8): 981-994.

Phua, Voon Chin. 2007. "Contesting and Maintaining Hegemonic Masculinities: Gay Asian American in Mate Selection." Sex Roles 58 (11/12): 909-918.

Poon, Maurice Kwong-Lai and Peter Trung-Thu Ho. 2008. "Negotiating Social Stigma Among Gay Asian Men." Sexualities 11 (1/2): 245-268.

2001. "Pride Down Under: what Toronto can learn from Sydney's Gay and Lesbian Mardi Gras." Fab Magazine (159), March 1-4.

Rieger-Ladich, Markus. 2010. "Governmentality Revisited: Bourdieu Meets Foucault." Pp. 105120 in International Educational Governance, edited by S. Karin Amos. Bradford: Emerals Group Publishing Ltd.

Said, Edward. 2007. "Latent and Manifest Orientalism." Pp. 45-55 in Race and Racialization: Essential Readings, edited by T. Das Gupta, C. James, R. Maaka, G.E. Galabuzin, \& C. Andersen. Toronto: Canadian Scholar's Press.

Seidman, Steven. 2002. Beyond the Closet: The Transformation of Gay and Lesbian Life. New York: Routledge.

Seidman, Steven. 2004. "The Critical Sociology of Anthony Giddens and Pierre Bourdieu." Pp. 142-154 in Contested Knowledge: Social Theory Today. $3^{\text {rd }}$ ed. Oxford: Blackwell.

Seidman, Steven. 2004. "Critical Race Theory." Pp. 231-244 in Contested Knowledge: Social Theory Today. $3^{\text {rd }}$ ed. Oxford: Blackwell.

Sharp, Joanne. 2009. Geographies of Colonialism: Spaces of Power and Representation. London: Sage.

Skeggs, Beverly. 2004. "Context and Background: Pierre Bourdieu's Analysis of Class, Gender, and Sexuality." Pp. 19-33 in Feminism After Bourdieu, edited by L. Adkins and B. Skeggs. Oxford: Blackwell Publishing.

Skeggs, Beverly. 2004. "Exchange, value, and affect: Bourdieu and 'the self'." Pp. 75-95 in Feminism After Bourdieu, edited by L. Adkins and B. Skeggs. Oxford: Blackwell Publishing.

Smith, Dorothy. 1999. "From Women's Standpoint to a Sociology for People." Pp. 65-82 in Sociology for the Twenty-first Century: Continuities and Cutting Edges, ed. by Janet Abu-Lughod. Chicago: University of Chicago Press.

Sudarto, Budiadi. 2008. "'Without love, there won't be us': A Narrative of GAM-GWM Couple." Gay and Lesbian Issues and Psychology Review 4 (1): 23-34. 
Tandy, Erin. 2008. "How extra super fab can it get?" Ryerson Review of Journalism. Retrieved April 13, 2011 (http://www.rrj.ca/m4123/).

Taywaditep, Kittiwut Jod. 2001. "Marginalization Among the Marginalized: Gay Men's AntiEffeminacy Attitudes." Journal of Homosexuality 42 (1): 1-28.

_. 2003. "The Bridal Issue." Fab Magazine (239), April 8-21.

—. 2002. "The Travel Issue." Fab Magazine (202), November 12-25.

—. 2003. "Textual Temptation." Fab Magazine (279), August 26-September 8.

Thorne, Adrian and Justine Coupland. 1998. "Articulations of same-sex desire: Lesbian and gay male dating adverstisements." Journal of Sociolinguistics 2 (2): 233-257.

Thorpe, Holly. 2009. "Bourdieu, Feminism and Female Physical Culture: Gender Relexivity and the Habitus-Field Complex." Sociology of Sport Journal 26: 491-516.

Van Dijk, Teun. 2001. "Critical Discourse Analysis." Pp. 352-371 in Handbook of Discourse Analysis, edited by D. Tannen, D. Schiffrin, and H. Hamilton. Oxford: Blackwell.

Wacquant, Loic. 2006. "Pierre Bourdieu." Pp. 261-277 in Key Contemporary Thinkers, edited by R. Stones. London: Macmillan.

Ward, Jane. 2000. "Queer Sexism: Rethinking Gay Men and Masculinity." Pp. 152-175 in Gay Masculinities, edited by Peter Nardi. Thousand Oaks: Sage.

Webb, Jenn, Tony Schirato and Geoff Danaher. 2002. Understanding Bourdieu. London: Sage.

Wetherell, Margaret, Stephanie Taylor, and Simeon Yates. 2001. "Introduction." Pp. i-iv in Discourse as Data: A Guide for Analysis, edited by S. Yates, S. Taylor, and M. Wetherell. London: Sage.

Whittier, David Knapp and Rita Melendez. 2007. "Sexual Scripting and Self-Process: Intersubjectivity among Gay Men." Pp. 191-208 in The Sexual Self: The Construction of Sexual Scripts, edited by M. Kimmel. Nashville: Vanderbilt University Press.

Yuval-Davis, Nira. 2006. "Intersectionality and Feminist Politics." European Journal of Women's Studies 13 (3):193-209. 


\section{Appendix A. Fab Magazine Front Covers}

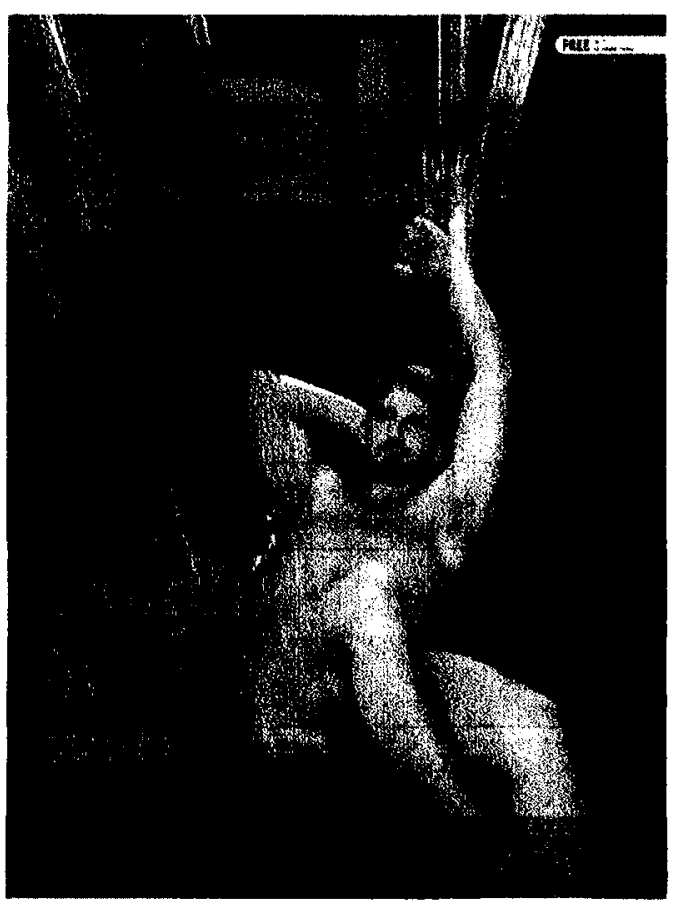

Figure Al. Issue 339, "Caught in his web".

Figure A2. Issue 189, "Desire Exposed".

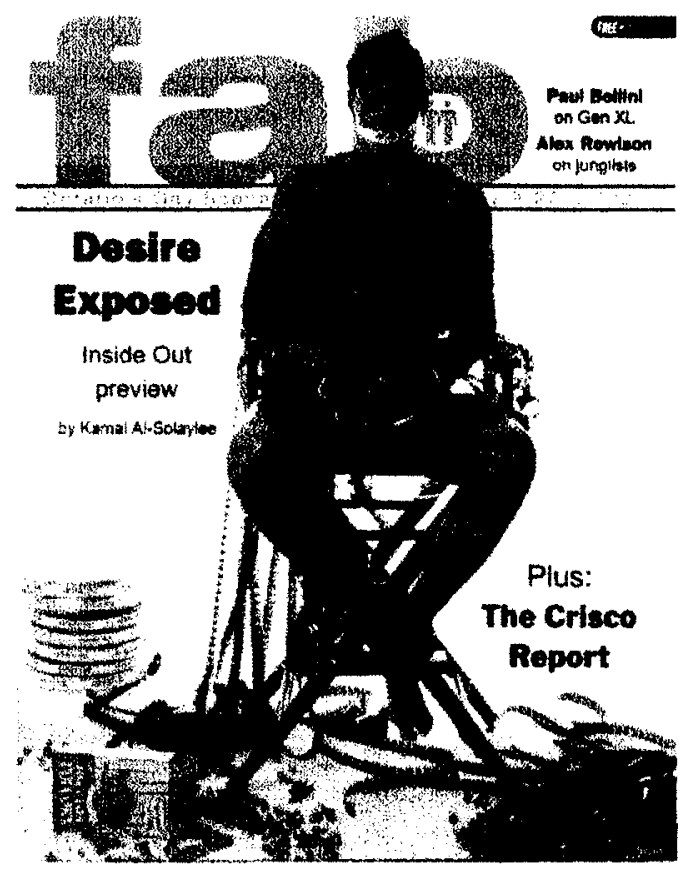




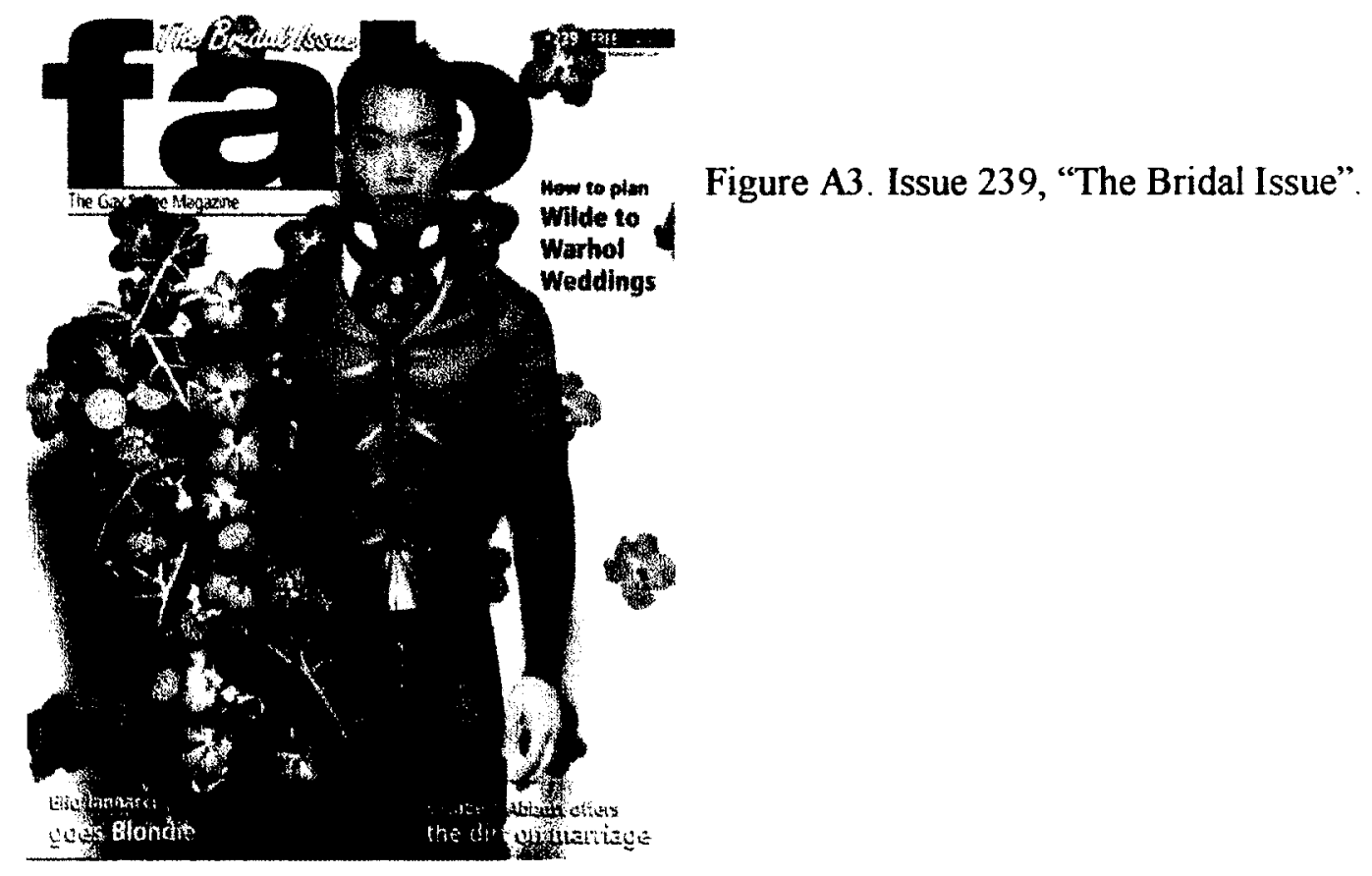

Figure A4. Issue 249, "Textual Tempation".

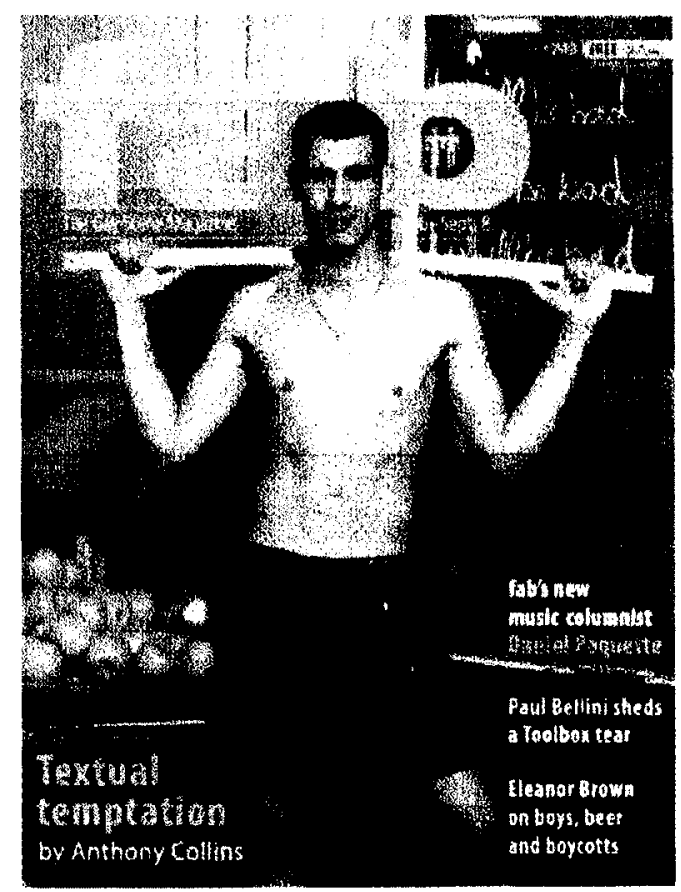




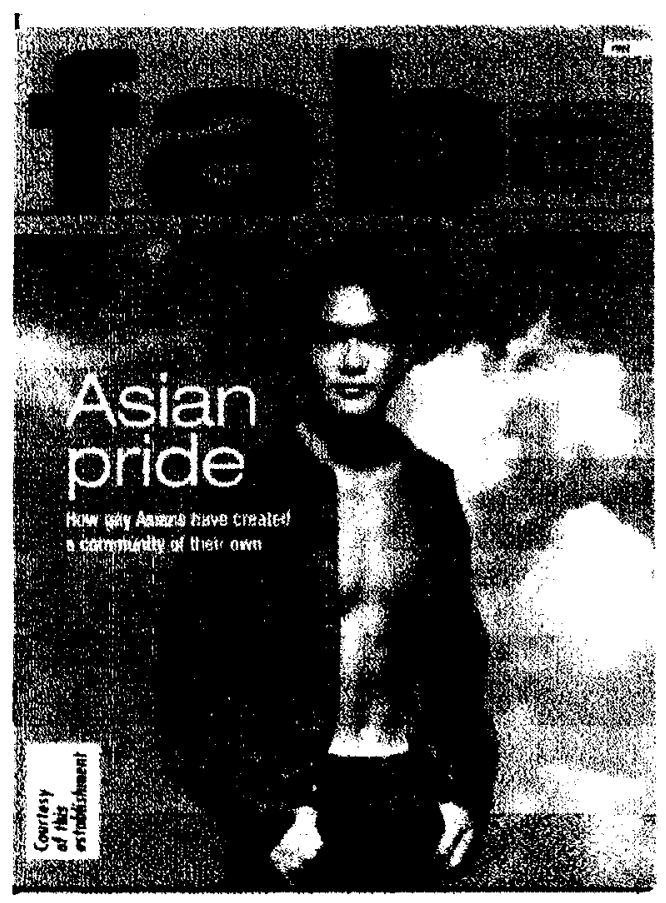

Figure A5. Issue 146, “Asian Pride".

Figure A6. Issue 399, "Onward 'mo".

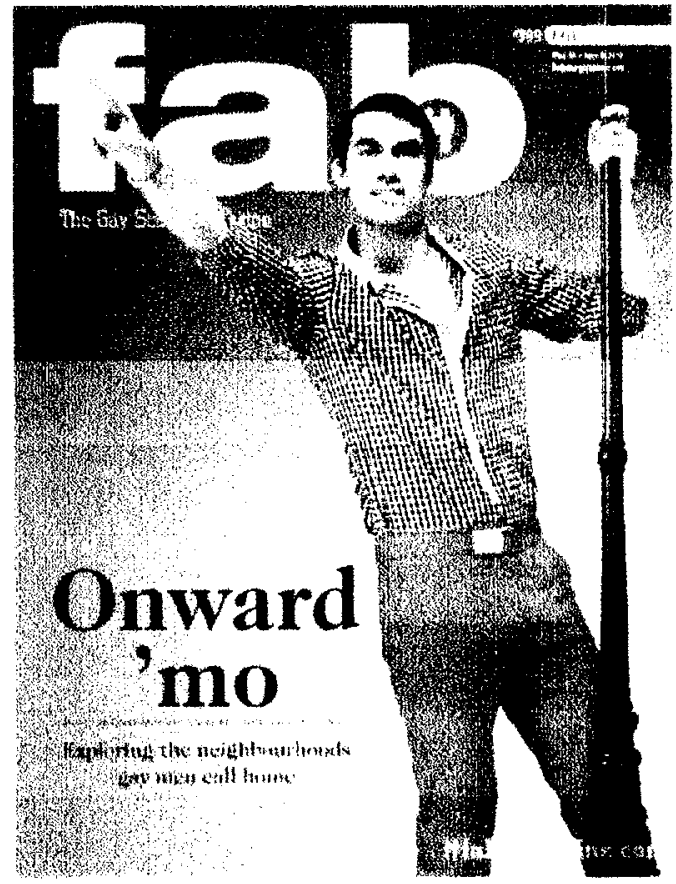




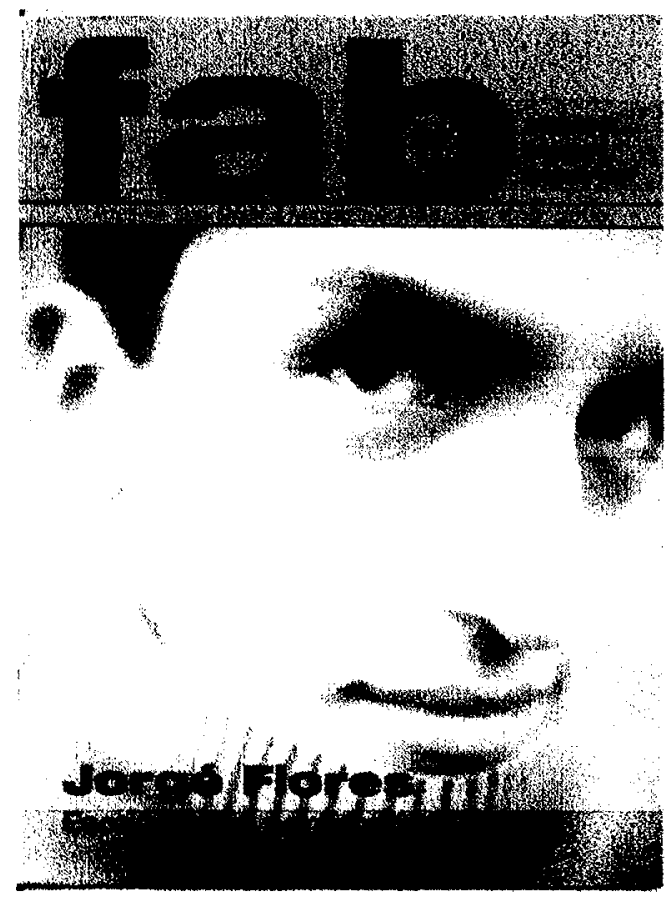

Figure A7. Issue 129, "Jorge Flores".

Figure A8. Issue 202, "The Travel Issue".

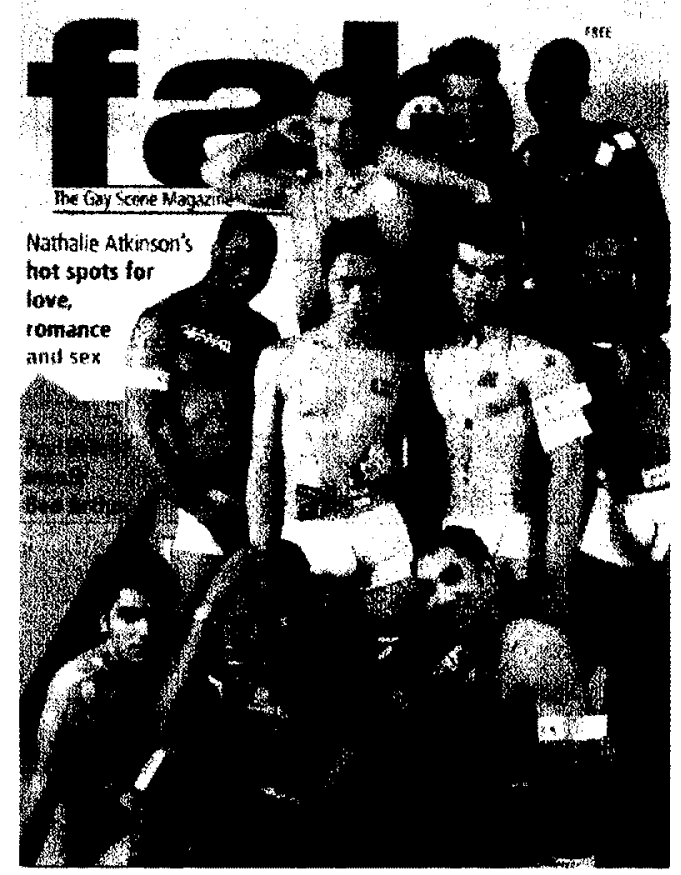




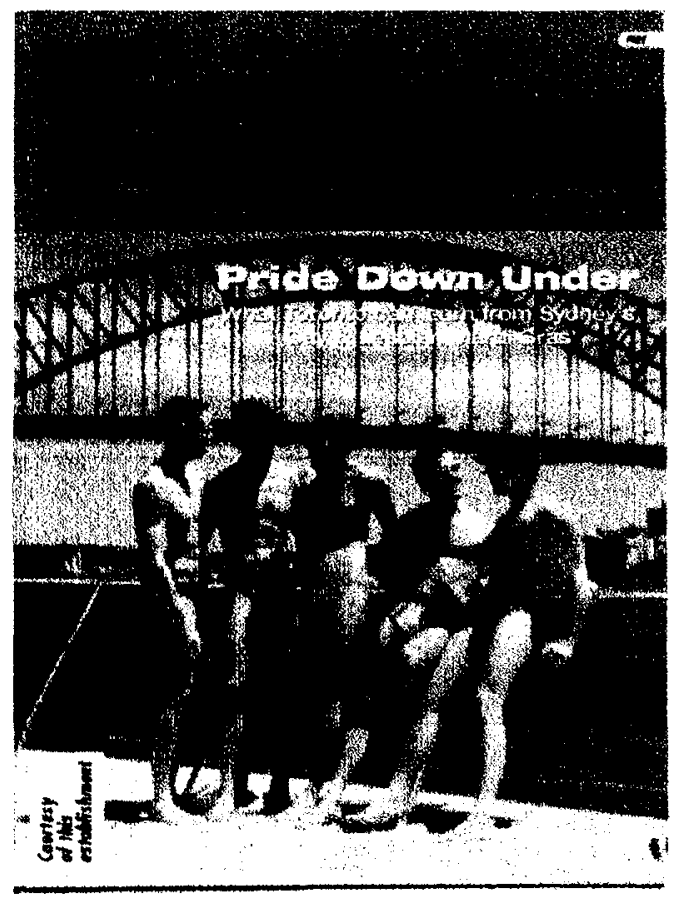

Figure A9. Issue 159, "Pride Down Under".

Figure A10. Issue 279, "How to get boned on Halloween".

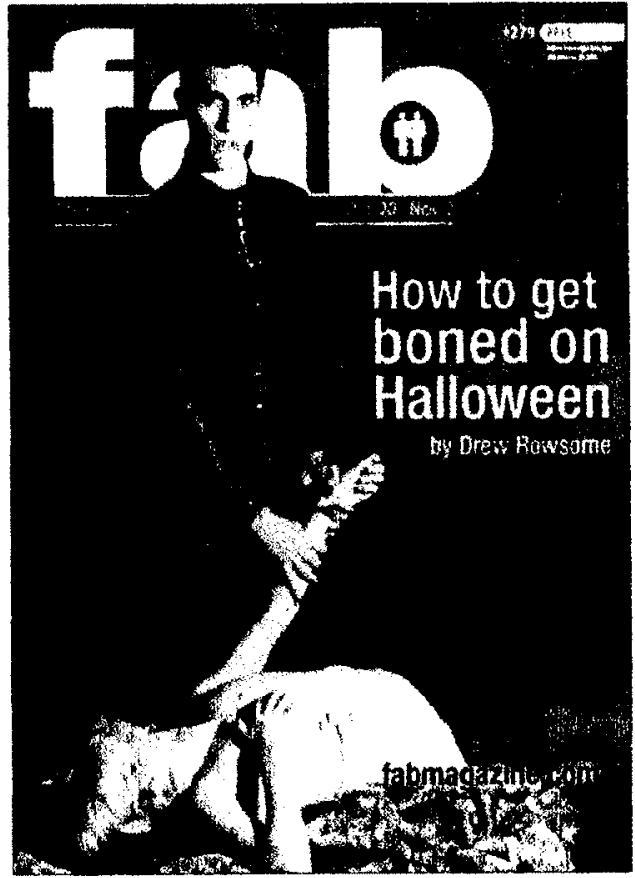




\section{Appendix B. Craigslist Personal Ads Pictures.}

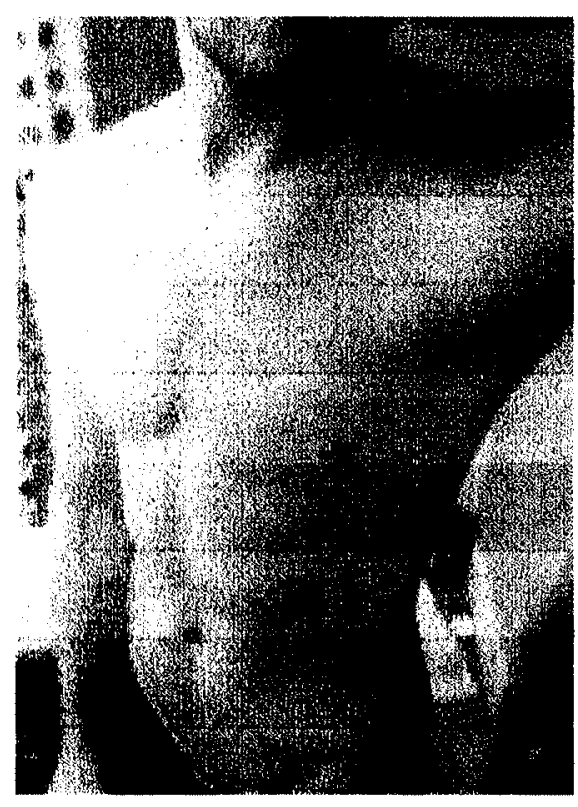

Figure B1. Attached picture for 21 year old college guy. horny for a hookup. (davisville).

Figure B2. Attached picture for young college prof visiting mcgill - looking for students - 35 (mcgill plateau)

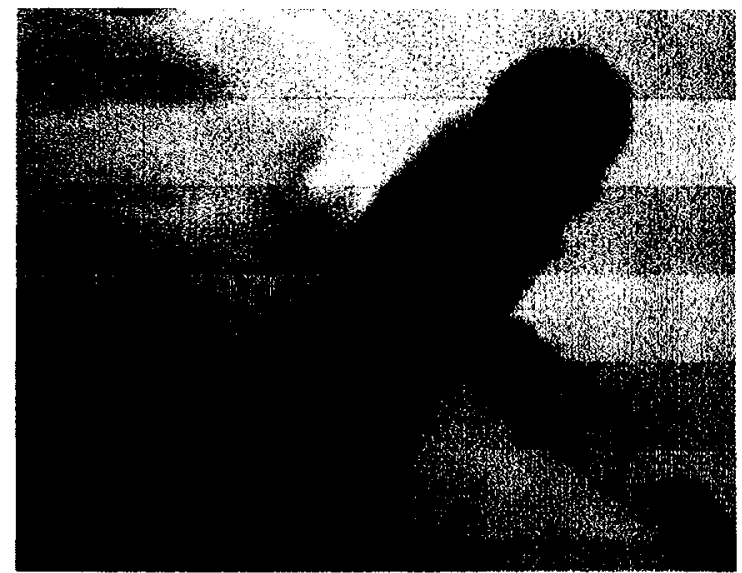


Figure B3. Attached pictures for VGL Asian Hottie looking for Masculine TOP.
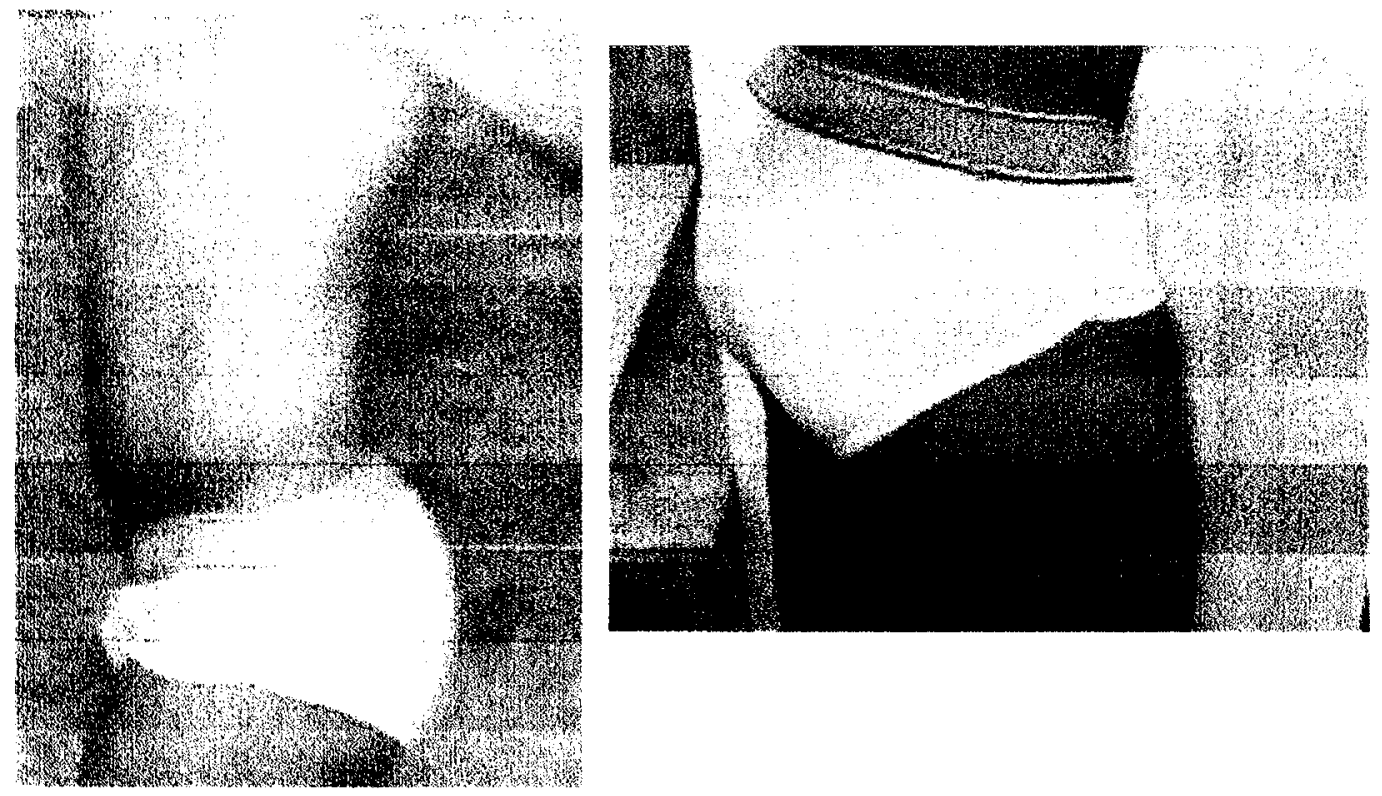


\section{Appendix C. Tables}

Table 1. Ads from Toronto General Sample.

\begin{tabular}{|c|c|c|c|c|c|c|c|}
\hline $\begin{array}{l}\text { Ads from } \\
\text { Toronto }\end{array}$ & $\begin{array}{l}\text { Looking } \\
\text { for White }\end{array}$ & $\begin{array}{l}\text { Looking } \\
\text { for Asian }\end{array}$ & $\begin{array}{l}\text { Looking } \\
\text { for Black }\end{array}$ & $\begin{array}{l}\text { Looking } \\
\text { for Latino }\end{array}$ & $\begin{array}{l}\text { Looking } \\
\text { for Other }\end{array}$ & $\begin{array}{c}\text { Not Spe- } \\
\text { cified }\end{array}$ & Total \\
\hline $\begin{array}{c}\text { Self- } \\
\text { identified } \\
\text { as white }\end{array}$ & $\begin{array}{c}24 \\
(46.2 \%)\end{array}$ & $\begin{array}{c}3 \\
(5.8 \%)\end{array}$ & $\begin{array}{c}3 \\
(5.8 \%)\end{array}$ & $\begin{array}{c}1 \\
(1.9 \%)\end{array}$ & $\begin{array}{c}2 \\
(3.8 \%)\end{array}$ & $\begin{array}{c}19 \\
(36.5 \%)\end{array}$ & $\begin{array}{c}52 \\
(100 \%)\end{array}$ \\
\hline $\begin{array}{c}\text { Self- } \\
\text { identified } \\
\text { Asian }\end{array}$ & $\begin{array}{c}4 \\
(50 \%)\end{array}$ & $\begin{array}{c}2 \\
(25 \%)\end{array}$ & $\begin{array}{c}0 \\
(0 \%)\end{array}$ & $\begin{array}{c}0 \\
(0 \%)\end{array}$ & $\begin{array}{c}0 \\
(0 \%)\end{array}$ & $\begin{array}{c}2 \\
(25 \%)\end{array}$ & $\begin{array}{c}8 \\
(100 \%)\end{array}$ \\
\hline $\begin{array}{c}\text { Self- } \\
\text { identified } \\
\text { as black }\end{array}$ & $\begin{array}{c}1 \\
(12.5 \%)\end{array}$ & $\begin{array}{c}1 \\
(12.5 \%)\end{array}$ & $\begin{array}{c}0 \\
(0 \%)\end{array}$ & $\begin{array}{c}0 \\
(0 \%)\end{array}$ & $\begin{array}{c}0 \\
(0 \%)\end{array}$ & $\begin{array}{c}6 \\
(75 \%)\end{array}$ & $\begin{array}{c}8 \\
(100 \%)\end{array}$ \\
\hline $\begin{array}{c}\text { Self- } \\
\text { identified } \\
\text { as Latino }\end{array}$ & $\begin{array}{c}1 \\
(100 \%)\end{array}$ & $\begin{array}{c}0 \\
(0 \%)\end{array}$ & $\begin{array}{c}0 \\
(0 \%)\end{array}$ & $\begin{array}{c}0 \\
(0 \%)\end{array}$ & $\begin{array}{c}0 \\
(0 \%)\end{array}$ & $\begin{array}{c}0 \\
(0 \%)\end{array}$ & $\begin{array}{c}1 \\
(100 \%)\end{array}$ \\
\hline $\begin{array}{c}\text { Self- } \\
\text { identified } \\
\text { as Other }\end{array}$ & $\begin{array}{c}1 \\
(25 \%)\end{array}$ & $\begin{array}{c}0 \\
(0 \%)\end{array}$ & $\begin{array}{c}0 \\
(0 \%)\end{array}$ & $\begin{array}{c}0 \\
(0 \%)\end{array}$ & $\begin{array}{c}0 \\
(0 \%)\end{array}$ & $\begin{array}{c}3 \\
(75 \%)\end{array}$ & $\begin{array}{c}4 \\
(100 \%)\end{array}$ \\
\hline $\begin{array}{l}\text { Not Spe- } \\
\text { cified }\end{array}$ & $\begin{array}{c}0 \\
(0 \%)\end{array}$ & $\begin{array}{c}1 \\
(2.9 \%)\end{array}$ & $\begin{array}{c}0 \\
(0 \%)\end{array}$ & $\begin{array}{c}0 \\
(0 \%)\end{array}$ & $\begin{array}{c}0 \\
(0 \%)\end{array}$ & $\begin{array}{c}34 \\
(97.1 \%)\end{array}$ & $\begin{array}{c}35 \\
(100 \%)\end{array}$ \\
\hline Total & $\begin{array}{c}31 \\
(28.7 \%)\end{array}$ & $\begin{array}{c}7 \\
(6.5 \%)\end{array}$ & $\begin{array}{c}3 \\
(2.7 \%)\end{array}$ & $\begin{array}{c}1 \\
(0.9 \%)\end{array}$ & $\begin{array}{c}2 \\
(1.9 \%)\end{array}$ & $\begin{array}{c}64 \\
(59.3 \%)\end{array}$ & $\begin{array}{c}108 \\
(100 \%)\end{array}$ \\
\hline
\end{tabular}


Table 2. Ads from Montreal General Sample.

\begin{tabular}{|c|c|c|c|c|c|c|c|}
\hline $\begin{array}{l}\text { Ads from } \\
\text { Montreal }\end{array}$ & $\begin{array}{l}\text { Looking } \\
\text { for White }\end{array}$ & $\begin{array}{l}\text { Looking } \\
\text { for Asian }\end{array}$ & $\begin{array}{l}\text { Looking } \\
\text { for Black }\end{array}$ & $\begin{array}{l}\text { Looking } \\
\text { for Latino }\end{array}$ & $\begin{array}{l}\text { Looking } \\
\text { for Other }\end{array}$ & $\begin{array}{c}\text { Not Spe- } \\
\text { cified }\end{array}$ & Total \\
\hline $\begin{array}{c}\text { Self- } \\
\text { identified } \\
\text { as white }\end{array}$ & $\begin{array}{c}25 \\
(53 \%)\end{array}$ & $\begin{array}{c}3 \\
(6.4 \%)\end{array}$ & $\begin{array}{c}2 \\
(4.2 \%)\end{array}$ & $\begin{array}{c}2 \\
(4.2 \%)\end{array}$ & $\begin{array}{c}2 \\
(4.2 \%)\end{array}$ & $\begin{array}{c}13 \\
(28 \%)\end{array}$ & $\begin{array}{c}47 \\
(100 \%)\end{array}$ \\
\hline $\begin{array}{c}\text { Self- } \\
\text { identified } \\
\text { Asian }\end{array}$ & $\begin{array}{c}4 \\
(100 \%)\end{array}$ & $\begin{array}{c}0 \\
(0 \%)\end{array}$ & $\begin{array}{c}0 \\
(0 \%)\end{array}$ & $\begin{array}{c}0 \\
(0 \%)\end{array}$ & $\begin{array}{c}0 \\
(0 \%)\end{array}$ & $\begin{array}{c}0 \\
(0 \%)\end{array}$ & $\begin{array}{c}4 \\
(100 \%)\end{array}$ \\
\hline $\begin{array}{c}\text { Self- } \\
\text { identified } \\
\text { as black }\end{array}$ & $\begin{array}{c}1 \\
(0 \%)\end{array}$ & $\begin{array}{c}0 \\
(0 \%)\end{array}$ & $\begin{array}{c}0 \\
(0 \%)\end{array}$ & $\begin{array}{c}0 \\
(0 \%)\end{array}$ & $\begin{array}{c}0 \\
(0 \%)\end{array}$ & $\begin{array}{c}0 \\
(0 \%)\end{array}$ & $\begin{array}{c}1 \\
(100 \%)\end{array}$ \\
\hline $\begin{array}{c}\text { Self- } \\
\text { identified } \\
\text { as Latino }\end{array}$ & $\begin{array}{c}1 \\
(100 \%)\end{array}$ & $\begin{array}{c}0 \\
(0 \%)\end{array}$ & $\begin{array}{c}0 \\
(0 \%)\end{array}$ & $\begin{array}{c}0 \\
(0 \%)\end{array}$ & $\begin{array}{c}0 \\
(0 \%)\end{array}$ & $\begin{array}{c}0 \\
(0 \%)\end{array}$ & $\begin{array}{c}1 \\
(100 \%)\end{array}$ \\
\hline $\begin{array}{c}\text { Self- } \\
\text { identified } \\
\text { as Other }\end{array}$ & $\begin{array}{c}0 \\
(0 \%)\end{array}$ & $\begin{array}{c}0 \\
(0 \%)\end{array}$ & $\begin{array}{c}0 \\
(0 \%)\end{array}$ & $\begin{array}{c}0 \\
(0 \%)\end{array}$ & $\begin{array}{c}0 \\
(0 \%)\end{array}$ & $\begin{array}{c}2 \\
(100 \%)\end{array}$ & $\begin{array}{c}2 \\
(100 \%)\end{array}$ \\
\hline $\begin{array}{l}\text { Not Spe- } \\
\text { cified }\end{array}$ & $\begin{array}{c}2 \\
(4.4 \%)\end{array}$ & $\begin{array}{c}0 \\
(0 \%)\end{array}$ & $\begin{array}{c}0 \\
(0 \%)\end{array}$ & $\begin{array}{c}0 \\
(0 \%)\end{array}$ & $\begin{array}{c}0 \\
(0 \%)\end{array}$ & $\begin{array}{c}44 \\
(95.6 \%)\end{array}$ & $\begin{array}{c}46 \\
(100 \%)\end{array}$ \\
\hline Total & $\begin{array}{c}33 \\
(33 \%)\end{array}$ & $\begin{array}{c}3 \\
(3 \%)\end{array}$ & $\begin{array}{c}2 \\
(2 \%)\end{array}$ & $\begin{array}{c}2 \\
(2 \%)\end{array}$ & $\begin{array}{c}2 \\
(2 \%)\end{array}$ & $\begin{array}{c}59 \\
(58 \%)\end{array}$ & $\begin{array}{c}101 \\
(100 \%)\end{array}$ \\
\hline
\end{tabular}


Table 3. Fab Magazine Covers

\begin{tabular}{|c|c|c|}
\hline $\begin{array}{c}\text { Fab Magazine Cov- } \\
\text { ers (from June } \\
\text { 1994-June 2010) }\end{array}$ & Number & Percentage \\
\hline $\begin{array}{c}\text { Covers featuring } \\
\text { white-looking men } \\
\text { (alone or in groups) }\end{array}$ & 297 & $74.25 \%$ \\
\hline $\begin{array}{c}\text { Covers featuring } \\
\text { non-white looking } \\
\text { men (alone or in } \\
\text { groups) }\end{array}$ & 29 & $7.25 \%$ \\
\hline $\begin{array}{c}\text { Covers featuring a } \\
\text { group of white and } \\
\text { non-white men }\end{array}$ & 29 & $7.25 \%$ \\
\hline $\begin{array}{c}\text { Covers featuring } \\
\text { women (alone or in } \\
\text { groups) }\end{array}$ & 12 & $8.25 \%$ \\
\hline $\begin{array}{c}\text { Covers featuring } \\
\text { Others' including, } \\
\text { but not limited to, } \\
\text { drag queens, trans- } \\
\text { individuals, non- } \\
\text { human subjects }\end{array}$ & 33 & \\
\hline $\begin{array}{c}\text { Total } \\
\text { (a) }\end{array}$ & & \\
\hline
\end{tabular}

